\title{
Snow White's heritage : gender, social roles and alcohol use
}

Citation for published version (APA):

Kuntsche, S. (2011). Snow White's heritage : gender, social roles and alcohol use. [Doctoral Thesis, Maastricht University]. Maastricht University. https://doi.org/10.26481/dis.20111208sk

Document status and date:

Published: 01/01/2011

DOI:

10.26481/dis.20111208sk

Document Version:

Publisher's PDF, also known as Version of record

\section{Please check the document version of this publication:}

- A submitted manuscript is the version of the article upon submission and before peer-review. There can be important differences between the submitted version and the official published version of record.

People interested in the research are advised to contact the author for the final version of the publication, or visit the DOI to the publisher's website.

- The final author version and the galley proof are versions of the publication after peer review.

- The final published version features the final layout of the paper including the volume, issue and page numbers.

Link to publication

\footnotetext{
General rights rights.

- You may freely distribute the URL identifying the publication in the public portal. please follow below link for the End User Agreement:

www.umlib.nl/taverne-license

Take down policy

If you believe that this document breaches copyright please contact us at:

repository@maastrichtuniversity.nl

providing details and we will investigate your claim.
}

Copyright and moral rights for the publications made accessible in the public portal are retained by the authors and/or other copyright owners and it is a condition of accessing publications that users recognise and abide by the legal requirements associated with these

- Users may download and print one copy of any publication from the public portal for the purpose of private study or research.

- You may not further distribute the material or use it for any profit-making activity or commercial gain

If the publication is distributed under the terms of Article $25 \mathrm{fa}$ of the Dutch Copyright Act, indicated by the "Taverne" license above, 


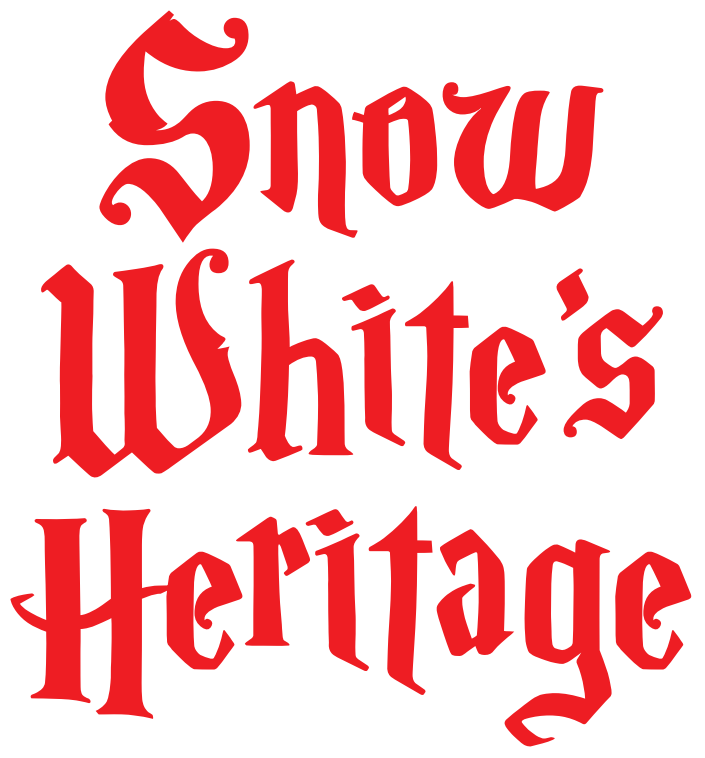

Gender, social roles and alcohol use

Sandra Kuntsche 
Illustrations: ZAK

Cover Design: Ramon Schelleman

Printed by: Copy Quick Pierre-Alain Muttet AG

(c) Sandra Kuntsche

All rights reserved. No parts of this publication may be reproduced, stored in retrieval system or transmitted in any form or by any means, electronic, mechanical, photocopying, recording, or otherwise, without prior permission of the author. 


\section{Snow white's heritage: \\ gender, social roles and alcohol use}

\section{Proefschrift}

Ter verkrijging van de graad van doctor

aan de Universiteit Maastricht,

op gezag van de Rector Magnificus,

Prof. dr. G.P.M.F.Mols

volgens het besluit van het College van Decanen

in het openbaar te verdedigen op

donderdag 8 december 2011 om 16.00 uur

door

\section{Sandra Kuntsche}

geboren op 19 september 1977

Pössneck (Germany) 


\section{Promotor}

Prof. Ronald A. Knibbe

\section{Co-Promotor}

Dr. Gerhard Gmel, Addiction Info Switzerland, Lausanne, Switzerland

\section{Beoordelingscommissie}

Prof. Dr. Nanne de Vries, (voorzitter)

Dr. Hans Bosma

Prof. Dr. Peter Andersen

Prof. Dr. Moira Plant, University of West of England, Bristol, United Kingdom

Prof. Dr. Dike van de Mheen, Erasmus University/IVO Addiction Research Institute, Rotterdam, the Netherlands 


\section{CONTENTS}

CHAPTER 1: INTRODUCTION ..................................................................................... 13

CHAPTER 2: RELEVANCE OF PSYCHOLOGICAL FACTORS.................................................... 33

CHAPTER 3: PARENT'S ALCOHOL: A MATTER OF OPPORTUNITIES .................................57

CHAPTER 4: FAMILY ROLES, SOCIAL STRATIFICATION, AND ALCOHOL USE .............. 77

CHAPTER 5: NUMBER OF SOCIAL ROLES AND ALCOHOL USE...........................................99

CHAPTER 6: RELEVANCE OF SOCIETAL FACTORS...................................................... 121

CHAPTER 7: DISCUSSION ..................................................................................... 139

Appendix..................................................................................................................... 159

References ................................................................................................................... 165

Summary of results..................................................................................................... 185

Samenvatting .............................................................................................................. 191

Zusammenfassung.......................................................................................... 197

Thank you - Dankeschön - Merci beaucoup .................................................... 203

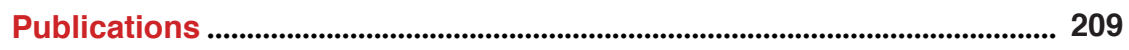

Curriculum vitae ................................................................................................ 215 


\section{Why Little Snow White ?}

"If you will keep house for us, and cook, sew, make beds, wash, and knit, and keep everything clean and orderly, then you can stay here, and you'll have everything that you want. We come home in the evening, and supper must be ready by then, but we spend the days digging for gold in the mine. You will be alone then. Watch out (...), and do not let anyone in."

Jakob and Wilhelm Grimm (1812). Kinder- und Hausmärchen, Berlin: Realschulbuchhandlung, , pp. 238-50. translated by D. L. Ashliman

With these words the dwarfs permitted Little Snow White to remain in their house after she had drunk a little drop of wine from each of their glasses, had eaten a bit from each plate and slept in their beds. When reading this story to my daughter for the first time, I skipped this paragraph as I deemed the content no longer relevant for a girl born in $2003^{1}$. Nevertheless, my husband was less conscious about the political correctness of these sentences, making my daughter wonder why daddy was reading something mommy did not. This started a fascinating discussion with my (then) three-year-old daughter about gender differences in social roles. A discussion that - later on - made me wonder why I left out the homekeeping part of the story and not Little Snow White's wine drinking ....

${ }^{1}$ Luckily, our second child is a boy with no interest in Little Snow White (mostly due to the lack of dinosaurs in the story), so I did not need to come up with re-distribution of household chores among the dwarfs... 
Meiner Familie! 


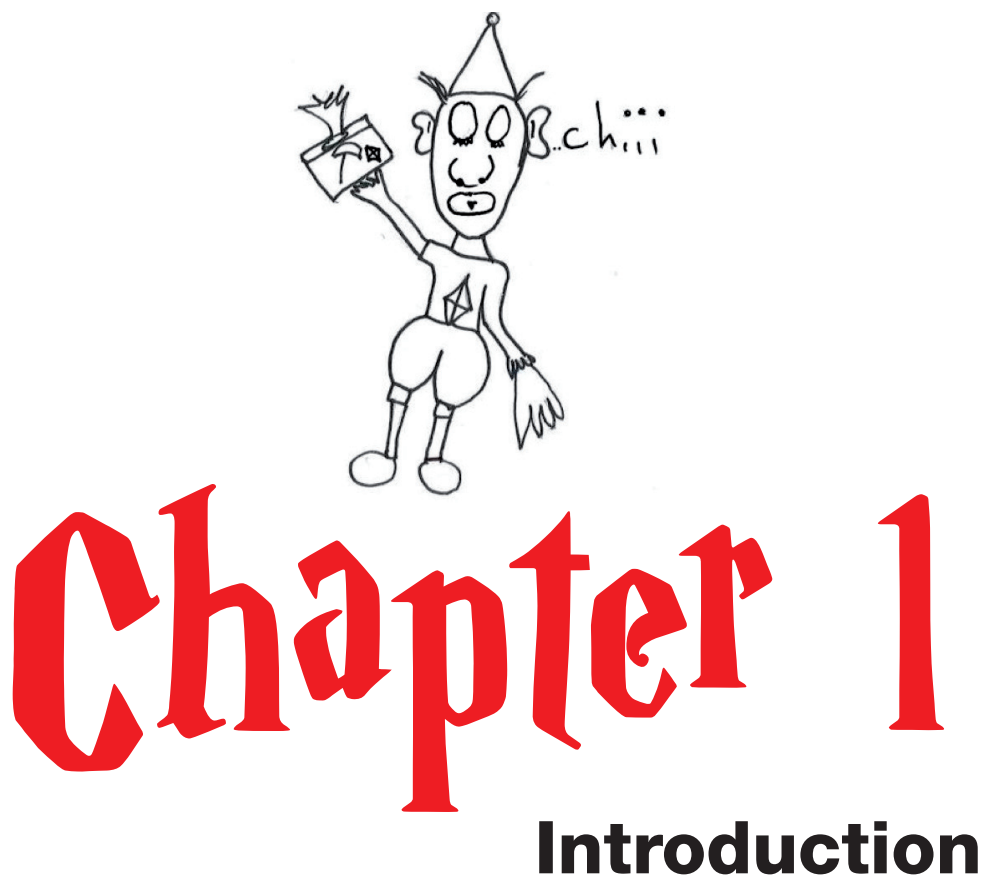




\section{Alcohol use, social roles and public health}

Although alcohol is part and parcel of our culture, alcohol use is also associated with a range of major disease outcomes (Rehm, Room, Graham, et al., 2003). In 2004, the Global Burden of Disease Study confirmed that alcohol use was a leading risk factor, responsible for $4.5 \%$ of the overall global burden of disease. In $2004,7.6 \%$ of the disease burden in middle income countries was attributable to alcohol use; in high income countries alcohol use was responsible for $6.7 \%$ of the disease burden, surpassed only by tobacco use (10.7\%) (World Health Organization (WHO), 2008, 2009). According to current knowledge, alcohol use has been shown to be responsible for more than 60 different causes of ill-health (Gutjahr \& Gmel, 2001; Rehm, Room, Monteiro, et al., 2003). This highlights the importance for public health of developing an extensive understanding of the underlying mechanisms to establish effective prevention and intervention measures targeting alcohol use generally and risky drinking in particular. There is widespread agreement in the academic community that if prevention is to be effective, it must be based on well conducted research projects and sound scientific evidence (“evidence-based prevention”: Babor et al., 2003; Room, Babor, \& Rehm, 2005; Spoth, Greenberg, \& Turrisi, 2008).

Studies among young adults have found evidence that entering stable employment, becoming involved in a steady relationship and becoming a parent reduce alcohol use to a more moderate level (Labouvie, 1996; Moffitt, 1993). Some researchers consider this decline as a "maturing out" of problem drinking (Fillmore, 1988; Johnstone, Leino, Ager, Ferrer, \& Fillmore, 1996), a process that may be the result of adopting adult roles and responsibilities (Bachman et al., 2002; Yamaguchi \& Kandel, 1985). This conclusion suggests a rather strong preventive impact of such social roles on the individuals' drinking behaviour. Nevertheless, few studies have examined the impact of these preventive factors later in life (e.g. Knibbe, Drop, \& Muytjens, 1987; R. J. Neve, Lemmens, \& Drop, 1997). Research on adult alcohol use and especially alcohol misuse has been based on theoretical frameworks from a psychological or sociological background. Most of these theories focused on either the explanatory value of individual characteristics and / or on external factors like peers or group phenomena (Leonard \& Blane, 1999; White, 1996). However, the results of studies on "maturing out" suggest that the structural aspects of social roles may prevent excessive alcohol use as they help to organise days around regular and recurring activities. So far little research has examined the question as to how structural aspects and cultural differences in 
these may contribute to differences in alcohol use or the question of why such differences occur. The impact of these more socially structured factors, in particular social roles such as being in employment, living with a partner and being a parent, on alcohol use is the central theme of this doctoral thesis. Based on the assumptions of role theory, this thesis aims to shed more light on cultural and gender differences in the relationship between social roles and alcohol use.

Social roles, such as parenthood, partnership or paid labour, describe an individual's position in a given social system and are based on enduring relations with other people. Hence they provide the individual both with a sense of identity and behavioural guidance (McCall \& Simmons, 1996; Stryker, 1980; Stryker \& Serpe, 1982; Thoits, 1991) and affect the individual's health and health behaviour by providing direction and meaning to his or her life (Durkheim, 1951). Several studies have shown that social roles are related to a wide range of health aspects such as depression (e.g. Brown, 2002), psychological distress (Matthews \& Power, 2002; Menaghan, 1989; Wheaton, 1990), subjective well-being (Pinquart \& Sörensen, 2000), and substance use (e.g. Bachman, et al., 2002; Galea, Nandi, \& Vlahov, 2004).

\section{The interplay between social roles and public health}

The example of treatment for alcohol problems may illustrate the potential relevance of social roles as important structural factors on problematic alcohol use: several studies on individuals undergoing treatment for alcohol problems have shown that those in treatment are more often unemployed and / or not living with a partner (Copeland \& Hall, 1992; Zywiak, Longabaugh, \& Wirtz, 2002). One could ask whether the lack of important roles contributes to alcohol problems and - of course - in what way treatment policy should anticipate the effect of a lack of roles on the probability of treatment completion and substance misuse remission once treatment is ended.

It seems likely that the incidence of excessive and problematic alcohol use is also influenced by social factors such as the acquisition and fulfilment of social roles important to both the individual and society. Of course, the causality of this relationship may be reversed not that the lack of social roles may lead to risky alcohol use but that the alcohol use may limit the accessibility of certain roles, as the individual will be seen as less attractive as a potential partner or reliable employee. But social roles are not only closely linked to the incidence of alcohol related problems; they also impact the chronicity of alcohol use and related health consequences. Providing people with a comprehensive and regular structure in 
their daily lives may be an important factor in overcoming alcohol dependence or misuse. This might also be of particular importance for treatment. The aim of such treatment should be to replace the alcohol-related activities and behaviours with new meaningful activities. Being in regular employment from 8 a.m.to 5 p.m. already covers a large part of the day that the person would usually spend on other most probably alcohol-related activities.

\section{The interplay between social roles and alcohol use: aims of the present doctoral thesis}

The focus on structural elements like social roles does not, of course, deny the relevance of psychological factors in understanding alcohol use. This thesis assumes that psychological aspects and characteristics are embedded within the individual's social roles. On the one hand, the individual's psychological capacities or characteristics may either limit or enforce access to or fulfilment of specific social roles. To give an example: an individual with depressive symptoms may have difficulties adopting an important role like finding new employment. On the other hand, psychological characteristics will also provide the individual framework regarding how a social role is and can be performed in everyday life; e.g. in acute episodes, an individual with depressive symptoms will have difficulty reacting in an appropriate way to the demands of regular paid labour. Therefore, one of the central themes of this thesis is the question:

- Do psychological factors, more specifically mastery and depression, mediate or moderate the relations between social roles and alcohol use (Chapter 2)?

A quite different explanation of the relationship between social roles and alcohol use concerns characteristics inherent in the social roles themselves. A similar role may have quite different implications in terms of e.g. time spent on fulfilling the role obligations and their emotional impact. This theme will be investigated in this thesis by concentrating on possible gender differences in how social roles relate to alcohol use. More specifically:

- Are there gender differences in household and parenting activities and do these explain gender differences in alcohol use (Chapter 3)?

A third major theme is the extent to which the relationship between social roles and alcohol use can be generalised over different countries and cultures. In the context of this 
theme the explanatory value of cultural differences in gender equity for the effect of social roles on alcohol use will be explored:

- What are the cross cultural similarities and differences in the effect of the number of social roles on alcohol use (Chapter 5)? Do gender and culture influence how specific social roles influence alcohol use? (Chapter 4) and Do societal differences in gender equity explain how cultures differ in the way social roles are related to alcohol consumption (Chapter 6)?

This doctoral thesis focuses on cultural comparisons in established market economies, since most of these places share a common idea of what constitutes a meaningful adult life, which include being able to take care of oneself, in other words having paid labour, but also living in a stable partnership and having children.

The following section explores in more detail the mechanisms and processes underlying the relationship between social roles and alcohol use. In addition, the relevance of cultural and gender differences on the relationship between social roles and alcohol use will be considered.

\section{Social role theory: Role concepts and the classic role theory}

\section{Types of roles}

The German sociologist Ute Gerhardt (1971) offers an analytical framework of types of roles, specifying how social roles may influence health and health behaviours. She distinguished three different types of social roles: status roles, positional roles and situational roles (see Table 1-1 for an overview).

Status roles are constituted by social expectations based upon personal characteristics that an individual cannot change easily, e.g. gender, birth cohort, parental religion or culture,. They have an impact on the individual's life over a long period of time and in a range of situations (e.g. appropriate behaviour with respect to family, neighbours, colleagues, suitable professions, etc.). The obligations and opportunities which a status role entails are either laid down in laws and official regulations like legal ages to purchase alcohol and gender differences in paid leave when becoming a parent, or rooted in unofficial expectations and societal disapproval such as cultural or religious differences in reaction to intoxication (Joosten, Knibbe, Derickx, Hradilova-Selin, \& Holmila, 2009; Knibbe, et al., 1987; Room \& 
Mäkelä, 2000). Each individual holds several status roles, as we all belong to a given cultural background and to a gender group. Against this background status roles define the general framework in which positional roles and situational roles can be adopted and how these positional and situational roles are enacted.

Table 1-1 Different type of social roles by Gerhardt

\begin{tabular}{|c|c|c|}
\hline Status roles & Positional roles & Situational roles \\
\hline $\begin{array}{l}\text { Social expectations based } \\
\text { upon characteristics of the } \\
\text { individual that cannot be } \\
\text { changed easily } \\
\text { Predominate someone's } \\
\text { entire life within a society }\end{array}$ & $\begin{array}{l}\text { Social expectations based } \\
\text { upon the position an } \\
\text { individual occupies in } \\
\text { his/her social networks }\end{array}$ & $\begin{array}{l}\text { Behaviours or activities } \\
\text { facilitating the social } \\
\text { behaviour in short-term } \\
\text { situations }\end{array}$ \\
\hline $\begin{array}{l}\text { Define the framework behind } \\
\text { social norms and co- } \\
\text { determine the enactment of } \\
\text { positional and situational } \\
\text { roles }\end{array}$ & $\begin{array}{l}\text { Based on a balanced system } \\
\text { of reciprocal obligations }\end{array}$ & $\begin{array}{l}\text { Enable individuals to make } \\
\text { appropriate choices in very } \\
\text { specific social situations }\end{array}$ \\
\hline $\begin{array}{l}\text { Influence an individual's } \\
\text { opportunity to occupy } \\
\text { powerful, profitable or } \\
\text { prestigious positions in a } \\
\text { society }\end{array}$ & $\begin{array}{l}\text { Require the individual to } \\
\text { perform certain activities } \\
\text { regularly }\end{array}$ & $\begin{array}{l}\text { Characterized by the specific } \\
\text { situation }\end{array}$ \\
\hline $\begin{array}{l}\text { e.g. birth cohort, sex, social } \\
\text { class, ethnicity }\end{array}$ & $\begin{array}{l}\text { e.g. parental role, the role as } \\
\text { an employee }\end{array}$ & $\begin{array}{l}\text { e.g. eating out, having a } \\
\text { party, first date }\end{array}$ \\
\hline
\end{tabular}

Positional roles are based upon the place that an individual occupies within more permanent social networks (like the family or work environment). With these roles come regular, reciprocal and recurring obligations. These obligations structure daily life into meaningful activities. Whereas status roles give more general guidance regarding social expectations and how someone should behave in general, positional roles (like parenthood, partnership or paid labour) structure life on a daily level. With positional roles come major everyday obligations like going to work and spending time with a partner or children on a regular basis. These obligations can be simple but recurring activities like taking children to school, having regular working hours in the office or spending time doing shopping, cooking 
and cleaning for the family. Nevertheless, these recurring activities structure the role holder's everyday life and the more roles someone holds, the more his or her life is structured by such activities. The acquisition of these positional roles will be limited or aided by status roles and, in return, positional roles will limit or facilitate the accessibility to certain situational roles like for example the possibility of socialising with colleagues after work when having childcare responsibilities.

Situational roles are rules and behaviours that facilitate social interaction and conduct in given social situations like being in a pub or bar, going on a shopping trip or going for dinner in a restaurant. Situational roles can be characterized by the extent they are instrumental or expressive. Instrumental situational roles concern situations where the main aim is to get from one situation to another, like traffic, waiting for the doctor in the waiting room, or waiting in a supermarket line. These kinds of situations have either formalized (traffic) or rather general rules (waiting in line at the supermarket) on how to behave. They do not offer any immediate gratification for the individual beside the pure transition between different situations. A second set of situational roles is characterized by a more expressive and leisure time character. Examples of these roles are attending parties or receptions, going shopping or eating. From these situational roles the individual achieves immediate gratification in the form of social interaction with others, a full tummy or the relaxing effect of alcohol. The more expressive situational roles offer the individual positive enforcement and form the central scene where most alcohol use takes place. Both sets of situational roles share the short time span in which the role influences the individual's behaviour and the fact that they are mostly determined by concrete aspects of the given situation. Expressive situational roles in particular are performed with the status and positional roles in the back of one's mind.

In conclusion, the three different types of social roles described by Gerhardt (1971) cannot be seen as independent from each other. The fact that a married woman has to respect different social norms than an unmarried one when going out illustrates this assumption. Both will have to take into account that certain behaviours are (still) seen as improper for women, but are totally appropriate for men. Therefore, it is important to understand that the performance of status roles (gender) may take place in the context of positional roles (living in a partnership) or situational roles (being in a bar). In addition, elements of status and positional roles may also guide the individual's behaviour in a given situational role. For example, the behaviour of an individual at a party (situational role) will be influenced by 
status role expectations based on the individual's gender or social class; but the individual's alcohol use in this situation will also be determined by positional roles, e.g. being a surgeon on call or being unemployed.

\section{Classic role theory or role accumulation theory}

A theory summarizing these different role types and explaining the impact of social roles on human behaviour and health is the role accumulation or classic role theory. This theory focuses on the beneficial health effects of having multiple positional roles (Aneshensel, Frerichs, \& Clark, 1981; Hibbard \& Pope, 1991; Hong \& Seltzer, 1995). It posits that the greater the number of positional roles a person holds, the more his or her life is structured by meaningful activities that others expect one to engage in. Positional roles, like partnership, parenthood, and paid labour, more than any other, bring individuals into regular contact with others and are associated with activities that are defined by the expectations of significant others. The central assumption of the theory is that the more everyday life is structured around regular social activities and reciprocal obligations which the individual and others deem important, the more likely it is that he or she will take care to ensure that the time spent in situational roles not linked to these regular activities does not interfere with his or her role obligations due to the position(s) he/she occupies (e.g. Knibbe, et al., 1987; R. J. Neve, et al., 1997). Given this background, all expressive situational activities offering immediate gratification, such as shopping and eating, but also alcohol use, may interfere with the adequate performance of these roles by limiting the necessary time and energy spent for positional role obligations and the fulfilment of related expectations. Among individuals holding a higher number of positional roles with regular obligations, the available time spent in expressive situational roles not related to the role as e.g. father or mother will be limited. In addition, when an individual has more positional roles, a larger number of people depend on adequate performance of these positional roles and will therefore monitor whether one adequately fulfils all obligations connected to one's roles. This again will limit the accessibility of expressive situational roles.

It should be mentioned that the basic assumption of classic role theory that the more social roles, the lower the engagement in heavy drinking, is controversial. Especially among women, an alternative theory, namely the multiple burden hypothesis, has been proposed. This hypothesis implies that women performing more social roles may feel overburdened (Arber \& Khlat, 2002; Lahelma, Arber, Kivela, \& Roos, 2002) and as a result may be more likely to use 
alcohol to cope with the burden, as suggested by (Cappell \& Greeley, 1987). In the paragraph Multiple burden: similarities and differences versus the classic role theory below, more details are provided on the multiple burden hypothesis and its implications on alcohol use.

Throughout the following chapters the term "social role" will be used as a synonym for positional roles and the term "situational role" will in the following signify expressive situational roles offering immediate gratification.

\section{Mechanisms explaining the effect of social roles on alcohol use}

In general, social roles affect an individual's health via two underlying mechanisms: first via a limitation of opportunities to engage in situational roles offering immediate gratification. To give an example: a parent who works until 5 p.m. and has to pick up their child by 6 p.m. from childcare would have an hour spare to spend with colleagues in a bar for an after-workdrink. Thus, the opportunities to spend time in situational roles will decrease with the number of social roles an individual holds. In line with the assumption that social roles may limit the opportunities to engage in such situations, Paradis et al. (2011) found that both fathers and mothers reported significantly lower ratios of heavy episodic drinking in a bar or outside home than non parents.

In addition, even when participating in situational roles, one may limit one's participation depending on positional role obligations, e.g. a parent may decide to go home earlier from a party than a non-parent. The study by Paradis et al. (2011) indicates that this may be less significant by showing that parents and non parents do not differ in drinking behaviour when they participate in a drinking situation.

A second way in which social roles may influence health behaviour and related activities is a lack of structure and meaning in everyday life due to a lack of relevant social roles. This lack of positional roles will lead to time gaps not filled with regular activities deemed to be meaningful by the individual and by significant others. For example, an individual without employment who is not in a partnership will have a great deal of spare time to engage in situational roles. As there are no regular activities demanding time and energy, both will be spent in a less structured way by looking for situational activities to fill the day instead of regular activities with positive impacts on the self. Formulated more generally, in such cases situational roles may be used to structure everyday life. This use of situational roles may take the form of extending regular situational roles like taking much longer to have breakfast or 
dinner. It may also take the form of more frequent participation in other situational roles: e.g. visiting friends on workdays, spending time in bars or restaurants, taking more time to do shopping or browsing the internet. Knabe and colleagues (2010) clearly showed that unemployed individuals in Germany extended situational roles like eating or watching TV but also spent more time on childcare or housework to fill the day. However, they reported less satisfaction with these activities than their employed counterparts. Hayes and Halford (1996) compared unemployed men, men with schizophrenia and a group of employed men regarding their time use and activity participation. He found that unemployed men and those with schizophrenia participated less in occupational role activities, as expected, and spent more time on leisure activities than the employed group.

Also the interplay between these two processes - limitation of opportunities and lack of structure - is of relevance in understanding the mechanisms behind the role theory. Individuals with fewer social roles and therefore a less structured life will have more opportunities to engage in situational roles offering immediate gratification like alcohol use, shopping or gambling. But this engagement may at least partly be due to a certain frustration linked to not having other meaningful activities to engage in.

A central focus of this work was to examine which underlying factors may affect the relationship between social roles and alcohol use. Two different aspects in which social roles may influence alcohol use will be presented. First, depending on the number of social roles a person has, the psychological status of the person may differ. Such a variation in the psychological status of a person may either explain the relationship (mediate) or have an influence on the interplay between social roles and alcohol use (moderate). This will be discussed in more detail in the paragraph Psychological variables: mediating or moderating effects in the relationship between social roles and alcohol use?. Second, specific aspects inherent to a given social role may determine the opportunities and inclination to use alcohol. In other words, it is not the simple fact of being a parent per se but the characteristics of this role, like the age of the children etc., which determine whether or not an individual uses alcohol. This will be further articulated in the paragraph Role related aspects and alcohol use: the role of family and household characteristics. In a final step, more details on cross cultural similarity and differences in the effect of social roles on alcohol use will be given. The theoretical considerations leading one to expect that culture and gender may moderate the 
effect of social roles on alcohol use will be examined in detail in the paragraph Gender and culture as factors influencing the effect of social roles.

\section{Psychological variables: mediating or moderating effects in the relationship between social roles and alcohol use?}

As previously mentioned, we assume that social roles are fulfilled and acquired based on the individual's psychological characteristics. Classic role theory leads to the expectation that having no or few social roles makes it potentially more difficult to structure one's life around meaningful relationships. Consequently, this may be more often associated with negative emotions resulting from this lack of social roles deemed important by society and the individual. Two more general psychological variables for which an association with alcohol consumption has been established are depression (Berger \& Adesso, 1991; Flynn, 2000; Sexton, Lipton, \& Nilssen, 1999; van Gool et al., 2007) and mastery (Prescott, Neale, Corey, \& Kendler, 1997; Thomas \& Hsiu, 1993). This study will examine whether negative emotions, like feeling externally controlled or depressed may mediate the relationship between social roles and alcohol use.

Psychological variables may also moderate the effect of social roles on alcohol use. Those with sound mental health and psychological well-being may benefit from holding more social roles, as the classic role theory suggests. The opposite, however, may also be true: individuals whose psychological well-being is less good may suffer from having more roles, as these are likely to generate tension with regard to how individuals manage their time and whether they are able to give their partner, co-workers, or children the attention and time they expect. These tensions may lead someone to increase his or her alcohol use. More specifically, individuals with few roles but differing in depression and the extent to which they feel externally controlled may also differ in the extent to which these roles relate to more drinking. Further, the protective effect of having multiple roles may be absent or even lead to increased vulnerability if the individual performing all these roles feels a lack of mastery and/or feels depressed. Chapter 2 will examine the extent to which the relationship between the number of social roles and alcohol use is mediated or moderated by depressed mood and external control.

\section{Role related aspects and alcohol use: the role of family and household characteristics}

As described above, social roles relate to alcohol use via two underlying mechanisms: by limiting the opportunities to engage in heavy drinking and by providing a guiding structure in 
everyday life. These considerations lead one to expect that the more roles a person holds, the less likely he or she is to engage in situational roles that may conflict with their role obligations due to the limited time and opportunities. But, the fewer social roles a person has, the more likely he or she is to engage in situational roles offering immediate gratification to compensate for the lack of structure in everyday life.

Various studies have identified the impact of a lack of social roles on alcohol use. Wilsnack and Cheloha (R. W. Wilsnack \& Cheloha, 1987) identified the age-related effects of role deprivation on heavy drinking among women in the US. For example, younger unmarried women with an unstable employment status were more likely to engage in heavy volume drinking than married women with a stable working situation. The relationship between specific social roles and alcohol use was also the focus of several longitudinal studies (e.g. Hajema \& Knibbe, 1998; S. C. Wilsnack, Klassen, Schur, \& Wilsnack, 1991). The most consistent effect was a drop in alcohol use when the respondents became parents (Hajema \& Knibbe, 1998; Power \& Estaugh, 1990b). This was confirmed in a meta-analysis of social role changes conducted by Temple et al. (1991). The authors found a negative association between becoming married and drinking for both women and men.

The studies mentioned above focused on the simple fact of holding a social role or not. Characteristics of the parental role and associated family and household chores were not considered. To the best of our knowledge there are precious few studies looking into the issue of whether the influence of social roles is mediated by opportunities and/or frustration about lack of structure in everyday life. Yet, it is highly plausible that the number of children, the children's age as well as the distribution of childcare and household chores between mothers and fathers play an important role in predicting parental alcohol use. In line with the role accumulation theory, more children, the younger the children and the greater the share in household and childcare duties, the fewer the opportunities to engage in alcohol use. In this study the extent to which social role related aspects influence alcohol use will be assessed in an indirect way. Men and women are likely to differ in the extent to which family and household related characteristics influence their alcohol use as there is a longstanding difference in the time each gender spends on the role of partnership - more specifically household activities - and parenthood, i.e. childcare. Chapter 3 will analyse gender differences in the time spent on household and childcare and examine whether this may explain gender differences in the effect of the role of parenthood on drinking. 


\section{Gender and culture as factors influencing the effect of social roles}

We assume that the impact of positional roles on alcohol use may be conditioned at least partly by the status roles an individual holds. This thesis will focus on two status characteristics: gender and cultural background. Gender is an important factor in the adaptation of positional roles and their translation and fulfilment in everyday life. The same is true for the individual's cultural background. An example to illustrate the interplay between positional and status roles for the parental role is the fact that these days, the obligations and societal expectations related to the parental role still vary tremendously for mothers and fathers (Coltrane, 2000; Crompton, Brockmann, \& Lyonette, 2005). Despite all emancipation efforts and developments, mothers still carry out the majority of childcare duties, especially when children are young. Gender may therefore condition the extent to which the parental role influences opportunities to drink. But this is not the only factor intervening in the relationship between positional roles and alcohol use. As each country provides a specific set of explicit and implicit regulations, expectations and societal demands regarding a positional role like parenthood, the relationships between the role and alcohol use may depend on the cultural background. The following example may illustrate this better: whereas Northern European countries, like Sweden or Finland have a long standing tradition and strong societal support for mothers to remain in paid labour after childbirth, the picture of a good mother in Central and Southern European countries is still a stay-at-home mum without paid labour. But also the extent to which drinking situations are used to compensate for the lack of structure in everyday life varies across different societies. In cultures where drinking is to a large extent restricted to eating situations (e.g. Mediterranean countries), there is probably no connection, or a less strong one, between a lack of positional roles and drinking than in cultures where most of the drinking takes place outside meals in informal social situations like meeting friends, a visit to a bar, or private parties. The following section explores the two status roles, cultural background and gender, in more detail. 


\section{Cultural background: Cross cultural similarities or differences?}

As previously mentioned, social roles are defined by the society an individual lives in and describe what is socially expected, accepted, forbidden or not tolerated for e.g. a mother or a married man. But these definitions of what is expected, accepted or forbidden will vary across different countries, depending on their history, religion and tradition. Hence, the meaning of the single social role and role combination may vary across societies, too.

The findings of Gmel et al. (2000) indicated that differences in the social position of women in a country were strongly related to differing associations between specific role combinations and heavy drinking and gender equality across countries. Whereas in Switzerland single mothers and married women without children drank higher amounts of alcohol than women in all other role combinations, in Finland the group of women without any social role reported the highest levels of alcohol use. In this study no single role combination was consistently associated with higher alcohol use across all cultures. Gmel and colleagues (Gmel, et al., 2000) concluded that the differences in which role combinations made women most vulnerable to heavy alcohol use have to be interpreted in terms of macro differences in the position of women across different societies. Thus, micro-level (individual) and macro-level (societal factors) are closely linked and influence each other. Research has to integrate aspects at the macro and micro-levels to study the impact of socio-economic and role variables in relation to the inequalities in female and male health (Moss, 2002).

This thesis addresses the question of whether or not the impact of social roles on alcohol differs cross- culturally in two separate chapters. Chapters 4 and 5 focus on the cross-cultural uniformity or diversity in the impact of the three major positional roles, namely partnership, parenthood and paid labour, among men and women. Chapter 6 focuses on a more specific question: Is the effect of roles on women's drinking conditioned by the gender equity in a society?

The following paragraph provides a brief explanation of the theoretical background behind this research question.

\section{Gender equity: minor difference, major impact}

Within a society the meanings of social roles vary depending on the specific set of explicit and implicit regulations, expectations and societal demands regarding positional roles. Due to the emancipation which has taken place over the past four decades, the roles of women and 
men have become more equal than ever before. As a result, the classic distribution of roles, whereby women take care of the household and children and men are responsible for financial security and breadwinning is no longer the standard model. In parallel, female labour participation has increased significantly since the Second World War, which may well have contributed to the increasing equity in labour force participation between the genders nowadays. Reflecting this increase in female participation in the labour force, there has been a shift in research on health inequalities to include the structural and material situation of women in societies (Arber \& Cooper, 2000; Bartley, Popay, \& Plewis, 1992; Macran, Clarke, Slogget, \& Bethune, 1994). Chapter 4 follows this suggestion and focuses on both socioeconomic factors and family roles in both genders. Previously, the main emphasis had been on investigating social stratification (educational level, employment) for men, and on household and family roles for women (Arber, 1991; Arber \& Khlat, 2002; Lahelma, et al., 2002; Matthews \& Power, 2002; Nathanson, 1980; Townsend, Davidson, \& Whitehead, 1992; Verbrugge, 1983). Nevertheless, women still perform the majority of household labour despite the general assumption that greater emancipation of women would result in a redistribution of household and childcare duties. At best most studies only reported a slight increase in household chores carried out by men in recent decades (e.g. Coltrane, 2000; Crompton, et al., 2005), an aspect that is addressed in Chapter 3 of this thesis. Considering this, women may experience the role of being in paid labour on top of their household and childcare duties as an additional burden. The higher participation and resulting social expectation that women contribute to breadwinning requires individual solutions on how to combine motherhood and paid labour in a productive and stress-free way. The implementation of such new societal developments in real life is rarely without conflicts and problems. A central focus of this thesis was therefore not only on gender differences in the relationship between social roles and alcohol use, but also on cultural variations and the implications of societal developments, especially for women's alcohol use (Chapters 5 and 6). Based on this assumption another theoretical strand became prominent in the literature: the multiple burden hypothesis. While the classic role theory assumes that more positional roles are associated with lower alcohol use, there have been studies stating that in some cases more roles may lead to 'role overload', or 'multiple burden'. In such cases alcohol use may be seen as a way to cope with this multiple burden. The multiple burden hypothesis has been mainly studied in the context of women's health when holding multiple roles (e.g. Doyal, 1995). However, societies differ in gender equity. Thus, mothers may differ in the extent to which the role of paid labour relates to alcohol use. In cases where supplementary paid labour is 
experienced as an additional burden, maternal alcohol use may increase to cope with this. In contrast, in cases (countries) where the role of paid labour is experienced as a meaningful and productive way of spending time as suggested by the classic role theory, mothers in paid labour report lower alcohol use, following the assumptions of the classic role theory. The following section describes the multiple burden hypothesis in more detail.

\section{Multiple burden: similarities and differences versus the classic role theory}

The theory assumes that especially among women, heavy domestic and child-rearing responsibilities in addition to demands due to paid work may lead to stress, and that the potential positive effects of employment, for example, may be mitigated by such a role overload (Doyal, 1995; Macran, Clarke, \& Joshi, 1996; Ross \& Mirowsky, 1992). The main reasons behind the assumption that women are more likely to feel overburdened by holding all three roles compared to men are:

(1) they may spend more time running the (shared) household than men do; and

(2) they may spend more time on childcare than men do.

Therefore, an unequal distribution of household chores may result in women feeling overburdened by holding several positional roles (Arber \& Khlat, 2002; Lahelma, et al., 2002). Given that previous studies based on the multiple burden hypothesis have focused on physical and mental health issues (e.g. Maclean, Glynn, \& Ansara, 2004) and not on alcohol use, this thesis, to the best of our knowledge, will be the first to investigate the relevance of this theory for alcohol use in a multi-country context. The inclusion of a set of different countries allows the identification of circumstances and societal conditions under which the multiple burden hypothesis is of greater relevance on the relationship between social roles and drinking than the classic role theory.

Temple et al. (1991) and Darrow and colleagues (1992) suggested that there is no easy or simple way of combining the roles of paid labour and parenthood. Several adaptations and regulations, e.g. organized childcare or reduced working hours are necessary to achieve the required balance between these roles to ensure a stress-free structure of daily life (see paragraph on Cultural background). This particular role combination is therefore highly dependent on societal factors. As the large majority of childcare duties and related organisational responsibilities are still performed by women, the societal support in childcare or the lack of it probably has a greater impact on women than on men. Especially in societies 
where childcare and social services (day care, after-school care, paid maternity leave, paid leave to care for a sick child) are less common, working women may suffer from higher stress levels due to the fact that they must bear a heavier burden of responsibility for care of children and the family (Arber \& Khlat, 2002; Lahelma, et al., 2002). Thus, the effect of different role combinations, more specifically the combination of parenthood and paid work among women, may vary across different countries, depending on the social welfare systems and gender equality in the societies in question.

However, most studies based on the multiple burden perspective have studied dependent variables other than alcohol use and most of these studies were conducted in countries (namely the USA and UK) where at the time the social support specifically for mothers was rather poor compared to other countries. Therefore, one might wonder whether in societies in which gender equity is high, the effect of the combination of motherhood and paid work is protective for alcohol use rather than leading to women feeling overburdened and using alcohol to cope with this burden.

Given the context of cross cultural differences in the effect of positional roles on women's drinking in particular, special attention will be paid to Northern European countries as they are shown to have better conditions for women combining parenthood and paid work than many other countries.

\section{Advanced organizer and outline of following chapters}

The following section provides an overview of the subsequent chapters of this doctoral thesis, summarizing the assumptions presented above.

Concerning the link between social roles and psychological well-being, classic role theory suggests that having no or few roles makes it potentially more difficult to structure one's life around meaningful relationships. Consequently, this may be more often associated with negative emotions such as feeling externally controlled or feeling depressed, thus suggesting a mediating effect. However, the effect of the number of roles on alcohol use may also differ depending on the psychological background of the individual. Therefore, the aim of Chapter 2 is to examine the extent to which the relationship between the number of social roles and alcohol use is mediated or moderated by two psychological factors, namely depressed mood and external control. 
Research has indicated that involvement in each social role can have both beneficial and harmful effects. Previous studies (Gmel, et al., 2000; Knibbe, et al., 1987; Kuntsche et al., 2006; R. W. Wilsnack \& Cheloha, 1987), however, have focused on the effects of simply being a partner or an employee or on the combinations. Nevertheless, the effect of roles may vary depending on particular characteristics of the demands of a role (e.g. part-time or fulltime paid work; age of children), the interrelations between these roles and women's socioeconomic circumstances (Barnett \& Marshall, 1991).

Therefore, Chapter 3 will shed more light on the impact of specific family characteristics on parental drinking, such as the age of the youngest child, the number of children in the household and the share of household and childcare duties. The central aim of this chapter is to answer two central questions: (1) Do family related factors influence men's and women's alcohol use in a comparable way? (2) Are the effects of family related factors moderated by level of paid labour?

In the context of a cross-national comparison, Chapter 4 explores gender differences in the impact of social stratification variables on alcohol use, e.g. education and paid labour, and family factors, namely partnership and children. The chapter further aims to seek an explanation of country differences in the associations of social stratification and family roles with alcohol use by societal level variables.

In the last 20 years, several studies have demonstrated the link between alcohol use and individual social roles, such as being a partner or parent (Gmel, et al., 2000; Knibbe, et al., 1987; R. W. Wilsnack \& Cheloha, 1987). Only a handful of studies have concentrated on how consistent this association is across genders (Knibbe, et al., 1987) or across countries (Gmel, et al., 2000). This raises the question as to how the integration in societal networks provided by partners, colleagues or children or the absence thereof influences the association between social roles and alcohol use and how these associations may vary across the two genders and different cultures.

The primary focus of Chapter $\mathbf{5}$ is the extent to which the relationship between the number of roles and alcohol use is similar across countries and gender. For these purposes 10 (western) industrialised countries were selected. The starting point was the classic role theory, which posits that holders of all three social roles have the lowest alcohol consumption. However, particular attention was paid to whether in some countries there is any evidence to 
support the multiple burden hypothesis, that is increased alcohol use among those combining all three social roles.

Despite the substantial increase in female labour force participation, women still spend more time running the (shared) household and performing childcare duties than men (Bird, 1999). Yet, countries may differ in the extent to which they provide the societal circumstances to enable equal sharing of household and childcare responsibilities. Besides national differences in childcare provision, gender-income equity may be a factor facilitating maternal employment. Mothers in countries with less gender-income equity may experience paid labour as an additional burden, and therefore report higher levels of alcohol use (e.g. to compensate for additional stress). By contrast, for mothers in countries with fewer gender differences in income equity, the additional responsibilities of being in paid labour on top of being a parent is likely to result in lower alcohol use among mothers in paid labour.

Chapter 6 tests whether gender-income equity on a societal level moderates the effect of paid labour on maternal alcohol use. The chapter aims to understand underlying processes and therefore, explore the considerations of chapters 2 and 3 in more depth by focusing on the relevance of gender equity in the interplay between maternal paid labour and alcohol use.

Chapter 7 summarises and discusses the results of chapters 2 to 6 and draws conclusions regarding the relationship between social roles and alcohol use. Implications for public health, alcohol prevention and subsequent research are raised and the limitations of this doctoral thesis discussed. The chapter also provides an outline for the more detailed examination of the link between social roles and alcohol use.

A summarised description of the methodology and data used for the cross cultural comparisons is given in Appendix I. 


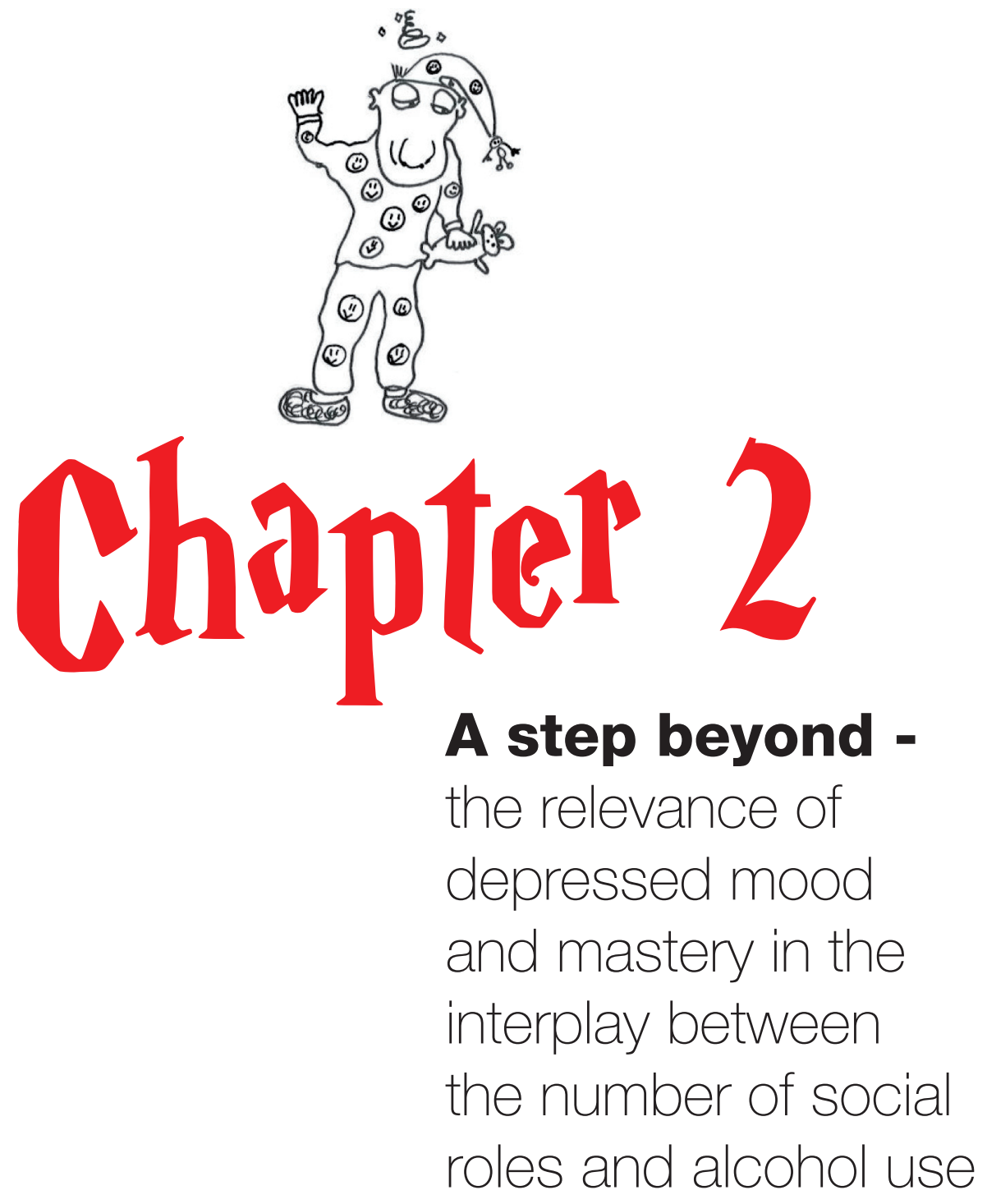




\section{Summary}

Objectives: The present chapter examined whether depressed mood and external control mediate or moderate the relationship between the number of social roles and alcohol use.

Participants: The analysis was based on a national representative sample of 25- to 45-yearold male and female drinkers in Switzerland.

Method: The influence of depressed mood and external control on the relationship between the number of social roles (parenthood, partnership, employment) and alcohol use was examined in linear structural equation models (mediation) and in multiple regressions (moderation) stratified by gender. All analyses were adjusted for age and education level.

Results: Holding more roles was associated with lower alcohol use, lower external control and lower depressed mood. The study did not find evidence of depressed mood or external control mediating the social roles-alcohol relationship. A moderation effect was identified among women only, whereby a protective effect of having more roles could not be found among those who scored high on external control. In general, a stronger link was observed between roles and alcohol use, while depressed mood and external control acted independently on drinking. With the exception of women with high external control, the study found no link between a higher number of social roles and greater alcohol use.

Conclusion: Results indicate that drinking behaviours are more strongly linked to external control and depressed mood than they are to the number of social roles. It is also demonstrated that in any effective alcohol prevention policy societal actions that enable individuals to combine more social roles play a central role.

Published as:

S. Kuntsche, R. A. Knibbe \& G. Gmel (2010). A step beyond - the relevance of depressed mood and mastery in the interplay between the number of social roles and alcohol use. Addictive Behaviors, Vol. 35 (11), pp. $1013-1020$. 


\section{Introduction}

Social roles are defined as an individual's position within a society based on enduring relations to others, which provide a sense of identity and behavioural guidance (McCall \& Simmons, 1996; Stryker, 1980; Stryker \& Serpe, 1982; Thoits, 1991). In the alcohol field, the concept of "social roles" was used to explain the relationship between drinking behaviour and social characteristics like family background and employment status (Jennison, 1992; Johnson, 1982). Over the last 20 years several studies have focused on the relationship between alcohol use and social roles, such as being a partner, a parent, or an employee (e.g. Gmel, et al., 2000; Hajema, Knibbe, \& Drop, 1997; Kuntsche, et al., 2006). The aim of the present study was to examine the extent to which the relationship between the number of social roles and alcohol use are mediated or moderated by two psychological factors, namely depressed mood and external control.

The concept of external control - or personal control beliefs - is based on work by Rotter (1966) and reflects an individual's beliefs regarding the extent to which he is able to control or influence outcomes in his life. The present study, however, applies a broader definition, considering external control as a more general feeling of being at the mercy of fate rather than a specific feeling of not being able to master the demands and problems in one's life. The second psychological factor - depressed mood - refers to the experience of feeling unhappy, stressed, apathetic and unsettled within the past seven days. While depressed mood has been shown to be linked to social roles (Aneshensel, et al., 1981; Arber \& Khlat, 2002; Bird, 1999; Brown, 2002) and to alcohol use (Berger \& Adesso, 1991; Flynn, 2000; Sexton, et al., 1999; van Gool, et al., 2007), external control was found to be a relevant factor for health outcomes among care givers, for example (Kaplan \& Boss, 1999; Skaff \& Pearlin, 1992; Skaff, Pearlin, $\&$ Mullan, 1996). However, a handful of studies have observed a link with alcohol use (Prescott, et al., 1997; Thomas \& Hsiu, 1993).

Studies on social roles and alcohol use have found that the expected relationship varied according to gender, culture, and age group (Gmel, et al., 2000; Knibbe, et al., 1987; Kuntsche, et al., 2006; Kuntsche, Knibbe, \& Gmel, 2009; Paradis, Demers, \& Nadeau, 1999; R. W. Wilsnack \& Cheloha, 1987). According to research by Kuntsche et al. (2009), the number of social roles had a significant effect on alcohol use. In the large majority of the ten industrialized countries included in this study, the higher the number of social roles 
individuals held, the lower their risk of heavy alcohol use. However, the pattern was more consistent among men than it was among women. Furthermore, in some countries holding more social roles was not associated with lower alcohol consumption among women. Other studies which carried out cross-cultural comparisons of the relationship between social roles and alcohol use also found cultural variations (Gmel, et al., 2000; Kuntsche, et al., 2006). In a study of U.S. women, Wilsnack and Cheloha (1987) did not observe a common pattern, but they did identify age-dependent associations between heavy drinking and the number of social roles. The authors analysed the relationship between social roles and alcohol use in four different age groups $(21-34,35-49,50-64$ and the over 65s). They observed a consistent protective effect of being married, having children and being employed on alcohol use in the two younger age groups. However, the lack of important social roles was associated with higher levels of problematic alcohol use across both these groups.

The relationship between specific social roles and alcohol use was also the focus of several longitudinal studies (e.g. Hajema \& Knibbe, 1998; S. C. Wilsnack, et al., 1991). The most consistent effect was a drop in alcohol use when the respondents became parents (Hajema \& Knibbe, 1998; Power \& Estaugh, 1990b). This was confirmed in a meta-analysis of social role changes conducted by Temple et al. (1991). The authors found a negative association between becoming married and drinking for both women and men. Not getting married and divorce were associated with greater alcohol consumption among men aged over 39 , whereas only divorce led to increases in alcohol use among their female peers.

Two opposing theories have been suggested to explain the link between social roles and alcohol use. On the one hand, there is the "role accumulation hypothesis" or "classic role theory" (Aneshensel, et al., 1981; Hibbard \& Pope, 1991; Hong \& Seltzer, 1995). Central to this theory is the assumption that individuals with fewer social roles have a higher probability of becoming heavy drinkers than those with more roles. Accumulating more roles should result in a more structured life and thus fewer opportunities to drink heavily. On the other hand, there is the "multiple burden" or "role overload" hypothesis (Doyal, 1995; Macran, et al., 1996; Ross \& Mirowsky, 1992), which posits that the risk of role conflict rises concomitantly with the number of roles a person has. Domestic duties and child-rearing responsibilities coupled with career demands may lead to stress, which in turn may lead to a mitigation of the positive effects of holding multiple roles. Research in the alcohol field has found substantial evidence to support the "role accumulation hypothesis" (e.g. Kuntsche, et al., 2009). 
Both theories differ in how psychological aspects as well as the number of social roles are thought to influence alcohol use. Based on the assumptions of the "classic role theory", the greater the number of social roles a person holds, the more his or her daily life is structured by meaningful activities that others expect one to engage in. Partnership, parenthood, and paid labour bring individuals into contact with others and are associated with activities that are defined by the expectations of significant others. It can be assumed that the more everyday life is structured by social activities which the individual and others deem important, the more likely it is that he or she will take care that the time spent in drinking situations and/or drinking-related changes in behaviour (e.g. drunkenness) do not interfere with their rolerelated obligations (Knibbe, et al., 1987; R. J. Neve, et al., 1997). Concerning the link between social roles and psychological well-being, classic role theory leads to the expectation that having no or few roles makes it potentially more difficult to structure one's life around meaningful relationships. Consequently, this may be more often associated with negative emotions like feeling externally controlled or feeling depressed, thus suggesting a mediating effect. However, the combination of being depressed or feeling externally controlled and the number of roles a person holds may also be reflected in his or her alcohol use. In other words, the effect of the number of roles on alcohol use may differ depending on the psychological background of the individual. Those with lower scores on depressed mood or those who feel less externally controlled may benefit from holding more social roles, as classic role theory suggests, because these give a structure to one's life and offer fewer opportunities for heavy alcohol use. The opposite, though, may also be true: individuals who already feel depressed or controlled by external sources may suffer from having more roles, as these are likely to generate tension with regard to how to manage one's time and whether the person is able to give one's partner, co-workers, or children the attention and time they expect. When multiple roles protect or aggregate the tendency to drink when a person feels externally controlled or depressed, the person's psychological type serves as a moderator by affecting (buffering or increasing) the strength of the protective effect from holding several roles.

The "multiple burden hypothesis" assumes that the risk of role conflicts increases when several roles are held simultaneously, which in turn may lead to stress. As the "tension reduction hypothesis" suggests, the intake of alcohol as a depressant may diminish the resulting tension (Cappell \& Greeley, 1987). It seems plausible that the same role conflict may also lead to depressed mood or the feeling of being externally controlled. Given that the relationship between the number of social roles and alcohol use follows the assumptions of 
the "multiple burden theory", negative emotions like depressed mood or feeling externally controlled may mediate this. Besides a mediation effect, the assumptions of the "multiple burden hypothesis" also allow a moderation effect of depressed mood and external control on the relationship between roles and alcohol use. The strain of combining multiple roles together with negative emotions may cumulatively lead to an increased tendency to use alcohol to cope.

An examination of the possible impact of psychological well-being on the relationship between social roles and alcohol use is paramount for prevention policy. Sustained measures at the macro level are needed to influence the possibility of combining a set of social roles (job, partnership and parenthood) with a view to preventing problematic alcohol use. Even then, it is extremely difficult for a national government to exert any significant influence on factors like the job market or divorce rates. Interventions on depressive mood (e.g. medication) or on the locus of control (e.g. psychological therapy) are probably easier to develop and implement (DeRubeis \& Crits-Christoph, 1998; Kendall, Cantwell, \& Kazdin, 1989).

Therefore, the aim of the present study is to examine whether psychological factors mediate or moderate the relationship between the number of social roles and alcohol use. It focused on three specific adult roles: taking care of oneself by earning an income (paid labour), taking care of children (parenting), and forming a permanent and stable relationship with a partner (partnership). The present study will look specifically at two psychological factors, namely depressed mood and external control. The social role-alcohol use relationship will be examined for men and women separately, as previous studies have shown that it varied between the genders (e.g. Kuntsche, et al., 2009), with a greater tendency among men to use alcohol in order to cope with negative emotions like feeling depressed or externally controlled (e.g. Berger \& Adesso, 1991). The present study addressed the following research questions: (1) Do depressed mood and external control mediate the relationship between the number of social roles and alcohol use?; (2) Does the level of depressed mood and external control affect the relationship between the number of social roles and alcohol use?, and (3) Does this relationship differ for men and for women? 


\section{Methods}

\section{Study design}

Data was taken from the $3^{\text {rd }}$ Swiss Health Survey, a nationally representative survey conducted in 2002 under the direction of the Swiss Federal Statistical Office. The total sample size was 19,706 respondents (response rate $64 \%$ ) who were aged 15 or older and were taken from the electronic telephone directory. Information on social roles and alcohol use were integrated in a large set of questions on various aspects of general health (e.g. medical consultations, hospitalization and care-seeking) as well as health-related behaviours (e.g. eating habits, smoking, and use of illegal drugs). Data on social roles, depressed mood, and alcohol use were gathered via computer-assisted telephone interviewing (CATI). Questions on external control were asked by means of a paper-pencil questionnaire sent to the participants by post after completion of the telephone interview. The present study was limited to adults aged between 25 and $45(n=6,232)$. The lower age range was chosen to ensure that the respondents had completed their education, and that this was not the reason why some were not in paid work. The age range was also limited to ensure that children still lived in the household or were sufficiently young to generate a potential child-rearing impact. All analyses were adjusted for the possible confounding effects of age and level of education, stratified by gender and restricted to those who had consumed alcohol within the past 12 months (drinker, 5,059 respondents). Respondents with missing values on social roles and/or alcohol use were excluded from the analysis $(n=222 ; 4.4 \%)$. All respondents with more than three missing values on the remaining variables were also excluded $(n=169 ; 3.3 \%)$. For respondents with up to three missing values, imputation methods were applied (see section 2.3.). The analysed data set included 4,668 respondents, comprising 2,187 women $(46.9 \%)$ and 2,481 men (53.1\%).

\section{Measures}

\section{Social roles}

Employment status: A dichotomous indicator measuring employment: (0) not in paid employment, (1) employed.

Partnership: This dichotomous variable covered cohabiting respondents regardless of their marital status, and compared them with those living alone. 
Parenthood: The indicator is based on child(ren) who lived with the respondent, and the variable was dichotomised into parents (1) versus not (0).

Number of social roles: The indicator is the sum of the three variables, ranging from 0 to three. As a result, all roles contributed to this indicator with equal weight. The sum was chosen instead of a separate analysis of each individual role because classic role theory assumes that having more social roles is associated with a lower risk of heavy drinking. The role overload hypothesis was tested by analysing the effect of 2- and 3-way interaction of the three roles on the measures of alcohol consumption. The aim here was to evaluate whether specific combinations of the three social roles (employee, parent and partner) differ in terms of the influence they have on alcohol use.

As earlier studies (R. W. Wilsnack \& Cheloha, 1987) indicated that the relationship between social roles and drinking in general differ across age groups, the present study tested for age-related differences in the bivariate relations between these variables and for possible age-related effects in those models with significant mediation or moderation effects.

\section{Psychological factors}

Depressive mood: The measure was based on the four items of the following question: "On how many days during the last week did you feel: (1) depressed or unhappy; (2) relaxed, balanced, and composed; (3) strained, huffy, and nervous; (4) full of power, energy, and optimism. The response format was: never (4), on one or two days (3), on three or four days (2), almost every day (1). Item (1) and (3) were re-coded inversely so that high values on depressive mood indicated a high level of psychological distress. The four items were used to construct a latent variable for the linear structure equation models on mediating effects. The latent variable had an acceptable model fit $(\mathrm{CFI}=.968, \mathrm{RSMEA}=.080)$.

External control: This indicator is based on a reduced version of the Pearlin Mastery Scale (Pearlin, Lieberman, Menaghan, \& Mullan, 1981) which measures the respondents' internal versus external locus of control. The indicator was based on four statements with a four point Likert-scale: totally agree (4), rather agree (3), rather disagree (2), totally disagree (1). The statements were: "If you think about your whole life, to what extent can you agree or disagree with the following statements?" (1) There is no way I can solve some of the problems I have; (2) Sometimes I feel that I am pushed around in life; (3) I have little control over the things that happen to me; (4) I often feel helpless in dealing with the problems of 
daily life. These were presented in a paper-pencil questionnaire. High values on this indicator indicate a high level of external control. These four statements were used again to construct a latent variable. As for the former the latent variable had an acceptable model fit (CFI = .991, RSMEA $=.051)$.

Descriptive findings for both indicators were based on a summary score of the items. The Cronbach's alpha of summarised scales was sufficiently high (Depressed mood: .71, Mastery: .76: Bland \& Altman, 1997; Nunnally \& Bernstein, 1994).

\section{Alcohol use variables}

Average quantity per day: the total volume of alcohol consumption was measured in grams of pure ethanol per day by adding up the volumes of beer, wine, cider, and spirits consumed in the past 12 months and divided by 365 days.

Risky single occasion drinking (RSOD): indicates the annual frequency of drinking a certain amount during the last 12 months. The measure is gender-specific: "During the last 12 months, how often did you have eight or more (for men; six or more for women) glasses of beer, wine, spirits, or other alcoholic beverages on one occasion?"; one drink contains about 10 grams of pure ethanol.

\section{Missing value imputation}

The LISREL 8.51 program (Jöreskog \& Sörbom, 2001) was used to impute missing values. For respondents who did not answer three items at most (6.8\%), missing values were replaced by means of Markov Chain Monte Carlo (MCMC) estimates (Congdon, 2003; Gilks, Richardson, \& Spiegelhalter, 1996; Schafer, 1997) . MCMC is a simulation method in the Bayesian tradition. Starting with the prior distribution of observed values, random draws of missing values are made, which are conditional on an item and the individual parameters of the observed values. The individual missing value is imputed by randomly selecting a value from this conditional distribution for the given individual and his or her observed item response pattern. The procedure is iterative and uses Markov Chains until convergence of the posterior distribution is reached. The advantage of this method is that it takes into account information from the values observed for each individual, i.e. imputation is conditional on individuals that have the same response pattern on all but the missing items. As a result, we were able to draw on a maximum of information on one individual derived from other items. 


\section{Statistical analysis}

The analysis of the mediation effect was based on linear structural equation models (SEM). A mediation model is understood as a model that seeks to explain an observed relationship between an independent and a dependent variable via the inclusion of a third explanatory variable, i.e. the mediator variable (e.g. Baron \& Kenny, 1986). Rather than hypothesizing a direct causal relationship between the independent variable (here the number of social roles) and the dependent variable (here alcohol use, see path A in Figure 2-1), a mediation model hypothesizes that the independent variable causes the mediator variable (here psychological factors, see path $\mathrm{C}$ in Figure 2-1), which in turn affects the dependent variable (path D in Figure 2-1).

In the linear model, the indirect effect is the product of path coefficients $\mathrm{C}$ and $\mathrm{D}$. When the direct effect between the independent and the dependent variable (path B in Figure 2-1) is no longer statistically different from zero after inclusion of the mediator variable, the mediation effect is said to be complete, while a reduction compared with A is said to be partial. 
Figure 2-1 Mediation model of psychological factors in the link between social roles and alcohol use

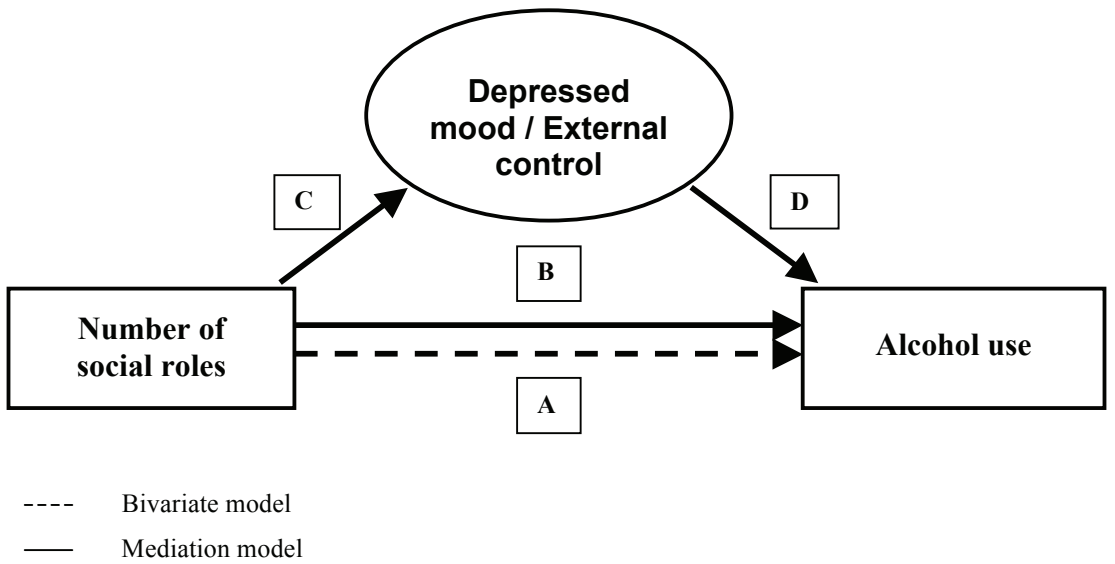

To test the moderation effect of the two psychological variables, an interaction effect between the continuous variable - number of social roles - and psychological factors was tested. All regression models were adjusted for age and education level.

The mediation models were estimated using the Mplus 4.0 software (Muthén \& Muthén, 2004). The indirect associations, i.e. the product of the path coefficients between the number of social roles and psychological variables, and between psychological variables and alcohol use, were generated directly by the linear structural equation model software, Mplus. The standard errors of indirect effects were obtained by means of the delta method (Muthén \& Muthén, 2004). Reported effect sizes are expressed as standardized regression coefficients (Betas). RMSEA values smaller than .08, and CFI values higher than .90 (e.g. Hu \& Bentler, 1999; Ullman, 2001) indicate an acceptable model fit. Moderation models were analysed with multiple ordinary least squares regressions.

\section{Results}

Women reported lower alcohol use than men, but had higher means when it came to depressed mood and external control (see Table 2-1). Women were less often employed, but 
more often lived with a partner and had children. This means that all three roles were more common among men, whereas two roles were more common among women.

Table 2-1 Quantity per day, RSOD, psychological factors (mean), and social roles (number) stratified by gender; drinkers only

\begin{tabular}{|c|c|c|c|c|c|}
\hline & & & & test & \\
\hline & & $\begin{array}{l}\text { Women } \\
(n=2,187)\end{array}$ & $\begin{array}{c}\text { Men } \\
(n=2,481)\end{array}$ & values & $\begin{array}{c}\text { Total } \\
(n=4,668)\end{array}$ \\
\hline \multirow[t]{2}{*}{ Alcohol use $^{1}$} & $\begin{array}{l}\text { Average quantity per day (in } \\
\text { gram pure ethanol) }\end{array}$ & 6.7 & 15.5 & $-17.4^{\star * *}$ & 11.3 \\
\hline & RSOD (annual frequency) & 1.8 & 3.5 & $-5.2^{* \star *}$ & 2.7 \\
\hline \multirow[t]{2}{*}{ Psychological factors $^{1 ; 3}$} & Depressed mood & 6.3 & 6.1 & $3.4^{* *}$ & 6.2 \\
\hline & External control & 6.8 & 6.7 & $2.15^{\star}$ & 6.7 \\
\hline \multicolumn{6}{|l|}{ Social roles ${ }^{2}$} \\
\hline Employment status & yes & 77.7 & 96.0 & $357.1^{\star \star *}$ & 87.4 \\
\hline Partnership & yes & 73.6 & 68.4 & $15.0^{* * *}$ & 70.8 \\
\hline Parenthood & yes & 54.9 & 50.9 & $7.5^{\star *}$ & 52.8 \\
\hline \multirow[t]{4}{*}{ Number of social roles } & no role & 1.8 & 2.4 & $231.9^{* \star *}$ & 2.1 \\
\hline & one & 25.0 & 29.5 & & 27.4 \\
\hline & two & 38.3 & 18.6 & & 27.8 \\
\hline & three & 34.8 & 49.6 & & 42.7 \\
\hline
\end{tabular}

Remark: ${ }^{1}$ Mean differences tested by t-tests; ${ }^{2}$ Mean differences tested by Pearson's $\chi$ squares; ${ }^{3}$ Descriptive findings were based on summary scores of the items. ${ }^{*} \mathrm{p}<.05,{ }^{* *} \mathrm{p}<.01, * * * \mathrm{p}<.001$

Regression models including 2- and 3-way interactions of the roles on alcohol consumption measures detected only one case where more social roles were associated with higher rather than lower consumption. It appeared that single fathers $(n=3)$ drank less than fathers who had more roles. As the number of single fathers in our study $(n=3)$ was very low, we do not consider this exception as a support for the role overload hypothesis (results not presented).

The bivariate relations between the number of social roles and alcohol use were, with the exception of quantity per day among men (men: $\beta=-.005, \mathrm{t}=-0.25$, n.s.), consistently negative, (quantity per day: women: $\beta=-.068, \mathrm{t}=-3.16, \mathrm{p}<.01 ;$ RSOD: $\beta=-.052, \mathrm{t}=-2.37$, $\mathrm{p}<.05$; men: $\beta=-.094 ; \mathrm{t}=-4.48, \mathrm{p}<.001)$, thus supporting classic role theory. Table $2-2$ 
gives an overview of the gender-specific correlations between the dependent and independent variables. The highest correlation across both genders was between depressed mood and external control (.346 among men and .369 among women). The correlation between all other independent variables appeared to be low, indicating a low risk of collinearity. A moderate correlation between both alcohol measures(Cohen, 1988) was found only among women (.353; see Table 2-2).

Table 2-2 Correlation matrix for alcohol measures, depressed mood, external control and number of social roles; gender stratified; drinkers only

\begin{tabular}{|l|l|c|c|c|c|c|}
\hline & & $\mathbf{1}$ & $\mathbf{2}$ & $\mathbf{3}$ & $\mathbf{4}$ & $\mathbf{5}$ \\
\hline $\mathbf{1}$ & RSOD & - & $.353 * * *$ & $.044 *$ & $.054 *$ & $-.052^{*}$ \\
\hline $\mathbf{2}$ & Average quantity per day & $.140 * * *$ & - & .001 & -.029 & $-.051^{*}$ \\
\hline $\mathbf{3}$ & Depressed mood $^{1}$ & .036 & $.092 * * *$ & - & $.369 * * *$ & $-.074 * *$ \\
\hline $\mathbf{4}$ & External control $^{1}$ & .043 & .043 & $.346 * * *$ & - & $-.066 * *$ \\
\hline $\mathbf{5}$ & Number of social roles & $-.103 * * *$ & .015 & $-.099 * * *$ & $-.067 * *$ & - \\
\hline
\end{tabular}

Remark: $\quad{ }^{1}$ based on summary scores of the items. Grey cells give values for women, white for men;. 
Regarding age-related differences in terms of the link between the number of social roles and both alcohol measures, no significant effects could be found for men, but among younger women the number of social roles had a stronger protective effect on alcohol use than it did for those aged 35 and over (average quantity per day: 25-35: -.074; 36-49: -.063; RSOD: 2535: -.065, 36-49: -.037).

Compared with the bivariate model, the multiple SEM hardly changed the relationship between the number of social roles and both alcohol use variables (see Figures 2-2 and 2-3). The relationship between social roles and depressed mood or external control was consistently negative for both genders. 
Figure 2-2 Mediation model including the gender specific (in)direct effects of the number of social roles via depressed mood (standardized Betas, t-values in brackets) on alcohol use

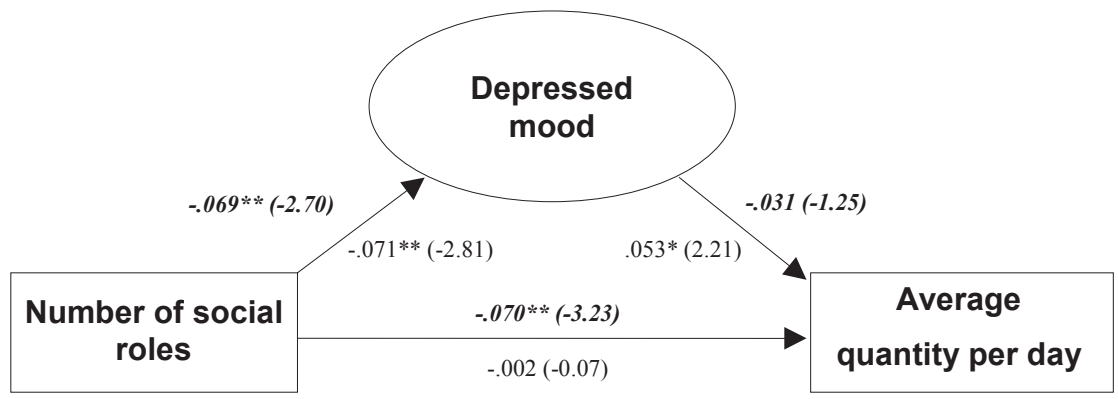

Indirect effect of number of social roles on quantity per day via depressed mood: women: .002 (1.14); men: -.004 $(-1.74)$

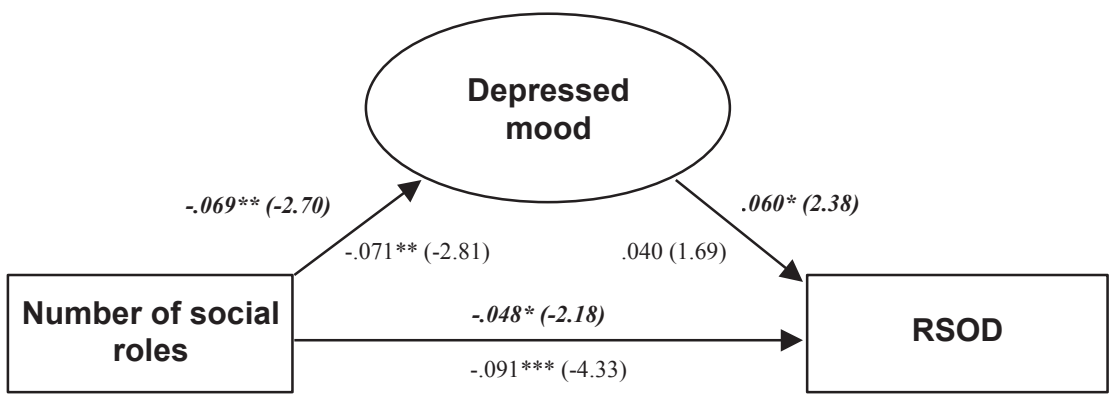

Indirect effect of number of social roles on RSOD via depressed mood: women: -.004 (-1.78); men: -.003 (-1.45)

Remark The upper standardized Betas (t-values) given above the line in bolt italic represent women; the below men. All models were adjusted for age and educational level; * $\mathrm{p}<.05, * * \mathrm{p}<.01, * * * \mathrm{p}<.001$. Quantity per day: Model fit CFI=.959; RMSEA =.042; RSOD: Model fit CFI=.961; RMSEA =.041 Average quantity per day: mean consumption per day in gram pure ethanol; RSOD: annual frequency of 6 or more drinks for women, 8 or more drinks for men 
Figure 2-3 Mediation model including the gender specific (in)direct effects of the number of social roles via external control beliefs (standardized Betas, t-values in brackets) on alcohol use

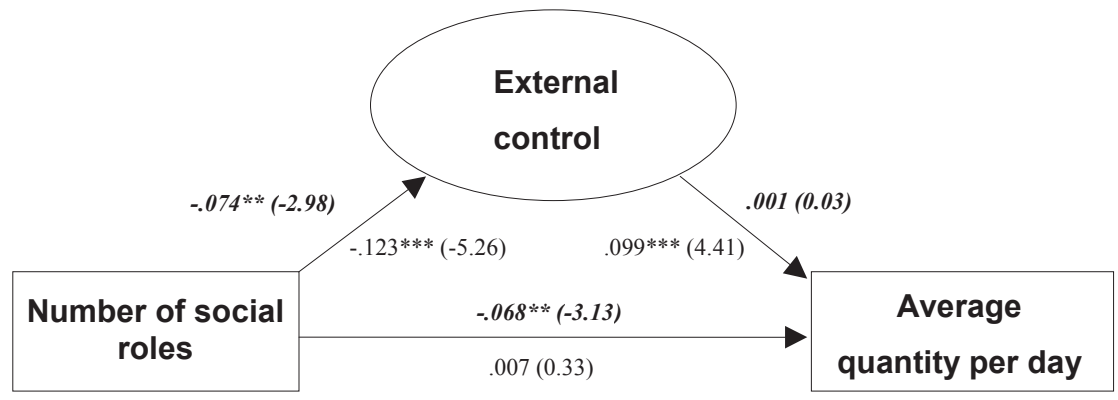

Indirect effect of number of social roles on quantity per day via external control: women: -.000 (-0.03); men: $.012^{* * *}(-3.37)$

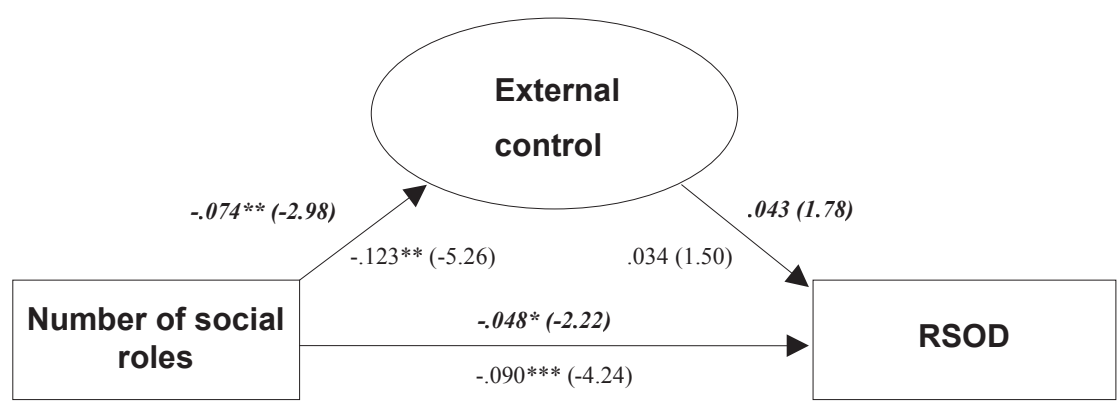

Indirect effect of number of social roles on RSOD via external control: women: -.003 (1.53); men: -.004 (-1.44)

Remark The upper standardized Betas (t-values) given above the line in bolt italic represent women; the below men. All models were adjusted for age and educational level; * $\mathrm{p}<.05, * * \mathrm{p}<.01, * * * \mathrm{p}<.001$. Quantity per day: Model fit CFI=.983; RMSEA =.032; RSOD: Model fit CFI=.982; RMSEA =.032 Average quantity per day: mean consumption per day in gram pure ethanol; RSOD: annual frequency of 6 or more drinks for women, 8 or more drinks for men 
Among men, external control as well as depressed mood were positively associated with alcohol use, but reached significance only for quantity per day (depressed mood: .053, $\mathrm{p}<$ .05 ; external control: .099, $\mathrm{p}<.001)$. Among women the associations of depressed mood and external control with drinking measures were low and, with one exception, insignificant for both alcohol measures. The only significant positive association was observed between depressed mood and RSOD $(\mathrm{p}<.05)$.

In the mediation models only one indirect effect of the number of roles obtained significance, i.e. external control and quantity per day among men. This indirect effect, however, cannot be seen as a mediator effect in the classical sense, because there was no bivariate direct effect of the number of roles on quantity per day (see above).

In the moderation models a significant interaction (tested with continuous variables based on the sum scores on psychological factors) was obtained among women only (compare Table $2-3)$. The interaction between the number of social roles and external control $(\mathrm{t}=2.62, \mathrm{p}<.01)$ was significant for average quantity per day. For the graphical representation of the interaction given in Figure 2-4 the variable external control was median split. Those below the median were labeled as low external control, while those above were labeled high external control. When comparing the two groups, there appeared to be no protective effect of multiple roles for women scoring high on external control. 


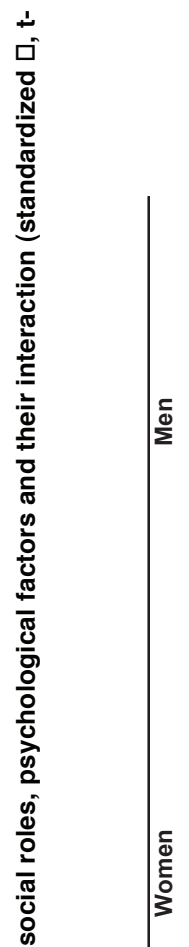

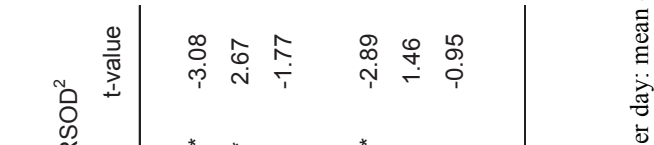

D

$\sum_{\Sigma}^{\infty}$

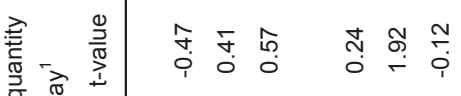

离

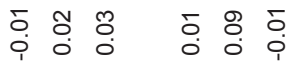

突

总

要

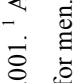

$\begin{array}{lll}v & \infty \\ * & .\end{array}$

药

*

อ. छ

$\checkmark 5$

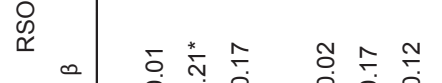

î

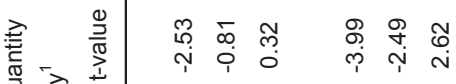
वे $\sqrt{\frac{0}{0}}+$

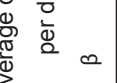

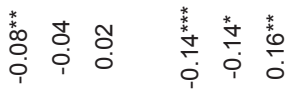

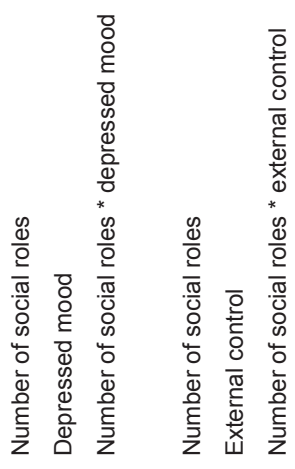

?

$\begin{array}{ll}v \\ 2 & 0\end{array}$

$*$

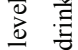

可

.

胥

$\stackrel{Ð}{\ddagger}$

ธ

ญ 巳

응

ธั ฮั

은 즐

过

就

กั

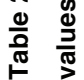

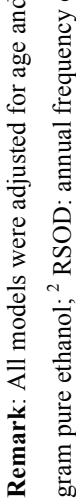


Figure 2-4 Graphical representation of the significant moderation model of external control on the link between average quantity per day and the number of social roles, women only

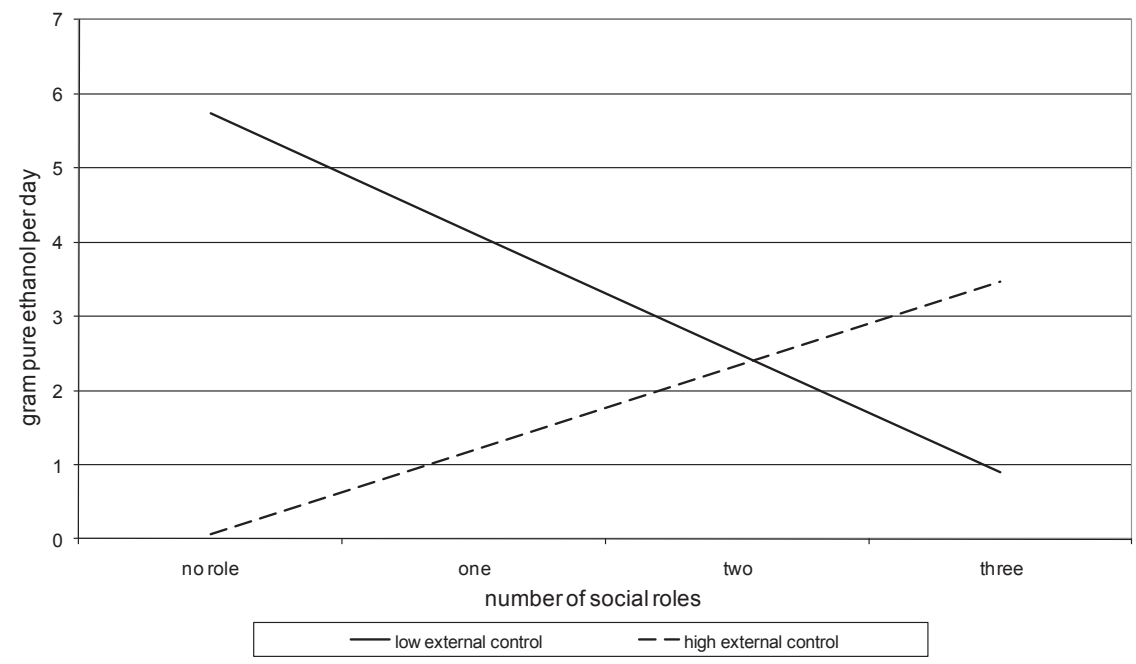

Remark: For the graphical representation of the interaction the variable external control was median split. Values below the median are labelled low external control, those above high external control.

\section{Discussion}

The main research questions of the present study were whether depressed mood and external control mediate or moderate the relationship between the number of social roles and alcohol use. The answers provided by the study were rather straightforward: no proof was found to support the assumption that depressed mood or external control mediate the relationship between the number of social roles and alcohol use. With one exception, there was no indication that either of these factors moderates the relationship between the number of social roles and the average quantity per day or RSOD. The only exception was among women who scored high on external control. However, no protective effect of multiple social roles on average quantity per day was found for this group. The findings on the relationship between the number of social roles and alcohol use confirmed the assumptions of classical role theory. The study observed that the more social roles a person holds, the lower the average quantity of alcohol consumed per day for women and the lower the frequency of 
RSOD for men. There was no support for the multiple role hypothesis which posits that the accumulation of social roles leads to greater alcohol consumption.

The reason why the two variables indicating psychological well-being do not mediate the relationship between the number of social roles and alcohol use was not due to a lack of interrelations between the sets of variables. The relations between multiple social roles and depressed mood and external control necessary for mediation, in fact, did achieve significance (Aneshensel, et al., 1981; Arber \& Khlat, 2002; Bird, 1999; Brown, 2002). The study also found a significant relation between depressed mood or external control and alcohol use, although not for all drinking measures (Sexton, et al., 1999). Finally, the number of social roles was associated with one drinking measure among men and with two among women. The lack of mediation appears to be due to the fact that the number of social roles and depressed mood/external control related to different aspects of drinking. For men the number of social roles was associated with RSOD, while depressed mood was associated with average quantity per day. For women, the number of social roles was associated with the average quantity per day, though the two psychological well-being variables were associated with RSOD. Two more general conclusions can therefore be drawn: (1) multiple roles and depressed mood or external control differ in terms of the aspect of drinking they are related to, and (2) there is a gender difference in the aspect of drinking that is influenced by the number of social roles and variables indicating psychological well-being. This last conclusion indicates that men and women differ substantially in terms of the variables may explain their alcohol consumption. Among men a considerable lack of psychological well-being was associated with a higher average consumption. This may signify that men tend to cope with negative emotions through higher alcohol use, an aspect suggested by alcohol regulation theory (e.g. McCreary \& Sadava, 1998; Peirce, Frone, Russell, \& Cooper, 1994). In addition, previous studies (Berger \& Adesso, 1991; Timmer, Veroff, \& Colten, 1985) suggested that this coping style is more prevalent among men. For women a lack of structure in everyday life due to a limited number of social roles seems to fulfil the same process as a man's lack of social well-being. Women with fewer social roles reported higher levels of average alcohol use, confirming the assumptions of the classic role theory (e.g. Hong \& Seltzer, 1995). Increased frequency of RSOD among men indicates a lack of structure in everyday life, while among women it is likely to be a reaction to poor psychological well-being. This gender difference, whereby the drinking behaviour adopted by the person aims to compensate for either an unstructured life or poor psychological well-being, explains why no mediation is found. 
Despite the significant effect of external control on the relationship between the number of social roles and the average quantity per day among women, the study could find no moderation effect of depressed mood or external control. The processes behind these findings are similar to those found for mediation, at least among men: average consumption was independent of both mood measures. RSOD was associated with depressed mood but the impact of this factor did not vary significantly between those with a high or low number of social roles. Men who reported depressed mood tend to have higher levels of RSOD, as suggested by alcohol regulation theory, but they do not necessarily drink more or less if this depressed mood is combined with a high or low number of social roles. For women reporting higher levels of external control, average consumption rose with the number of social roles they held. The opposite was observed for women scoring low on external control. These results suggest that women who feel externally controlled and not able to master their lives on their own suffer from holding multiple social roles. One reason may be that these social roles - parenthood, partnership, and employment - increase the pressure they feel or may even be the source of their perception of being externally controlled. The demands of family life with a partner and children or career demands may lead women to feeling at the mercy of external demands and wishes. For women in this category, holding more social roles did not prevent them from drinking more. Quite the opposite, in fact: No such relationship was found for depressed mood. It may be that women use other substances like prescribed or unprescribed drugs to cope with these negative emotions and the demand of social roles.

The present study has certain limitations. The first one concerns its cross-sectional design, which did not make it possible to establish any causal relationship between the number of social roles and alcohol use, and thus to identify whether the number of social roles someone holds results in reduced alcohol use or whether someone's alcohol use limits his/her access to certain social roles, such as finding a partner or work. The same holds true for psychological factors. The current study was not designed to answer the question of whether those with a higher number of social roles tend to have lower values on depressed mood or a higher internal control, or whether individuals with a lower "psychological burden" engage more easily in partnerships or other social roles.

A second limitation concerns the restricted number of psychological well-being variables. The same can be said of the number of social roles. This study uses only three: having a partner, being a parent and being in paid work. When seen from the wider concept of the structure of everyday life, a more differentiated measure of paid work should be used, e.g. in 
terms of the number of hours of paid work. Also, other roles which the study omitted, such as voluntary work and caring for (chronically) ill relatives, are very likely to structure everyday life and may be related to certain drinking behaviours. Another limitation is that the present study focused on the number of social roles per se but not on the relevance of each social role or specific role combinations on an individual's alcohol-related behaviour.

Even when these limitations are taken into account, the present study suggests that the central focus of preventive policy should not only be the psychological factors related to drinking but also the environmental factors which favour the adoption of social roles that structure everyday life (e.g. participation of women in the workforce) or which facilitate interplay (e.g. by providing better accompanying conditions, such as child care opportunities, paid leave for mothers or fathers with sick children) in order to avoid possible role conflicts and related negative outcomes. This may be particularly relevant for Switzerland, which is ranked No. 40 on the Gender Gap Index (Hausmann, Tyson, \& Zahidi, 2007) and No. 27 on the Gender Equation Measure (United Nations Development Programme (UNDP), 2007). Several studies have shown that a social welfare system that provides better childcare opportunities for example, and thus helps individuals manage the combined earner-parent role fosters the protective effect of multiple roles (Gmel, et al., 2000; Kuntsche, et al., 2006; Lahelma, et al., 2002). In the case of women who score high on external control, psychotherapeutic approaches like cognitive behavioural therapy aimed at increasing the internal (rather than external) locus of control (Dusseldorp, Spinhoven, Bakker, van Dyck, \& van Balkom, 2007; Katerndahl, 1991) may strengthen the beneficial effect of holding multiple roles. More generally, this study confirmed that individuals who feel pushed around in life or have a depressed mood may have a dysfunctional coping style (e.g. Folkman, Chesney, Pollack, \& Coates, 1993; Grassi, Righi, Sighinolfi, Makoui, \& Ghinelli, 1998), which is reflected in an increased average quantity (men) or increased frequency of RSOD (women). Therefore, interventions aimed at promoting more functional coping styles should be included in prevention policy. 


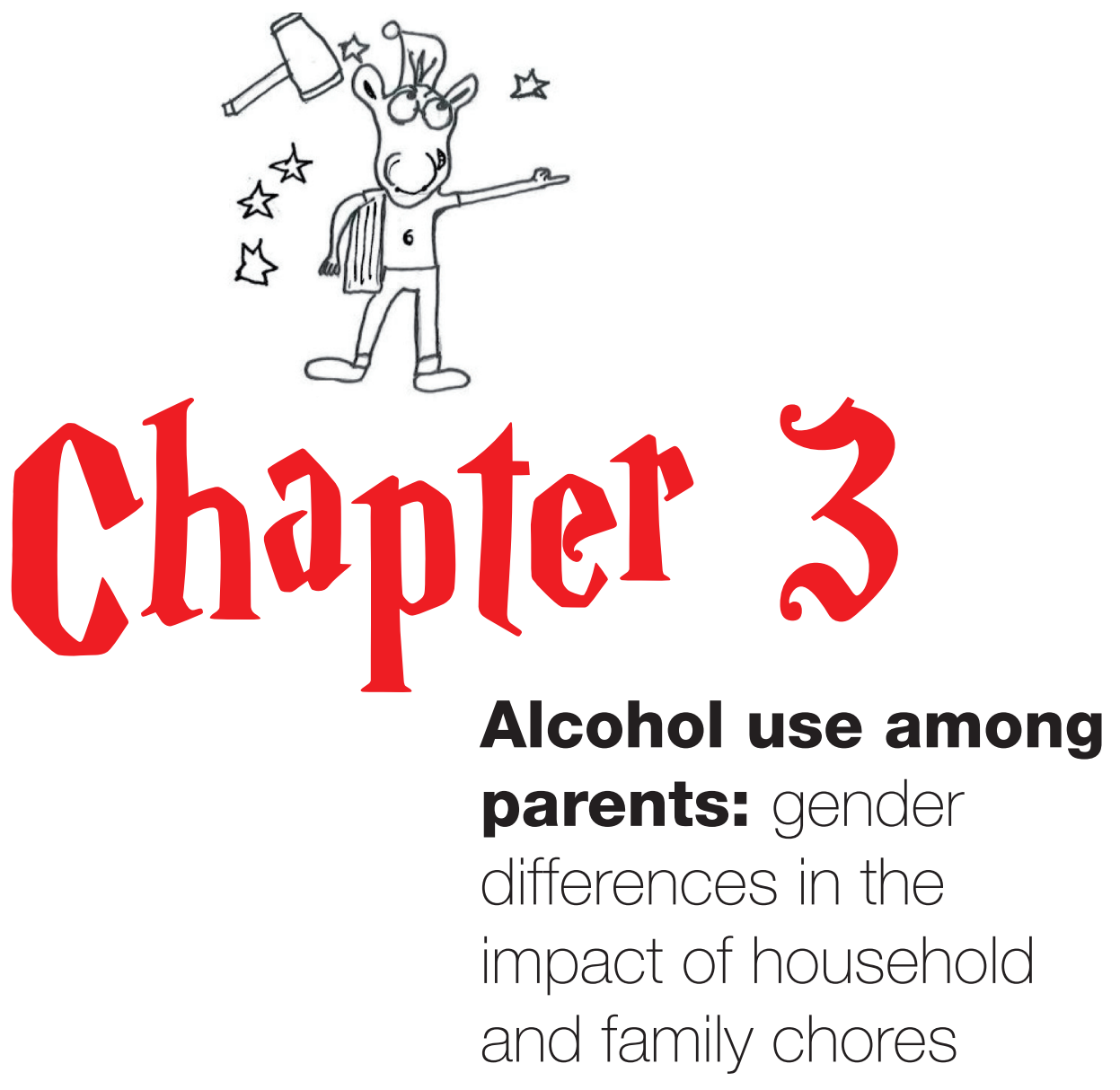




\section{Summary}

Objectives: Social roles such as parenthood influence alcohol use. Nevertheless, little is known about how specific aspects of a given role, in this case parenthood, may influence alcohol use. The research questions for this study were the following: (1) Are family-related factors linked to the alcohol use of mothers and fathers?; (2) Does the level of employment, i.e. full-time, part-time employment or unemployment, moderate the relationship between family-related factors and parental alcohol use?

Participants: Survey data of 3,217 parents aged 25 to 50 living in Switzerland.

Method: Mean comparisons and multiple regression models of annual frequency of drinking and risky single occasion drinking, quantity per day on family-related indicators (age of the youngest child, number of children in the household, majority of childcare / household duties).

Results: Mothers systematically demonstrated more protective relationships between familyrelated indicators and alcohol use than fathers. Whereas maternal responsibilities in general had a protective effect on alcohol use, the number of children had a detrimental impact on the quantity of alcohol consumed per day when mothers were in paid employment. Among fathers, the correlations between age of the youngest child, number of children and frequency of drinking was moderated by the level of paid employment.

Conclusion: The study showed that in Switzerland, a systematic negative relationship was more often found between family-related indicators and women's drinking than men's. Evidence was found that maternal responsibilities per se may protect from alcohol use but can turn into a detrimental triangle if mothers are additionally in paid employment.

Later version accepted for publication:

S. Kuntsche, R. A. Knibbe \& G. Gmel (submitted). Parents' alcohol use: gender differences in the impact of household and family chores. European Journal of Public Health 


\section{Introduction}

Social roles are of pivotal importance in everyday life. They define an individual's position within society based on enduring relations to others and therefore provide a sense of identity and behavioural guidance (McCall \& Simmons, 1996; Stryker, 1980; Stryker \& Serpe, 1982; Thoits, 1991). A theoretical framework often cited in previous studies on social roles is the role accumulation theory (Aneshensel, et al., 1981; Hibbard \& Pope, 1991; Hong \& Seltzer, 1995; Knibbe, et al., 1987; Kuntsche, et al., 2009). This theory focuses on the beneficial health effects in general (Aneshensel, et al., 1981; Hibbard \& Pope, 1991; Hong \& Seltzer, 1995) and not exclusively alcohol use. It assumes that the accumulation of social roles, such as parenthood, partnership and paid employment, results in a more structured life and thus fewer opportunities to participate in (heavy) drinking situations as this may interfere with important activities connected with these social roles. Several studies provide some evidence that social roles affect drinking behaviour (Gmel, et al., 2000; Knibbe, et al., 1987; Kuntsche, et al., 2006; Kuntsche, et al., 2009; Paradis, et al., 1999; R. W. Wilsnack \& Cheloha, 1987). Most of these studies suggest that social roles have a protective impact on alcohol use, which is more pronounced and culturally persistent among men than women (Knibbe, et al., 1987; Kuntsche, et al., 2009). The studies mentioned above focus on the simple fact of being a parent or not. Specific characteristics of the parental role and the associated family and household chores were not considered. Thus, the underlying mechanisms of how social roles influence the individual's alcohol use still remain largely unknown. Yet, it is highly plausible that being a parent is not a unitary concept but rather heavily dependent on the underlying characteristics of the role such as e.g. the number of children, the children's age as well as the distribution of childcare and household chores between mothers and fathers. These aspects may play an important role in the prediction of parental alcohol use. This paper therefore focuses on the relevance of family related indicators to the parental role and their relevance on alcohol use. Previous studies have already examined the underlying mechanisms between the parental role and alcohol use by focusing on specific aspects of parental alcohol use such as drinking locations (Paradis, 2011) or drinking contexts (Paradis, et al., 2011).

In this study it is expected that family related indicators, namely having more children, a younger age of the youngest child and a parent's share in household and childcare duties, will restrict the opportunities to engage in alcohol use. These assumptions are in line with role 
accumulation theory. However, men and women are likely to differ in the extent to which these family-related indicators influence their alcohol use. Based on the results of previous studies (Coltrane, 2000; Crompton, et al., 2005), this study expects that mothers bear a disproportionately large share of the responsibility for children and the household. Therefore, factors such as the number of children or the age of the youngest child are more likely to impact mothers' alcohol use than fathers'. In addition, variations in the extent to which women are responsible for childcare and household duties will have a greater influence on mothers' drinking than fathers'. Despite the fact that mothers tend to bear a disproportionately large share of childcare and household related responsibilities, there has been a strong increase in recent decades in the number of women who combine the role of mother with paid employment (Bird, 1999). By contrast, other studies have only identified a slight increase in the share of household chores undertaken by men in recent decades (Coltrane, 2000; Crompton, et al., 2005).

Especially among women, domestic and child-rearing responsibilities in addition to the demands of paid work may lead to stress, and possible positive effects of employment, for example, may be mitigated by such a role overload (Doyal, 1995; Macran, et al., 1996; Ross \& Mirowsky, 1992), an assumption based on the so called multiple burden hypothesis. A central reason behind the assumption that women are more likely to feel overburdened is that the combination of motherhood and paid work may result in double shifts with paid employment on the one hand and childcare and household chores on the other. If family work is unevenly distributed between men and women, women may end up feeling overburdened. Strains arising from conflicts between family roles and work can be defined as "between role stressors" and may lead to increased alcohol use (Frone, 1999). A few studies have reported a positive correlation between "between role stressors" and alcohol use (Bromet, Dew, \& Parkinson, 1990; Frone, Russell, \& Barnes, 1996; Frone, Russell, \& Cooper, 1997). In a cross-national study, Kuntsche et al. (Kuntsche, et al., 2009) found that in some countries, including Switzerland, combining paid employment and motherhood resulted in higher alcohol consumption than being a housewife. This is in line with the multiple burden hypothesis, and contradictory to the assumptions of the role accumulation theory. This indicates that among employed women, family related obligations may overburden women, thereby inciting them to drink to reduce stress (e.g. McCreary \& Sadava, 1998; Peirce, et al., 1994). This study will therefore also examine the importance of paid employment in the 
interplay between family-related indicators and alcohol use by including paid employment as a possible moderator. To sum up, the central aims of this study are:

- To identify whether family-related factors are linked to the alcohol use of mothers and fathers

- To determine whether the level of employment, i.e. full-time or part-time employment or unemployment, moderates the relationship between family-related factors and parental alcohol use

\section{Method}

\section{Data and sampling design}

The study is based on the third Swiss Health Survey (SHS), the largest health survey in Switzerland to date, conducted throughout 2002 among the general Swiss population aged over 14 as a representative telephone survey based on the Swiss electronic telephone register with a response rate of $63.9 \%$. For this study, the age range was limited to 25 to 50 year olds $(\mathrm{N}=9,117 ; 4,328$ men and 4,789 women). The chosen age range ensured that most people had completed their education and become parents or lived with children aged under 18. Older age groups were not considered to avoid possible health related effects on alcohol use. Those with missing information on one of the variables examined were excluded from the analysis $(n=663)$. As the aim of the study focused on the relevance of family characteristics on parental drinking, all analyses were limited to parents $(n=4,536 ; 2,130$ men and 2,406 women) and to those reporting alcohol use during the past 12 months ( $\mathrm{n}=3,555 ; 1,869$ men and 1,686 women). In addition only parents with a youngest child of 16 or younger were selected $(n=3,229 ; 1,759$ men and 1,470 women. All analyses were weighted throughout to counterbalance an oversampling and differential non-response of certain cantons and age groups. The Swiss Federal Statistical Office, which conducted the surveys in Switzerland, provided weightings to balance the sampling design and reflect the Swiss population.

\section{Dependent and independent variables}

\section{Dependent variables}

Annual frequency of drinking: Measuring the usual frequency of alcohol consumption in days per year. 
Annual frequency of risky single occasion drinking (RSOD): Indicates the annual frequency of drinking a certain amount during the last 12 months. The measure is genderspecific: "During the last 12 months, how often did you have eight or more (for men) or six or more (for women) glasses of beer, wine, spirits, or other alcoholic beverages on one occasion?" A drink signifies about 10 grams of pure ethanol.

Average quantity per day: Based on the consumed annual volume of alcoholic beverages (multiplication of beverage specific usual quantities and annual frequencies; all beverage volumes were summed up) divided by 365 , measuring the amount of pure ethanol in grams per day.

\section{Independent variables}

Number of children: Variable with three categories: (1) one child, (2) two children and (3) three or more children.

Age of the youngest child: A continuous variable measuring the age of the youngest child living in the same household as the respondent.

Respondents were asked how childcare and household chores were distributed within their household. The answers ranged between 0 and $100 \%$ and allowed a trichotomisation of participation in childcare (respondent does the majority, shared responsibilities, partner is primarily responsible). As the middle category was endorsed by less than $5 \%$ of the sample, the information was summarised as follows: Childcare: Indicator about the participation in childcare dichotomised into "respondent does the majority" (1) versus not (0). Household chores: Indicator about the participation in household chores dichotomised into "respondent does the majority" (1) versus not (0).

To test a possible moderating effect of paid employment on the relationship between family-related indicators and alcohol use, the Level of paid employment was measured in three categories: employed full-time (2), employed part-time (1), and unemployed (0).

All analyses were adjusted for the following variables: age of the respondent; cohabitation with a partner (1) or not (0) and educational level. The latter was used as the central indicator to measure socioeconomic status rather than income or occupation because it is a more static variable in relation to individuals than occupation, for example, which may change more often (Gottfredson \& Deary, 2004). The indicator provided by the Swiss Federal 
Statistical Office is based on the highest level of schooling the respondent has completed: compulsory school (0), secondary school diploma/apprenticeship/full-time trade school (1), and university degree/higher professional education (2).

All independent variables were z-transformed. The distribution of the independent variables and cell sizes are given in Table 3-1.

\section{Statistical analysis}

Statistical analysis was performed in two steps using PASW 18.0 (SPSS Inc., 2010). All analyses were performed stratified by gender. The first step involved a bivariate analysis of the relationship between family characteristics and alcohol use. To identify significant mean differences in alcohol use regarding indicators of family life (household chores and childcare duties) the study used t-tests. Differences in categorical indicators (age of the youngest child and number of children in the household) were tested via ANOVA. In a second step, multiple regression models were used to examine the relationship between family characteristics and alcohol use. Age of the respondent, cohabitation and educational level were used as adjusting variables. To study the impact of paid employment on the interplay between family characteristics and alcohol use, interaction effects of the level of paid employment with family characteristics were tested using a forward stepwise procedure. In two cases the distribution of variables appeared too skewed to analyse interactions. Due to the small number of respondents with RSOD in the past 12 months among both genders but especially among women, no interaction models were calculated for this indicator. Also, the distribution of the variables majority in childcare and majority in household chores were too skewed to study the interaction with paid employment. 


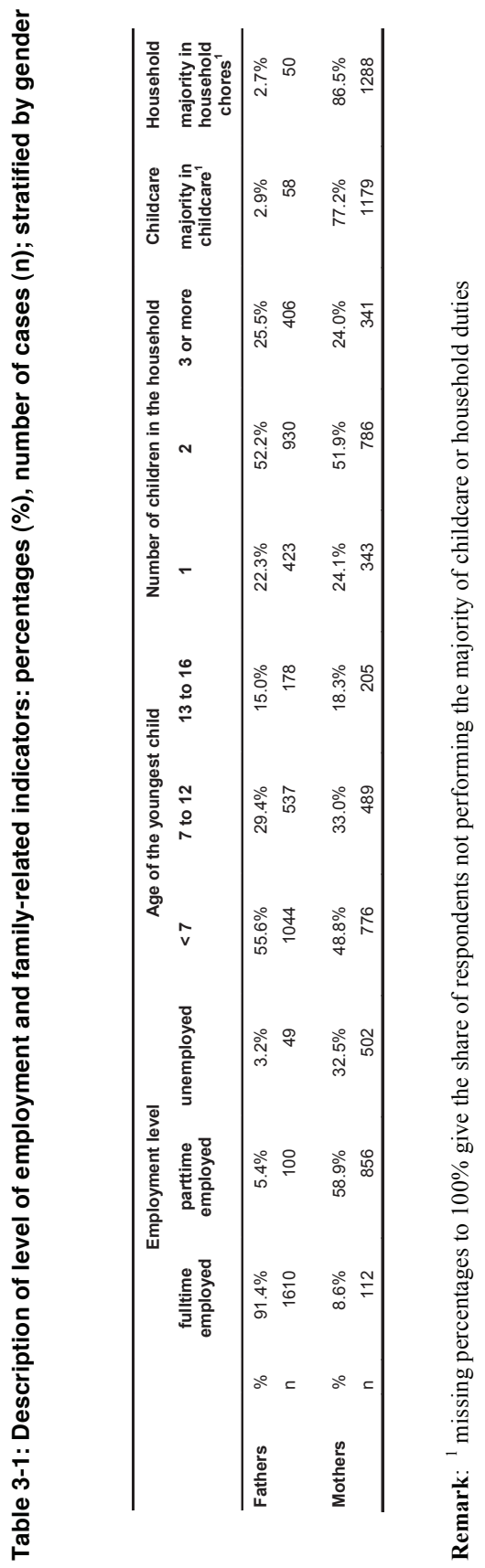




\section{Results}

\section{Bivariate relations}

Women drank less frequently than men $(t=18.6, d f=3664.3, p>0.001)$, consumed smaller quantities per day $(\mathrm{t}=17.0, \mathrm{df}=2684.1, \mathrm{p}>0.001)$ and reported RSOD less often $(\mathrm{t}=2.4$, $\mathrm{df}=3479, \mathrm{p}>0.05)$. Mothers had a lower mean age (38.1) than fathers $(39.3 ; \mathrm{t}=6.0, \mathrm{df}=3672$, $\mathrm{p}>0.001$ ) but mothers reported a higher mean age of the youngest child (7.2) compared with fathers $(6.5 ; \mathrm{t}=-4.7, \mathrm{df}=3380.1, \mathrm{p}>0.001)$.

Results (not presented) reveal that the more children living in a household, the more gender stereotypical the distribution of household chores and childcare (women doing familyrelated work, men as breadwinners) became. Irrespective of the age of the youngest child, the large majority of mothers reported performing the majority of household chores and childcare. An exception is the group of mothers of children aged 13 or older, with only $46.0 \%$ (compared to above $80 \%$ in the other two age groups) of mothers performing the majority of childcare. Mothers with younger children and more children at home were less likely to be employed than those with fewer children.

Table 3-2 displays the results of the bivariate relationship between alcohol use and indicators of family characteristics. Mothers' annual frequency of drinking was related to age of the youngest child and performing the majority of childcare in the expected direction: those with more obligations drank less frequently. Regarding average quantity per day, none of the family characteristics showed the expected influence, i.e. in line with the role accumulation theory. The only significant effect was found for age of youngest child. Although those with young children drank least, the correlation was not linear but u-shaped as those parents with the youngest child between 7 and 12 drank the highest quantities. Another unexpected finding, which is more in line with the multiple burden hypothesis, was the significantly higher frequency of RSOD among mothers with at least three children in the household. On the other hand, mothers performing the majority of childcare engaged in less RSOD than those without such an obligation. 


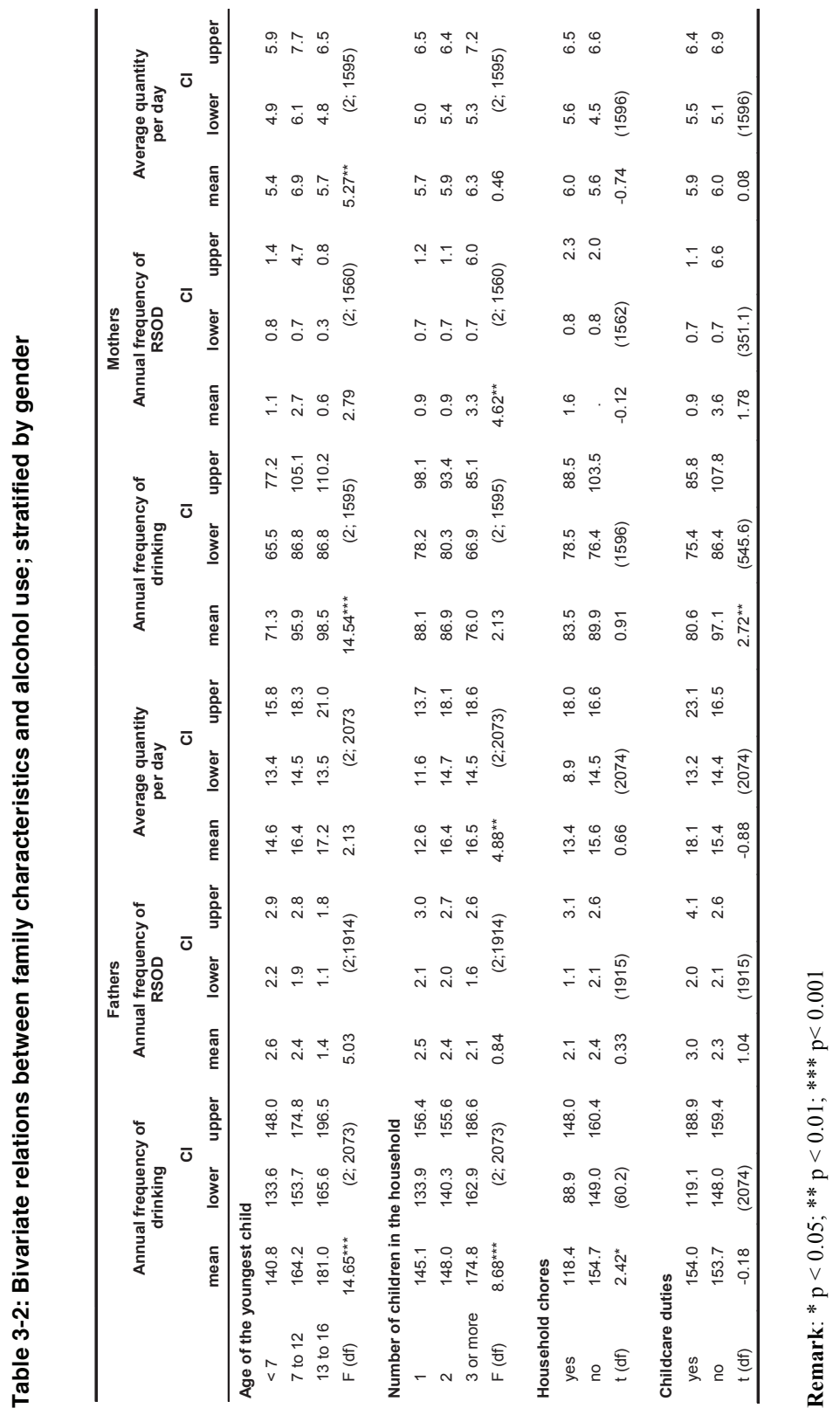


Among fathers, only two outcomes in the expected direction were of significance both on annual frequency of alcohol use: the younger the youngest child, the lower the annual frequency and fathers performing the majority of household chores reported a lower frequency compared to those who did not manage the majority of household chores. As the latter group of men performing the household chores consists of only 50 individuals it must be seen as a marginal result. Three unexpected findings were that fathers increased their quantity per day and the annual frequency of drinking as the number of children in the household increased (Table 3-2) and they reported a higher annual frequency of RSOD when having younger children.

\section{Multiple regression models}

Table 3-3 shows the results for gender-stratified multiple regression models of family characteristics on alcohol use. All regression models were adjusted for age of the respondent, partnership and level of education.

The multiple regressions largely confirm the bivariate analyses. Among mothers, the number of children had the expected protective impact on annual frequency of drinking. Mothers who were mainly responsible for childcare reported lower risks for frequent RSOD. In contrast to the bivariate analyses, age of the youngest child was not found to have any significant influence on mothers' drinking in the multiple regression models. Among fathers, family characteristics were not found to have any direct protective effect on alcohol use and annual frequency of drinking, despite the formerly mentioned small group of fathers doing the majority of household chores. Besides an unexpected positive correlation between annual frequency of RSOD among women, this is consistent with the bivariate relations reported previously. 


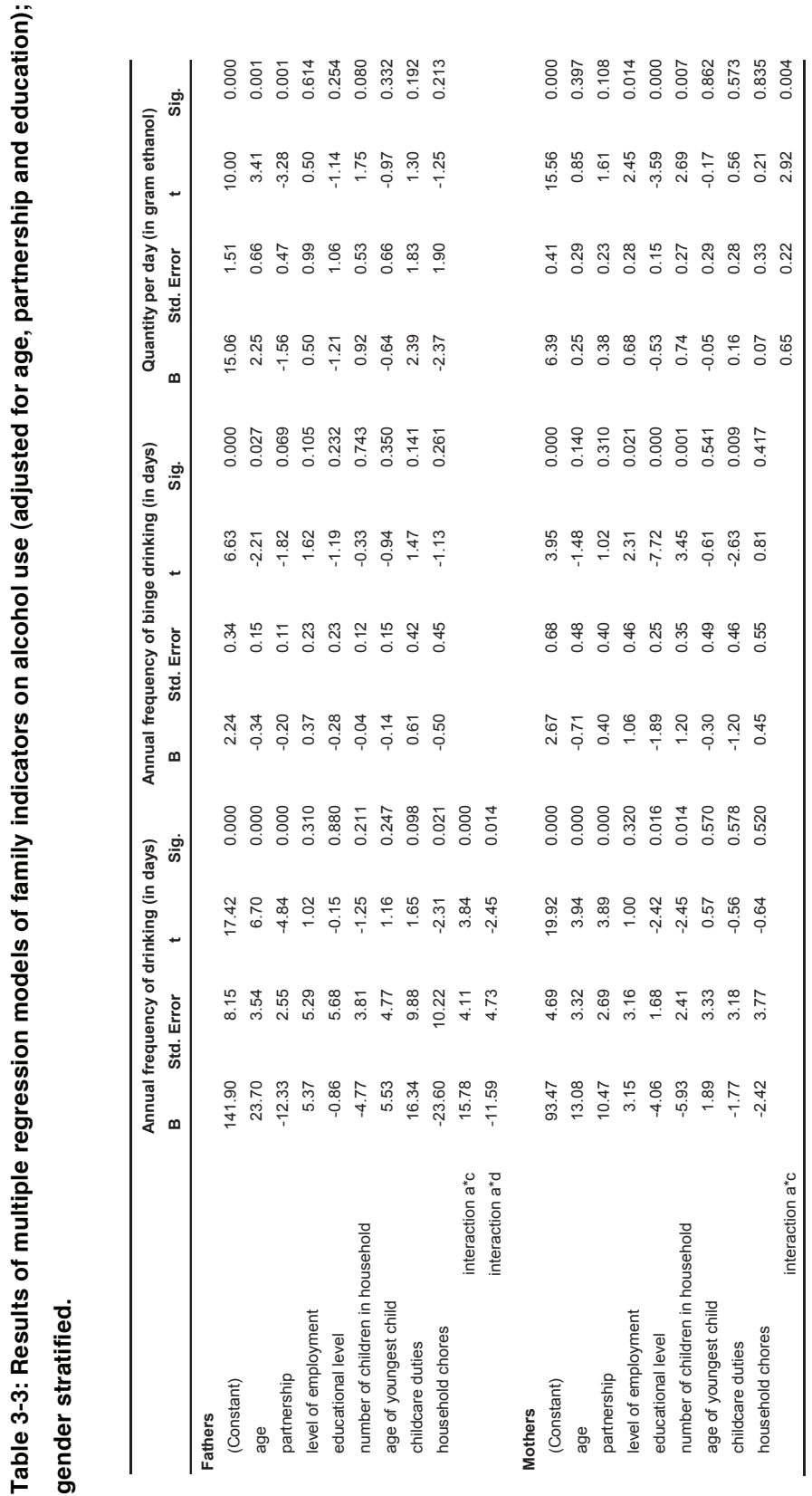


Interactions between paid employment and family-related indicators among fathers reveal a relationship between the number of children and annual frequency of drinking. There is also a second interaction between the age of the youngest child and annual frequency of drinking for the small group of unemployed fathers or fathers employed part time $(<10 \%)$, whereby annual frequency of drinking was lower among this group the younger the youngest child was or the more children there were (see Figure 3-1). 


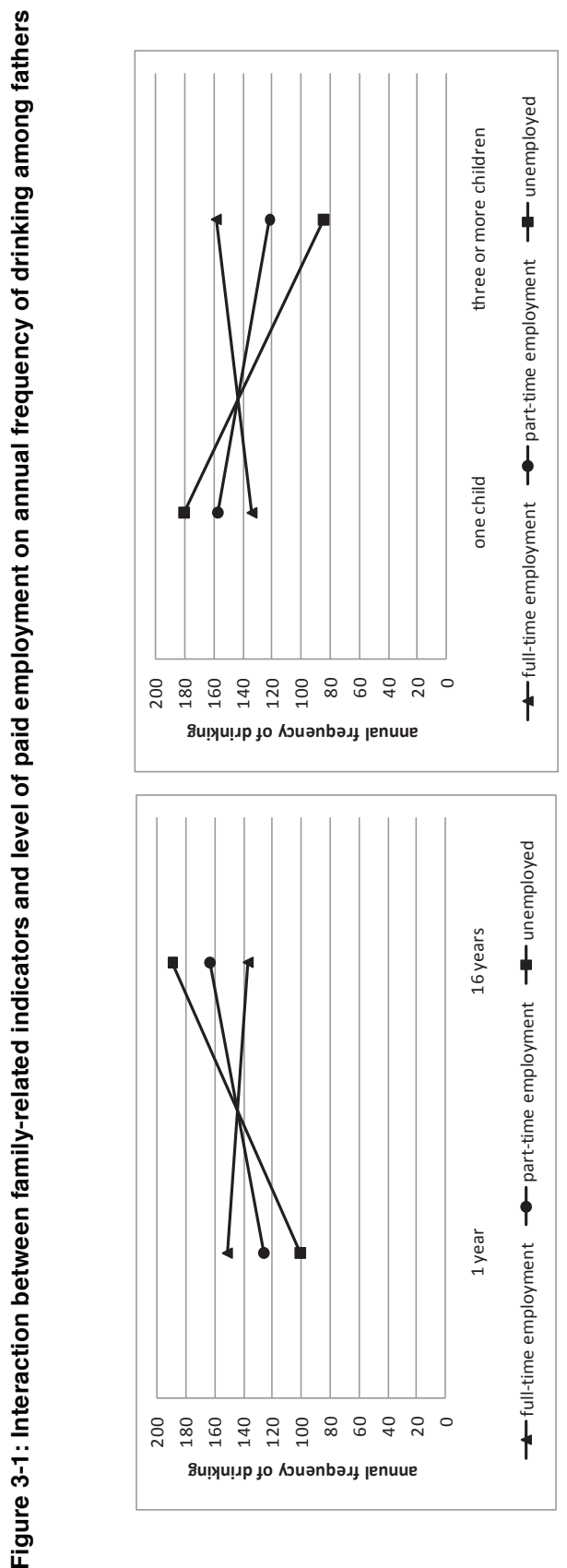


Among mothers, an interaction between the number of children in the household and quantity per drinking day revealed that only mothers who were not in paid employment showed a relationship between the number of children and alcohol use in the expected direction: a decrease in the quantity per day as the number of children increased. The opposite was found for part-time and, especially, full-time working mothers: the higher the number of children, the greater the alcohol intake per day (see Figure 3-2).

Figure 3-2: Interaction between number of children and level of paid employment on quantity per day among mothers

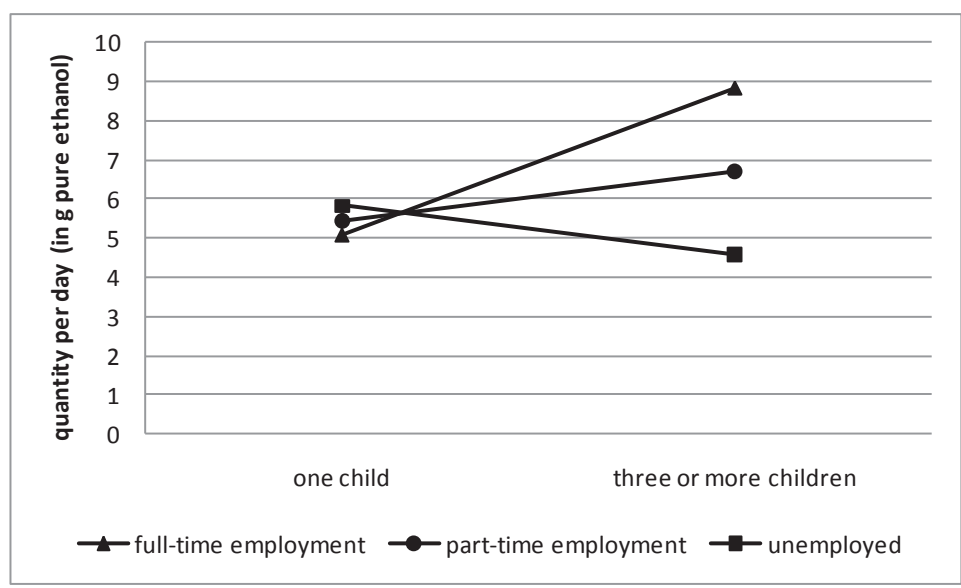

\section{Discussion}

The study raised the question as to whether family related factors are linked to the alcohol use of mothers and fathers. In addition, it aimed to answer the question of whether the level of employment, i.e. full-time or part-time employment or unemployment, moderates the relationship between family-related factors and parental alcohol use.

The results reveal that in Switzerland, women demonstrated more protective associations between family-related indicators and alcohol use than men. The latter, in contrast, showed more detrimental associations between family-related factors and alcohol use, such as an increase in quantity and frequency of drinking when having more children living in the household and engaging in more frequent RSOD when having younger children. This suggests a differentiation between male and female gender roles among parents living in 
Switzerland. This differentiation became even more pronounced the more children lived in a household or the younger these children were. Thus, the results on women largely confirm the assumptions of the role accumulation theory; the more obligations connected to a role there are, the less frequently alcohol will be consumed. Among men, only one indicator, the age of the youngest child, showed the expected negative correlation with annual frequency of alcohol use, whereby the younger the child was, the lower the annual frequency. Although fathers reported a lower annual frequency of drinking when being responsible for household chores, the group of men concerned was very small so the effect must be considered marginal. In contrast to men, an expected negative effect was found in relation to women's annual frequency of alcohol use for three of the four indicators: those with more family obligations drank less. Regarding the other two alcohol measures, average quantity per occasion and annual frequency of RSOD, for each only one factor, (age of the youngest child for quantity per occasion and childcare duties for frequency of RSOD) were seen to have a significant protective effect. The role accumulation theory therefore seems to be somewhat less relevant to mothers' heavy episodic drinking frequency (RSOD) and the usual quantity consumed. A possible interpretation of this is that family-related indicators tend to limit the opportunities to engage in drinking but not necessarily the amount drunk in a given situation. Among men, family-related indicators were less often associated with lower alcohol use as suggested by the theory. Given the results of former studies (e.g. Hajema \& Knibbe, 1998; Kuntsche, et al., 2009) parenthood had a protective effect on men's drinking, but this may be related to a more general responsibility for dependent children (e.g. financial security, providing a safe home) and not necessarily the responsibility for everyday matters related to childcare. Therefore this study may not have found strong effects of family-related indicators on father's drinking.

In addition, the results of this study suggest that there have been no relevant changes in terms of emancipation and equality in the distribution of family work and the effect sharing childcare and household chores could have on men's drinking. Switzerland still shows a rather strong differentiation between the gender roles. But this comes as no surprise, given the fact that paid maternity leave of 14 weeks (at $80 \%$ of the ordinary salary) was only introduced in July 2005 and childcare costs are high, places scarce and mostly limited to larger cities.

Nevertheless, when looking at the effect of paid employment on gender differences in alcohol use, the study found some indication for gender convergence at least among specific population groups. Whereas employed mothers drank alcohol more frequently in larger 
quantities per day, the study found that level of paid employment had no direct influence on alcohol use among men, but a moderation effect of this pattern on the correlation between age of the youngest child and annual frequency or quantity of alcohol use. The positive association between alcohol use and paid employment among mothers may be due to the weaker influence of family related variables among working mothers, particularly those working full-time. Consequently the study found an interaction between the level of paid employment and the number of children among mothers. Mothers in paid employment, especially full-time working mothers, failed to benefit from the protective effect of having a higher number of children at home and consequently reported larger quantities per day. This interaction suggests that maternal responsibilities may protect from alcohol use but can turn into a detrimental triangle if mothers are additionally in paid employment. Against this background it is important to assess how combining paid and unpaid labour affects women, and how this varies according to socio-economic conditions (Doyal, 1995; Macran, et al., 1996). Previous studies concluded that among women who are employed, the inequity of household chores can lead to role overload (Kuntsche, Knibbe, Kuntsche, \& Gmel, resubmitted; Lennon \& Rosenfield, 1994; Ross, Mirowsky, \& Huber, 1983).

This study faced some limitations. Due to the cross sectional design, no conclusions about the causal relations between family life and alcohol use can be drawn. It may be that those respondents with higher alcohol consumption have always made a limited contribution to family life or that those with limited support increase their alcohol use. In addition, the dichotomised measures on household chores and childcare duties used in this study only allow very general comparisons between men and women's participation to be drawn. Future studies should try to gauge household tasks in a more comprehensive and detailed manner.

To conclude, the results of this study suggest a clear differentiation between male and female gender roles among parents living in Switzerland. Although the parental role had a protective impact on fathers' drinking (Kuntsche, et al., 2006; Paradis, et al., 1999), none of the specific factors of the parental role considered in the study (age of the youngest child, number of children, majority of household chores or childcare) influenced paternal alcohol use. The study further provided evidence that maternal responsibilities per se may protect from alcohol use but can turn into a detrimental triangle if mothers are additionally in paid employment. Facilitating the combination of paid employment and maternal responsibilities may help women counterbalance the demands of both roles. Therefore, investment in 
affordable and sufficient childcare places, paid absences from work when children are sick and an increased acceptance of paternal involvement in childcare such as the possibility of reducing working hours in early childhood, will decrease the alcohol use of those women. 


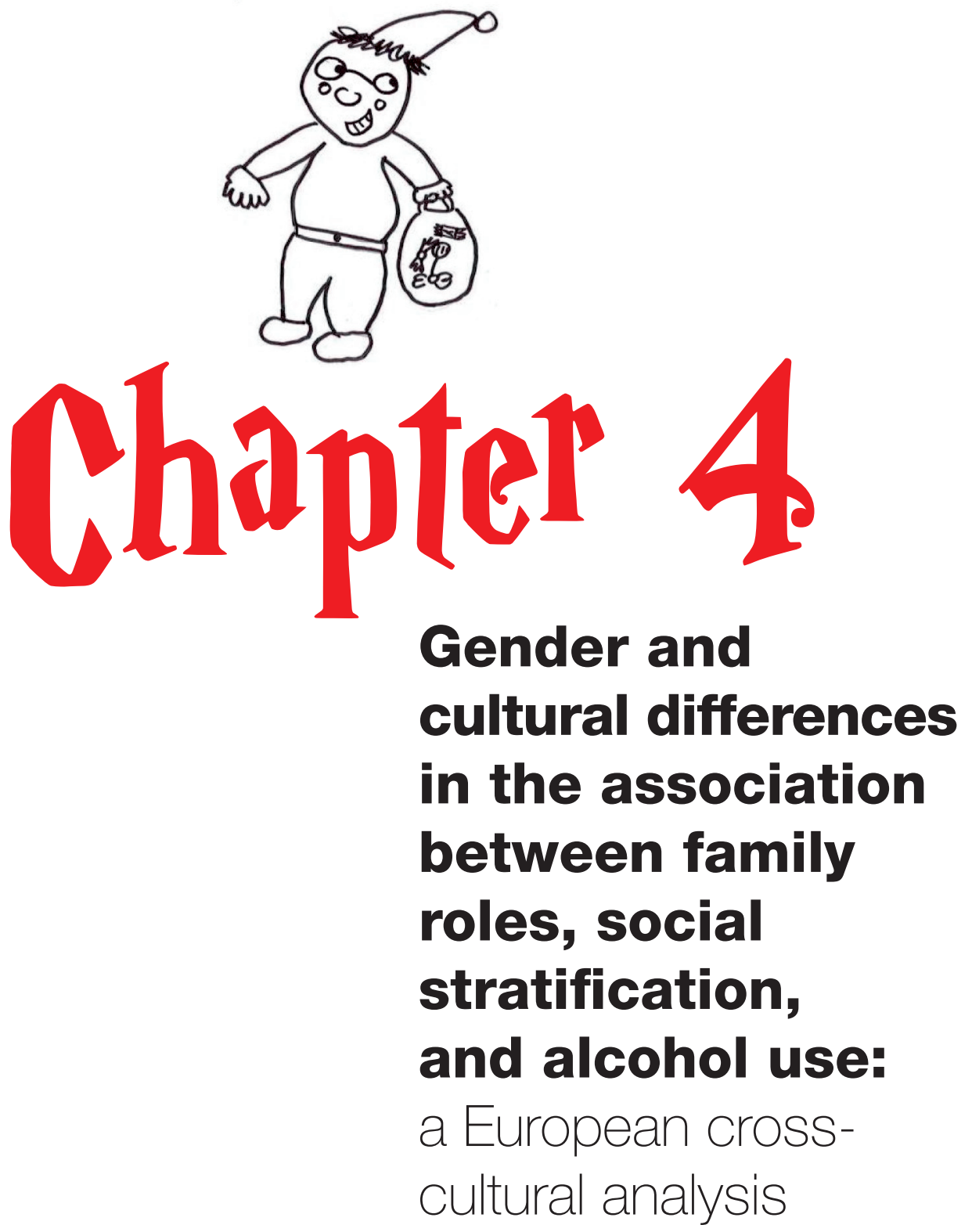




\section{Summary}

Objectives: Firstly, this chapter investigates a) gender differences in associations of social stratification, family roles, and heavy drinking, b) country differences in these associations. Secondly, it seeks to explain country differences in the associations of social stratification and family roles with alcohol consumption by societal level variables.

Participants: Analyses are based on survey data of 25 to 49 year olds from eight European countries (Austria, Czech Republic, Finland, France, Germany, Sweden, Switzerland, UK).

Method: Logistic regressions were used to analyse gender differences in the association between family roles (marriage, having children), social stratification (education, employment) and heavy drinking (> 20 grams/day for women; $30 \mathrm{~g} / \mathrm{day}$ for men). Gender differences were tested by means of interactions between gender and social stratification/family roles. Structural measures of work desirability, social welfare, and gender equity were used to explain differences in associations across countries.

Results: The associations between social stratification, family roles, and heavy drinking varied across gender and countries. A country's social welfare system was associated with heavy drinking only among women. Women in countries with a strong social welfare system, such as Nordic countries, tended to drink more heavily if employed, having lower formal education, and a non-traditional family role. In countries with weak social welfare systems or work desirability, heavy drinking was associated with high education, while effects of family roles and employment were small.

Conclusion: It appeared that the social welfare system and gender equity of a country determines to a large extent how education, employment and family roles are associated with heavy drinking.

Published as:

S. Kuntsche, G. Gmel, R. A. Knibbe, H. Kuendig, K. Bloomfield, S. Kramer \& U. Grittner (2006). Gender and cultural differences in the association between family roles, social stratification, and alcohol use: a European cross-cultural analysis. Alcohol \& Alcoholism Vol. 41, Supplement 1, pp. i37-i46. 


\section{Introduction}

Although there seems to be a recent shift in research on health inequalities to include the structural and material situation of women in societies (Arber \& Cooper, 2000; Bartley, et al., 1992; Macran, et al., 1994), the main emphasis has been on investigating social stratification for men, and on household and family roles for women (Arber, 1991; Arber \& Khlat, 2002; Lahelma, et al., 2002; Matthews \& Power, 2002; Nathanson, 1980; Townsend, et al., 1992; Verbrugge, 1983). The present paper analyses one of the major risk factors for health, namely alcohol consumption (World Health Organization (WHO), 2002), by applying both a social stratification and family role framework to both genders. It hypothesises that the inconsistency of findings encountered in the literature so far are related to structural differences (social welfare, gender equity) of societies. It therefore aims at explaining differences in the association between alcohol use, social roles, and social stratification across countries by structural differences at the macro-level.

There is a long tradition in the alcohol field of studying the associations between social strata and alcohol consumption (e.g. Mäkelä, 1999; van Oers, Bongers, van de Goor, \& Garretsen, 1999). Van Oers et al. (1999) found in the Netherlands that for men heavy drinking was more prevalent at lower educational levels, whereas for women no significant relation between educational level and heavy drinking was found. The negative association between educational level and heavy drinking has been found to exist only for men in some countries (Malyutina, Bobak, Kurilovitch, Nikitin, \& Marmot, 2004; Schnorr et al., 2004), for both genders in others (Fukuda, Nakamura, \& Takano, 2005; Parry et al., 2005), and in some countries even a positive association between educational attainment and heavy drinking has been evident (Bartley, Martikainen, Shipley, \& Marmot, 2004; Baumeister, Alte, Meyer, \& John, 2005). Such inconsistency demonstrates the need for international comparisons, where societal level differences across countries are taken into account.

Though there are many studies on the association between single roles such as marriage or employment and alcohol consumption (e.g. Gotham, Sher, \& Wood, 1997; Leonard \& Rothbard, 1999; Power, Rodgers, \& Hope, 1999; Temple, et al., 1991), there are few studies on role combinations and alcohol use. These have focused on the role accumulation theory (Aneshensel, et al., 1981; Hibbard \& Pope, 1991; Hong \& Seltzer, 1995) which assumes beneficial health effects of holding multiple roles such as being partner and parent. Knibbe et 
al. (1987) and Wilsnack and Cheloha (1987) showed cross-sectionally that individuals with fewer roles have a higher probability of being heavy drinkers than individuals with more roles. Longitudinal research on role transitions has supported the cross-sectional findings. In general, acquiring a new role, such as becoming married or employed, is associated with a reduction in heavy alcohol use (e.g. Gotham, et al., 1997; Labouvie, 1996). Hajema and Knibbe (1998), however, found that getting married or becoming a parent was associated with a decrease in heavy drinking, but becoming employed was not, and a meta-analysis by Temple and colleagues (1991) concluded that the association between drinking and marriage was generally protective for heavy drinking for men, and only for women at younger ages. Similarly, Neve et al. (2000) found that role changes led to decreases in alcohol use only among younger adults, whereas alcohol use increased among the older. These findings suggest that the beneficial effects of role accumulation may only hold at young ages, may not exist for both genders and vary across societies.

Responsibilities for domestic duties and childrearing in addition to work demands may lead to stress, and positive effects of employment, for example, may be mitigated by role overload (Doyal, 1995; Macran, et al., 1996; Ross \& Mirowsky, 1992). As domestic duties and childrearing still are mostly borne by women (Bird, 1999), role overload might be expected to be more prevalent among women than men, explaining some of the gender differences mentioned above. Alcohol might be used to reduce tension (Cappell \& Greeley, 1987) and individuals might drink for psychological relief of negative emotions (e.g. McCreary \& Sadava, 1998). Specific role combinations, such as being a single mother, seemed to be particularly disadvantageous (Hibbard \& Pope, 1987; Whitehead, Burstrom, \& Diderichsen, 2000). For single mothers the social welfare system determines to a large extent whether they live close to the poverty level or not, or are able to combine child care and employment (Arber \& Khlat, 2002; Lahelma, et al., 2002). Thus, the effect of different role combinations may vary across different societies based on countries' social welfare systems and levels of gender equity.

Little research has addressed these potential variations across countries. Findings of Gmel et al. (2000) for four European countries indicated that differences in the social position of women in a country were strongly related to differing associations between specific role combinations, heavy drinking, and gender equality. The present paper includes data on both men and women to shed light on gender differences in the relationship between heavy 
drinking, family roles, and social stratification in eight European countries. These countries differ in the nature of welfare policies especially in provision of child care and the level of paid employment among women (Forssén, 1999). We follow therefore the claim of Moss (2002) that research has to integrate both macro-level and micro-level aspects simultaneously to study the impact of socio-economic and role variables on inequalities in men's and women's health.

The present study investigates three connected hypotheses:

a) There are gender differences within countries in the associations between social stratification and heavy drinking on one hand and between combinations of social roles and heavy drinking on the other.

b) Gender differences in the aforementioned associations vary across countries.

c) Country variations can be explained by structural variables on the country level (social welfare, gender equity).

\section{Methods}

\section{Samples}

Data come from the GENACIS study. Datasets of participating countries were stored in a common databank in Lausanne (see introduction to this issue). Surveys of eight European countries with sufficient information on heavy drinking, social roles, and social stratification were analysed: Austria, Czech Republic, France, Finland, Germany, Sweden, Switzerland, and UK (Table 4-1).

The analysis focused on drinkers only and the age range was restricted to 25-49 years. This was done for two reasons: first, the measure used for formal education was the last education attained. Thus, at younger ages (i.e, under 25 years) this variable may often not represent final educational attainment. Second, for some countries the presence of children in the household only could be obtained, but not the age of these children. The potential contribution of children to role overload or role accumulation may differ with the age of children, e.g. less strain stemming from responsibilities for adult children. The restriction of the respondents' age range assumes that children in the household were likely to be younger. 
Table 4-1 Survey characteristics, sample size (n) 25-49 year olds

\begin{tabular}{llcrrrr}
\hline & $\begin{array}{l}\text { sampling } \\
\text { frame }\end{array}$ & survey mode & $\begin{array}{c}\text { survey } \\
\text { year }\end{array}$ & $\mathbf{n}$ & men & women \\
\hline Austria & national & face-to-face & 1993 & 3580 & 1783 & 1797 \\
Czech Republic & national & face-to-face & 2002 & 1428 & 706 & 722 \\
Finland & national & face-to-face (AUDIT+drugs: self- & & & & \\
France & national & administration) & 2000 & 927 & 481 & 446 \\
Germany & national & telephone & 1999 & 6765 & 3043 & 3722 \\
Sweden & national & postal & 2000 & 5092 & 2242 & 2850 \\
Switzerland & national & telephone & 2002 & 2411 & 1183 & 1228 \\
UK & national & telephone & 1997 & 6349 & 2974 & 3375 \\
& & face-to-face and CAPI & 2000 & 976 & 473 & 503 \\
\hline
\end{tabular}

\section{Measurement}

\section{Heavy drinking:}

Heavy drinking was defined as drinking more than 20 (30) grams a day of pure ethanol on average for women (men). These cutoffs reflect a compromise between commonly used thresholds in the literature (British Medical Association, 1995; Edwards et al., 1994; World Health Organization (WHO), 2000) and the need to have a sufficiently large number of individuals for some role combinations. Recall periods for quantity-frequency measures were the past 12 months with the exceptions of: a) France, where usual quantity was derived from "yesterday" and "past Saturday" consumption and the highest beverage-specific drinking frequency in the past seven days, and b) UK and Austria, where overall consumption across beverages in the past seven days was used.

\section{Social roles and social stratification:}

Family Situation: This variable combined marital status with having children and was used to operationalise social roles. Having children under the age of 18 was used for parenthood. In Germany the survey asked only about having children or not. Given the restricted age range used in the present study this could generally be assumed to mean children under the age of 18 and living in the household. Both variables were combined in a single variable measuring a) partner (married or cohabitating persons) with children, b) partner without children, c) single parents and d) singles without children.

Formal education: The ISCED-97 (International Standard Classification of Education) (UNESCO Institute for Statistics, 1997) was used to derive comparable educational groups 
across countries. The ISCED-97 manual breaks down education into seven categories. For the present analyses these seven categories were collapsed into three categories (low, middle and high), defining the categories where possible so that the bulk of the respondents (approx. 40$50 \%$ ) fell into the middle category (Bloomfield, Gmel, \& Wilsnack, 2006).

Employment: Questions on employment varied widely across countries. The only possibility to achieve a similar measure across all countries was to dichotomise the countryspecific questions in employment (working for pay) and unemployment (including apprentices or students).

Control variables: As control variables age in years and household income were used. Some countries asked for gross income, some for net income. To enhance comparability, household incomes for all countries were recoded into five categories approximating 20 percentiles of the distribution within each country.

Aggregate level variables: Several variables that may be indicative of a country's social system, welfare orientation and gender equity were used from the World Bank database (The World Bank Group, 2002):

a) average years of schooling for women, and the difference between men's and women's average years of schooling as a measure of educational differences;

b) the gross national product (GNP) as a measure of prosperity;

c) indicators of the female working situation:

1. female unemployment rate, and its difference to the male rate;

2. women's labour force activity rate, and its difference to the male rate;

3. the percentage of females' participation in total labour force as potential indications for the impact of a country's employment situation, job security and the corresponding gender equity as regards work roles;

4. birth rate, fertility rate, and the official number of weeks of maternity leave as an aspect of social welfare as well as an indication of the potential impact of being a mother in a country.

In addition, a scale published by Siaroff (1994) to measure female work desirability was used. It was constructed as a weighted average of gender ratios for unemployment, wages, 
and proportions in "elite" positions. Siaroff"s analysis was based on OECD countries only and thus did not include the Czech Republic.

\section{Statistical analyses}

Statistical analyses proceeded in two phases. First, logistic regressions were performed separately for each gender and each country. Because the variables in each block contained more than one degree of freedom, significance was tested as a block by likelihood ratio tests (Hosmer \& Lemeshow, 2000). The p-values in the Tables are aligned to the row of the reference group.

To test whether there were gender differences within countries we used logistic regressions stratified by country including the interaction between gender and social stratification or family role variables, respectively. Interactions were coded to show the effect for women compared with men. A positive interaction coefficient means that compared with men, women were more likely to be heavy drinkers in the particular category of social roles or social stratification variables.

Description and discussion of country differences were not based only on significance. Significance depends heavily on sample size. Following the suggestions of Rothman (2002), the importance or strength of findings does not depend on significance only, but also on consistency across different studies (here different countries). We used the following heuristics to describe and interpret findings across countries in addition to significances. We looked at regression coefficients with the same sign across surveys. Thus, a finding was of importance, if, for example, employment was positively associated with drinking across (almost) all countries, independent of whether this was significant in all countries. We also used a rule of thumb for the strength of associations. For example, an odds ratio of 2 (e.g. a regression coefficient of 0.7 or -0.7 for odds ratios below 1) has been assumed to be of sufficient strength (Kromhout, 1998). We assumed regression coefficients of \pm 0.4 to be indicative for potential associations (with 0.4 corresponding to an odds ratio of about 1.5).

In the second phase the regression coefficients of the first set of gender specific logistic regressions were used to scale countries according to their patterns of associations of control, social stratification and family situation variables with heavy drinking. Optimal scaling was used. Optimal scaling is comparable to principal component analysis (PCA), but has fewer restrictions on the scale level of variables. Given that regression coefficients and variations in 
regression coefficients also depended on sample size or differences in measures used across countries, these coefficients were conservatively assumed to indicate ordinal information instead of having an interval scale level. The interpretation of optimal scaling is similar to PCA, with component loadings indicating the strength of variables for the scale, and Eigenvalues to determine the number of dimensions needed. Object scores can be used as the final scale values of countries. Scales for heavy drinking were derived separately for men and women. It is important to note that the scale is not indicative of which country had the highest rates of heavy drinking, but orders countries relative to similar patterns of variables that were associated with heavy drinking across countries. Thus, two countries would have similar scale values if, for example, the odds ratios of heavy drinking were increased in a similar way with regard to income, age, education, employment, and family situation. The analysis therefore did not focus on similar rates of heavy drinking, but on similar risk factors for heavy drinking.

Optimal scaling was also used for the World Bank indicators to derive an indicator of the countries' work-welfare-equity-index. Finally, gender-specific scales for heavy drinking were correlated with Siaroff's work desirability index and the World Bank's index. High correlations would thus be indicative for an association between country specific risk factors for heavy drinking and the macro-level status of a country's social system, welfare and gender equity status.

\section{Results}

In all eight countries around $90 \%$ of men in this age range were current drinkers (Table 42). The prevalence of female drinkers varied between $78.7 \%$ (Switzerland) and $94.9 \%$ (Germany). Heavy drinking was least common for both genders in the Nordic countries (Sweden, Finland). As regards the family situation in all countries and for both genders around $50 \%$ of the respondents live together with a partner and children. The prevalence of this "traditional role model" was highest in Germany and lowest in Austria for both genders. The largest variation across countries and genders could be found for the prevalence of single parents, being lowest in Switzerland (men: 1.3\%, women: 6.2\%) and highest in France (men: $11.3 \%$ ) and UK (women: 17.7\%).

In all countries except Switzerland and Germany the number of school years was higher among women than men. The difference in unemployment rates commonly favoured men. Only the UK and Sweden showed lower unemployment rates for women than for men. 


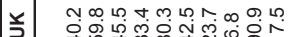

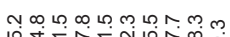

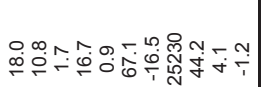

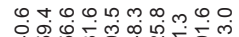

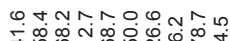

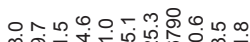

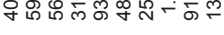

๑

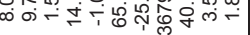

m

시요

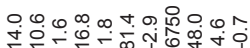

ய

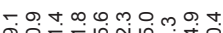

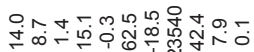

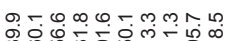

mก

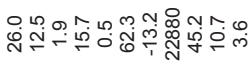

च

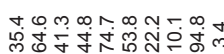

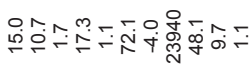

N

ก

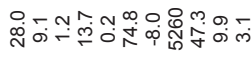

ำ

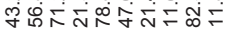

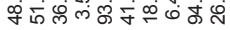

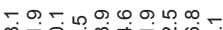

응

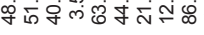

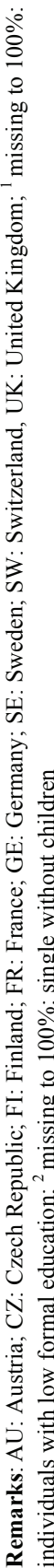

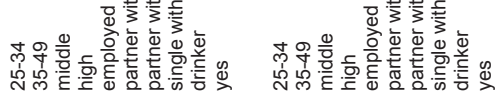
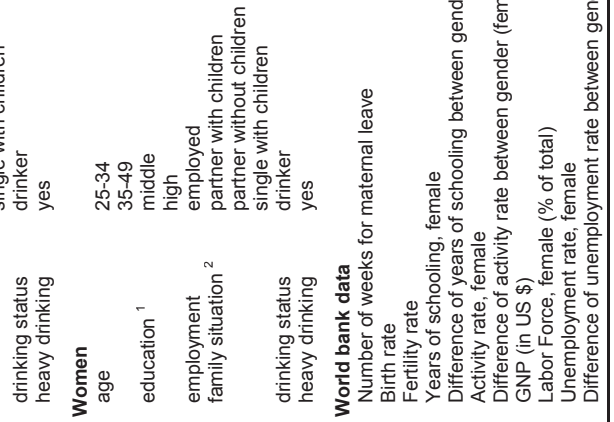

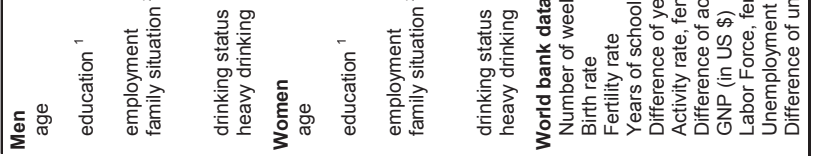


Heavy drinking appeared not to be consistently influenced by household income (Table 43). Significant was only the increase in the prevalence of heavy drinking with increasing income for women in Switzerland and Germany. For most countries heavy drinking increased with age. This could be found for both genders, with the exception of the UK and Sweden, where both sexes showed a negative association between heavy drinking and age. For men in all countries - with the exception of the UK - heavy drinking rates decreased monotonically with education. Thus, individuals with lower education were most likely to drink heavily. For women there were marked differences across countries. In three countries (Sweden, Finland, and Czech Republic) the same tendency was found as for men, namely, higher rates of heavy drinking among individuals with lower education. In three countries, Switzerland, Germany, and France the associations were opposite to those of men. For two countries, UK and Austria, no clear pattern for women could be identified.

Employment status showed no consistent association with heavy drinking across countries. A significant effect could only be found for men in Germany. For most countries the direction of effects was the same for men and women, with a significant exception of Finland. For the family situation, two broad tendencies emerged. First, for men, living in a partnership was associated with lower risks for heavy drinking compared with being single. However, some exceptions could be identified. For example, in Sweden, living with a partner and without children or being single and without children showed the highest risks of heavy drinking. Second, for women, living with a partner and having children was commonly the most protective role combination. Exceptions were Switzerland where single mothers were less likely to be heavy drinkers, and France where female singles had a lower risk of drinking heavily. In both countries associations were not significant, however. In general, female singles without children were most likely to be heavy drinkers. 


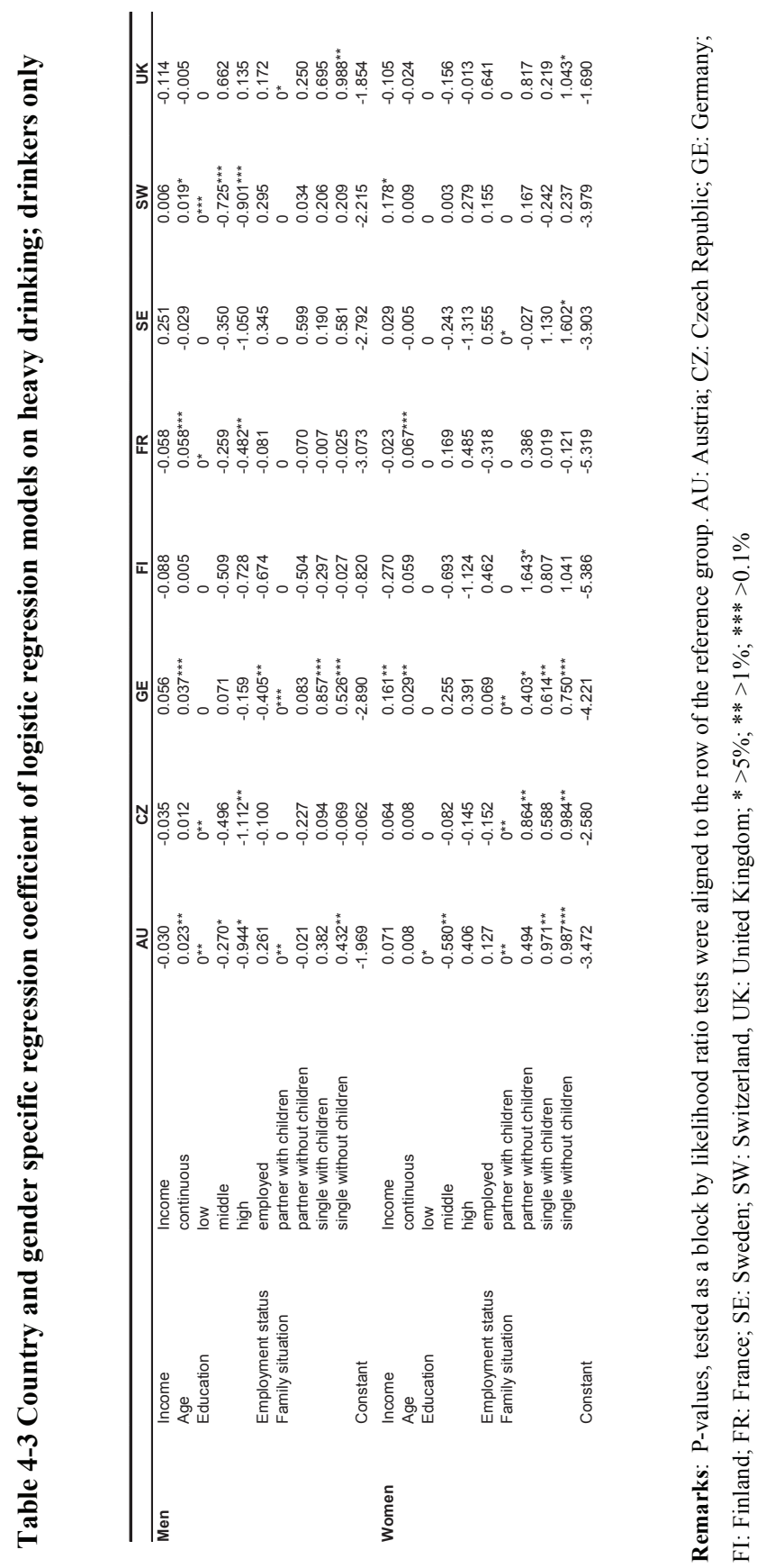


Tests for interactions are provided in Table 4-4. Employed women were statistically not more likely than men to drink heavily with the exception of Germany. As a general, but not significant tendency, employed women showed more often a detrimental association with heavy drinking than a beneficial one. For education the interaction with gender obtained significance in four countries (Switzerland, Germany, France, and Austria). Generally in these countries a dose response relation was found. Women were, compared with men, more likely to be heavy drinkers with increasing education. The same pattern was also found for the Czech Republic, but not significantly so.

For family roles only one country (Czech Republic) obtained significance for the interaction between gender and family situation as a block. In Germany and Finland being a partner without children compared with the traditional role was, as for Czech Republic, associated with the highest risk for heavy drinking among women, but not family roles as a block. 


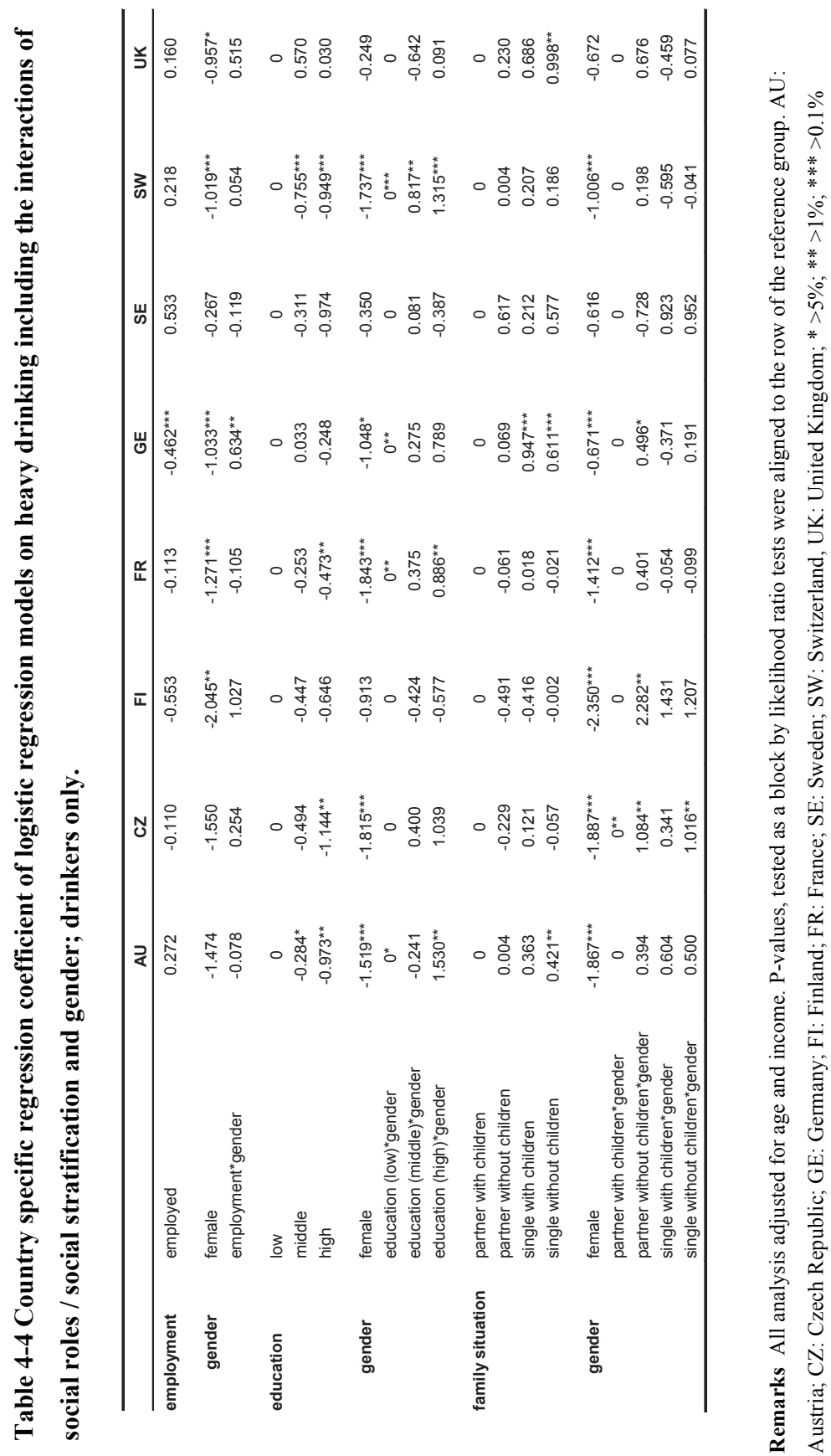




\section{Aggregated analysis}

As a final step, countries were scaled by means of optimal scaling for each gender regarding their associations with heavy drinking. As input for optimal scaling the regression coefficients of the logistic regression models for both genders were used (Table 4-5). A twodimensional solution was obtained (not presented). However, the second dimension was related to the control variables age and income. Thus, a one-dimensional solution was forced and explained about $50 \%$ of the variance in the models. The internal consistency was high, Cronbach's alpha being about 0.9 in both models. Component loadings showed the following for women:

a) Countries ranked higher, the higher the positive association between age (income) and heavy drinking,

b) Countries ranked higher, the higher the positive association between heavy drinking and formal education,

c) Countries ranked higher, the lower the impact of employment on heavy drinking, or the stronger the negative association between heavy drinking and employment.

d) Countries ranked higher, the lower the impact of family situations outside the "traditional" role on heavy drinking, or the stronger the negative association with these roles and heavy drinking.

To conclude, a country scored higher on the heavy drinking scale if higher education was positively associated, if employment was negatively associated, and if the traditional role model (i.e., partner and children) was positively associated with heavy drinking. 
Table 4-5 Unidimensional component loadings of optimal scaling of regression coefficient for the models on heavy drinking

\begin{tabular}{lcc}
\hline & \multicolumn{2}{c}{ Heavy drinking } \\
& men & women \\
\hline Income & -0.48 & 0.78 \\
Age & 0.81 & 0.61 \\
middle education & -0.79 & 0.66 \\
high education & -0.59 & 0.92 \\
employed & -0.32 & -0.92 \\
partner without children & -0.96 & -0.55 \\
single with children & -0.70 & -0.67 \\
single without children & -0.95 & -0.72 \\
constant & 0.75 & -0.20 \\
Cronbach's alpha & 0.89 & 0.87 \\
Variance explained (in \%) & 54.0 & 49.0 \\
\hline
\end{tabular}

The structural data from the World Bank database (Table 4-6) were similarly scaled. With the exception of the difference in employment rates all variables loaded positively on this scale, indicative of measuring a work-welfare-equity index. Thus, for example, the higher the number of weeks for maternal leave, the higher the fertility rate, the higher labour force participation and the more years of schooling, the higher was the rank of countries on this scale.

The positive loadings for differences between men's and women's rates for years of schooling, activity rates, and unemployment meant the following:

a) Years of schooling were generally higher for women compared with men. Thus, countries ranked higher if a larger difference between men and women existed.

b) Activity rates were commonly lower for women. Thus, countries ranked higher if this discrepancy was low.

c) Unemployment was usually higher for women compared to men. Thus, the negative loading meant that countries ranked higher on this scale if the discrepancy between men's and women's unemployment rates was low. 
In general, countries ranked higher if there was more gender equity, better education and a better social welfare system in a country, which was also related to better family care including more weeks of maternity leave and higher birth rates. The Cronbach's alpha for this scale was 0.90 .

Table 4-6 Unidimensional component loadings of optimal scaling of data from the world bank

\begin{tabular}{lr}
\hline Number of weeks for maternity leave & 0.44 \\
Birth rate & 0.80 \\
Fertility rate & 0.84 \\
Years of schooling, female & 0.91 \\
Difference of years of schooling between gender (female-male) & 0.91 \\
Labour force activity rate, female & 0.75 \\
Difference of labour force activity rate between gender (female-male) & 0.87 \\
GNP & 0.25 \\
Labor Force, female (\% of total) & 0.84 \\
Unemployment rate, female & 0.34 \\
Difference of unemployment rate between gender (female-male) & -0.20 \\
Cronbach's alpha & 0.90 \\
Variance explained (in \%) & 49.6 \\
\hline
\end{tabular}

To identify potential associations between predictors (regression coefficients) of drinking measures and structural data (scale of World Bank data and Siaroff's work desirability index) the scale values of countries were correlated. Significant associations were found for both the World Bank scale and Siaroff's work desirability scale for heavy drinking among women ( $\mathrm{r}=$ $-0.93, \mathrm{p}<0.01$ for work desirability; $\mathrm{r}=-0.73, \mathrm{p}<0.05$ for the world bank scale ), but not for men $(r=-0.13, p=0.77$ and $r=0.07, p=0.86)$. The negative association of the World Bank scale and the work desirability index with countries' scaling of women's heavy drinking was related to the inverse loadings for the heavy drinking scale (Table 4-5).

Figures 4-1 and 4-2 illustrate these associations between the heavy drinking scale and the scales of work desirability and World Bank work-welfare-equity respectively among women only, because no significant associations were found for men. At one end Finland, Sweden, and UK had high values for work desirability (scores on Y-axis are taken from Siaroff) and on the World Bank scale measuring social welfare and gender equity (scaled scores on Y-axis represent a normally distributed variable with mean 0 and unit variance). Heavy drinking 
being positively related to employment, low formal education, and non-traditional roles characterised these countries. On the other end, countries with low work desirability, lower social welfare and lower gender equity were Germany and Switzerland, where heavy drinking of women was associated with higher education, and small associations of traditional roles and employment.

Figures 4-1 Regression of the heavy drinking scale on the work desirability scale, women only

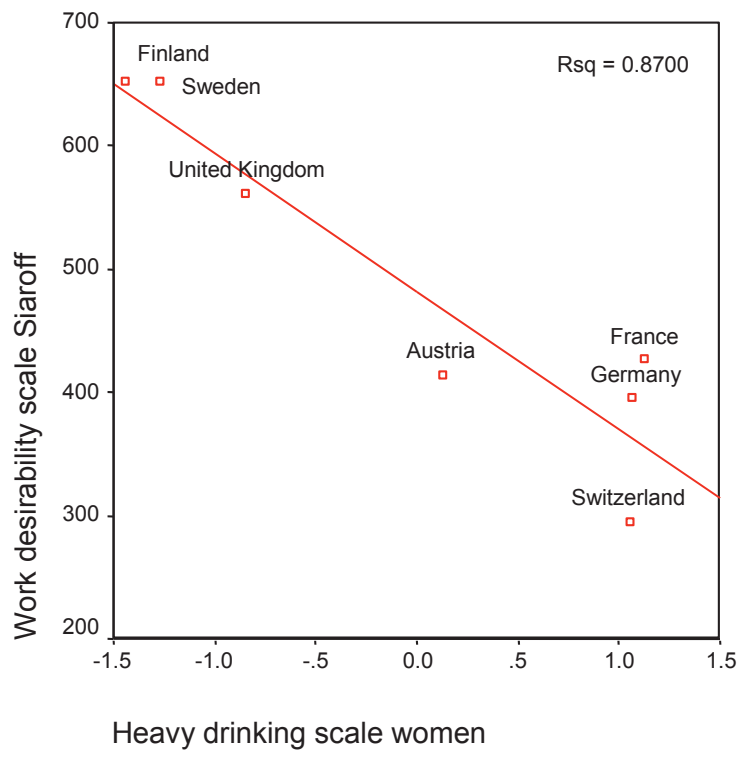


Figures 4-2 Regression of the heavy drinking scale on the work-welfare-equity scale, women only

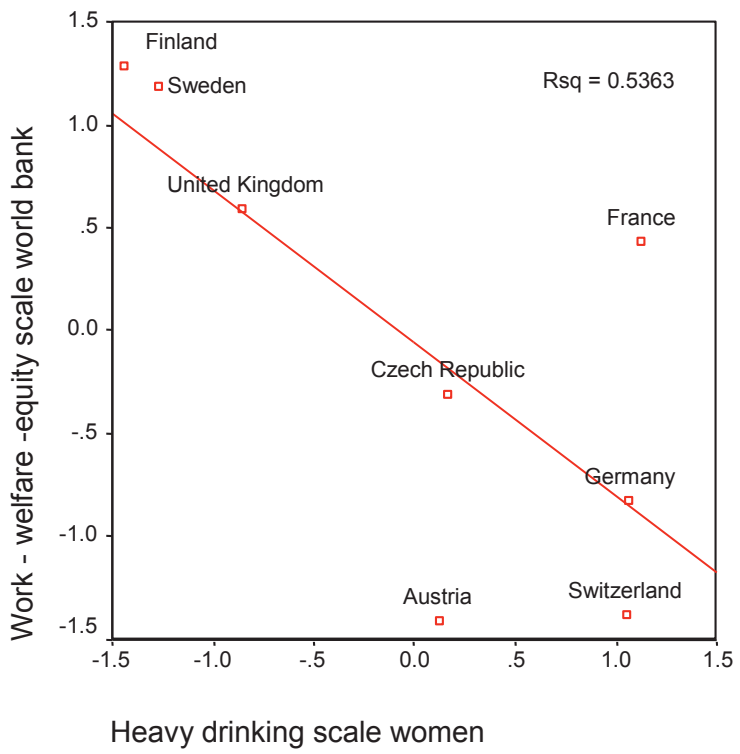

\section{Discussion}

The present study investigated the association between social stratification, family roles, and heavy drinking in eight European countries. It revealed few consistent findings either for genders within a country or within a gender across countries. Most consistent, though, was that heavy drinking decreased with increasing education among men. For women in several countries the opposite was true, confirming other studies (Ahlström, Bloomfield, \& Knibbe, 2001; Bloomfield, Gmel, et al., 2006). Better-educated women sometimes showed a higher vulnerability compared with their male counterparts to drink heavily. It has been argued that women in higher job positions (usually related with better education) more often behave similarily to men in the work world, or simply have more occasions to drink, e.g. in business meetings (Haavio-Mannila, 1991; Hammer \& Vaglum, 1989). For women, being in a "traditional role" (partner and parent) was commonly associated with the lowest risk of heavy drinking. 
There were many differences across countries as regards the association of social stratification or family roles and men's or women's drinking. These differences seemed to be explainable partly at the macro-level, i.e. how extensive the social welfare system is and how much gender equity is present in a country. Interestingly, those macro-level associations were found for women's heavy drinking but not for men's, which suggests that women's drinking depends more strongly on the level of gender equity in a society than men's.

The macro-level analysis showed, for example, that Germany and Switzerland lie at one end of scales of work desirability and work-welfare-equity, while Finland and Sweden at the other with respect to associations with heavy drinking. In the Northern countries, characterised by good social welfare systems and a high gender equity, women's heavy drinking was thus associated with being employed, a lower formal education, and nontraditional roles. On the contrary, in Germany and Switzerland, both characterised by lower gender equity and less elaborated social welfare systems, especially regarding child care, heavy drinking was associated with high formal education and small effects of traditional roles and employment. Germany and Switzerland were the only countries where income was significantly and positively associated with increasing heavy drinking rates among women. These were also countries where the interaction between gender and education became significant, indicating that education had opposite effects for men and women. On the other hand, in Sweden and Finland heavy drinking decreased with increasing education for both genders. Thus, gender differences regarding the association between heavy drinking and social roles or social stratification were less pronounced in these two Northern European countries. This indicates that in countries with strong social welfare and high gender equity men and women did not differ as regards to how social stratification or social role variables are associated with heavy drinking. To the contrary, in Germany and Switzerland gender differences were more pronounced, indicating different associations of heavy drinking and social roles or social stratification among men and women. We interpret the findings to mean the following. Only in countries with low gender equity better educated women have to behave in a way to demonstrate being the "better men" and thus to drink more in higher job positions. In countries, where women's holding of leading positions is well accepted they benefit like men from lower heavy drinking rates in higher economic status positions. Also, the traditional role does not lead to role strain in Nordic countries as the social welfare system does not pose stress on being a mother in addition to being employed, and household labour might be better shared between partners in societies with higher gender equity. Thus, the role 
accumulation can only evolve its full strength in countries with high social welfare and gender equity. In countries like Switzerland or Germany, women have to take decisions about either career or child raising, and thus a certain role combination might only be beneficial if such a decision (e.g. not to have children or not to chose a professional career) does not result in later ambivalence about the role. In addition, the role accumulation may lead to stress under a poorer social welfare system, and thus the beneficial effects are more often mitigated than in high welfare systems.

Due to the cross-sectional design of the study no causal directions of the relation between social roles or social stratification and alcohol use can be established. Thus, it cannot be determined whether social stratification or social roles trigger someone's drinking behaviour or vice versa. In the foreground of the present study stood the comparison of almost all European countries available in this EU concerted action and in the broader GENACIS project data set. This afforded the analyses to be restricted to comparable, but often crude measures. There is literature, for example, that the stress related to childcare varies with the age of children in a household. Similarly, not only employment status but also particular work conditions have been shown to have differential effects on health outcomes. Future comparative analyses should focus on specific aspects of roles while perhaps limiting the number of available countries for such an analysis.

As confirmed by many findings in the literature on health inequalities, there is a need to include both social stratification and family situation predictors to model men's and women's drinking (Lahelma, et al., 2002). There is a tendency in the literature to assume that social stratification is more important for men, whereas family roles are more important for women. With respect to heavy drinking, the present study indicated that educational differences are important for both sexes. Furthermore, it also revealed how social welfare systems are related to women's demands by multiple roles such as being mother and working at the same time . Thus, the understanding of women's and men's roles on drinking must include both social stratification and family roles, and analyses should consider both micro-level and macro-level influences within a country. 


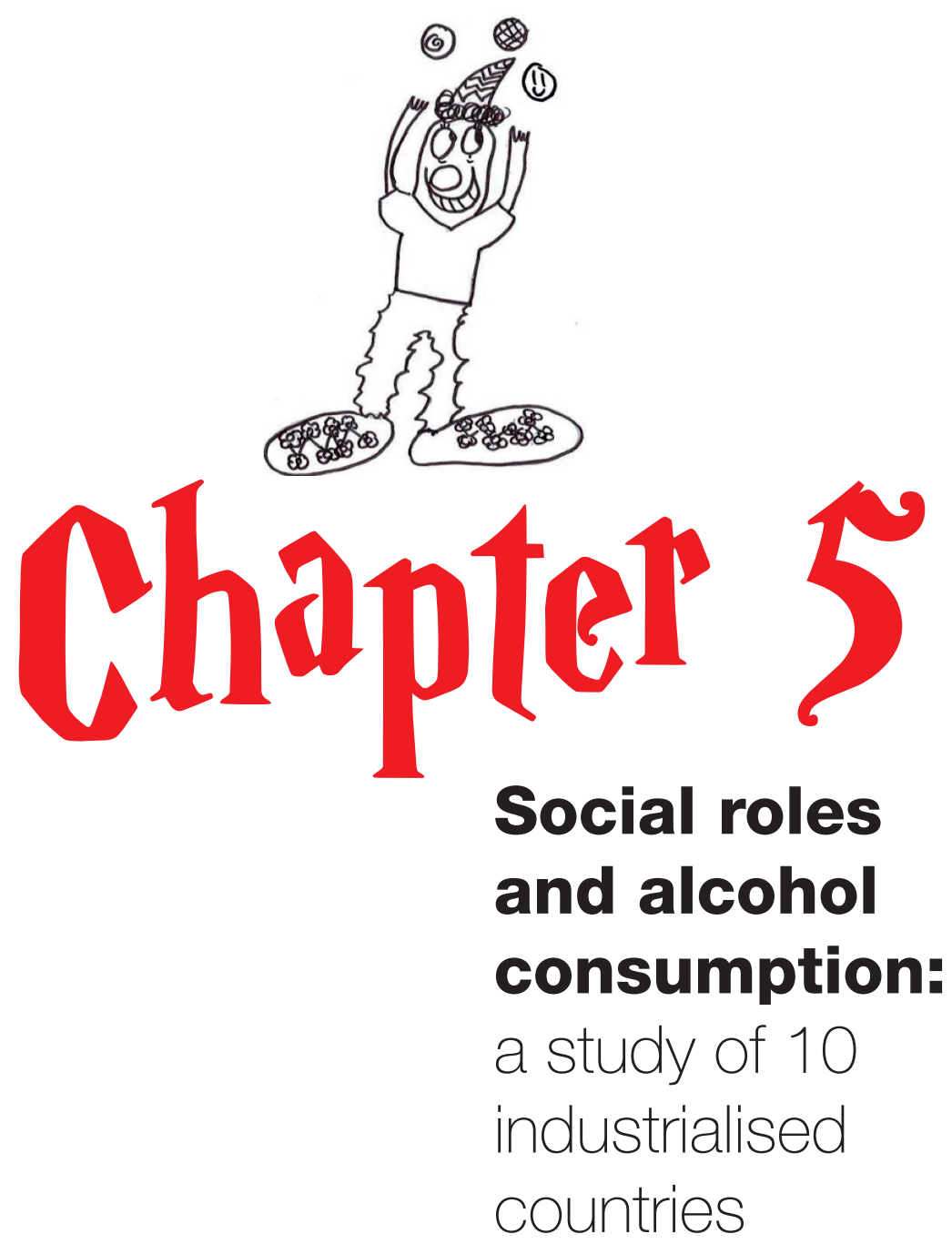




\section{Summary}

Objectives: The empirical evidence as regards the precise association between alcohol use and social roles, and these associations across genders and cultures is heterogeneous. The literature tends to focus on two central but conflicting theories. The first - classic role theory - assumes that a higher number of social roles is associated with a more structured life and thus fewer opportunities to drink heavily. The second - the multiple burden hypothesis - posits that the increasing complexity of multiple social roles leads to higher stress levels, and thus to increased alcohol use.

Participants: Survey data on 25- to 54-year olds in ten western industrialised countries which participate in the GenACIS project were used.

Method: Using logistic regression it was tested whether holding the three main social roles - partnership, parenthood, and paid labour - had a more protective or a more detrimental association with problematic alcohol use than holding fewer roles. Age and education were included as possible confounders, while the outcome variables were risky single occasion drinking (RSOD) and heavy-volume drinking.

Results: For both genders and in almost all countries, the study found that those who had all three roles were least likely to drink heavily or engage in RSOD, thus supporting the assumptions of classic role theory. It also found that the protective effect of multiple roles was more consistent for RSOD. There were a few countries where a two-role model gave a better fit. Results for Germany (RSOD), Switzerland, and the US (heavy volume) indicate that the role of paid labour appears to be particularly relevant for risky alcohol use among women.

Conclusion: Despite some variability in the association between paid labour and heavy drinking or RSOD among women, in almost all countries the greater the number of roles a person held, the lower their risk of this type of alcohol use was.

Published as:

S. Kuntsche, R. A. Knibbe \& G. Gmel (2009). Social roles and alcohol consumption: a study of 10 industrialised countries. Social Science and Medicine Vol. 68, pp. 1263-1270. 


\section{Introduction}

Social roles which define the social position of an individual within a given social system are based on enduring relations with other people and provide both a sense of identity and behavioural guidance (e.g. McCall \& Simmons, 1996; Stryker \& Serpe, 1982; Thoits, 1991). Holding a variety of social roles, such as partnership, parenthood or paid labour, may affect the health of the individual since these provide the "object" and "meaning" to her or his life (Durkheim, 1951). For example, several studies have shown that social roles are related to depression (e.g. Brown, 2002), psychological distress (Menaghan, 1989; Wheaton, 1990), and subjective well-being (e.g. Burton, Armstrong, \& Rushing, 1993), and substance use (e.g. Burton, Johnson, Ritter, \& Clayton, 1996; Schulenberg, Bachman, O'Malley, \& Johnston, 1994).

The primary focus of our study is the extent to which the relation between the number of roles and alcohol use is similar across countries and gender. For the purposes of our research, we selected 10 (western) industrialised countries, since most of these place greatest importance on three specific adult roles: taking care of oneself by earning an income (paid labour), taking care of dependents, in particular children (parenting), and forming a permanent and stable relationship with a partner (partnership).

Alcohol research literature often uses the concept of "roles" to explain associations between drinking behaviour and social characteristics like family background/support and working life (Jennison, 1992; Johnson, 1982). In the last twenty years several studies have demonstrated the link between alcohol use and individual social roles, such as being a partner or a parent (Gmel, et al., 2000; Knibbe, et al., 1987; R. W. Wilsnack \& Cheloha, 1987). Only a handful of studies have concentrated on how consistent this association is across genders (Knibbe, et al., 1987) or across countries (Gmel, et al., 2000). Consequently, the present paper does not focus on particular social roles or on all possible role combinations, but rather examines, based on two theoretical hypotheses, how the integration in societal networks provided by partners, colleagues or children or the absence thereof influences the association between these roles and drinking.

The first theoretical perspective concerns classic role theory, which focuses on the beneficial health effects of holding multiple social roles (Aneshensel, et al., 1981; Hibbard \& Pope, 1991; Hong \& Seltzer, 1995). As regards alcohol use, this theory posits 
that the greater the number of social roles a person holds, the more his or her life is structured by meaningful activities that others expect one to engage in. Partnership, parenthood, and paid labour bring individuals into contact with others and are associated with activities that are defined by the expectations of significant others. It can be assumed that the more everyday life is structured by social activities which the individual and others deem important, the more likely it is that he or she will take care that the time spent in drinking situations and/or behaviour changes due to drinking (e.g. drunkenness) does not interfere with their role obligations (Knibbe, et al., 1987; R. J. Neve, et al., 1997). There is the expectation that activities offering immediate gratification, such as drinking, should not interfere with the adequate performance of these roles. Therefore, the social control on drinking may be stronger among individuals who hold all three roles. These considerations lead one to expect that the more roles a person holds, the less likely he or she is to engage in heavy-volume drinking or risky single occasion drinking (Knibbe, et al., 1987; S. C. Wilsnack \& Wilsnack, 1991).

The second theoretical perspective, the multiple burden hypothesis, assumes that role overload arising from holding too many social roles and from possible conflicts between the demands of these roles (e.g. child care and having to take on paid labour) is related to stress, since each person only has a finite amount of time and energy. In alcohol regulation theory, for example, drinking is considered a possible mechanism for coping with distress or with negative stress-related emotions (e.g. McCreary \& Sadava, 1998; Peirce, et al., 1994).

The multiple burden hypothesis has been mainly used in studies of women (e.g. Doyal, 1995). These found that being a single mother was particularly disadvantageous (e.g. Bernstein, 2001; Whitehead, et al., 2000), since this group may experience contradictory pressures of working outside the home and their possible desire to be stayat-home mothers (Ali \& Avison, 1997). The main reasons behind the assumption that women are more likely to feel overburdened by holding all three roles compared to men are: (1) they may spend more time running the (shared) household than men; and (2) they may spend more time on childcare than men. This unequal distribution of work may mean that women feel overburdened by holding all three roles (Arber \& Khlat, 2002; Lahelma, et al., 2002). Given that previous research, which took the multiple burden hypothesis as their starting point, focused on physical and mental health issues (e.g. Maclean, et al., 
2004) and not on alcohol use, our study, to the best of our knowledge, will therefore be the first to investigate the relevance of this theory for alcohol use in a multi-country context. To be able to identify countries where the multiple burden hypothesis sheds greater light than classic role theory on the relation between social roles and drinking, especially among women, we shall adopt a gender-specific approach to evaluate the relevance of the two theories in explaining alcohol use.

The starting point of the present study was classic role theory, which posits that holders of all three social roles should have the lowest alcohol consumption. For this reason, we investigated whether the risk of harmful alcohol use decreased as the number of social roles increased, and whether this held for both genders.

In a second step, the study aimed to shed more light on those countries in which a higher number of social roles was not associated with a lower risk of harmful alcohol use. Particular attention was paid to countries supporting the multiple burden hypothesis. We examined which specific role or combination of roles may be responsible for the finding that holding all three social roles increases the risk of harmful alcohol use. Please note that for the purposes of this study, we defined harmful alcohol use as monthly risky single occasion drinking (RSOD) and heavy-volume drinking, measured as the average consumption in grams of ethanol per day.

\section{Method}

The study was based on data from the project Gender, Alcohol and Culture: An International Study (GenACIS). At the time of writing, this project comprised 40 surveys from more than 30 countries. The present study focused on ten industrialised countries from Europe and North America (Austria, Czech Republic, Finland, France, Germany, Norway, Sweden, Switzerland, UK, and the United States); the national data provided sufficient information on social roles and harmful alcohol use. The focus on western industrialised countries ensured a minimum level of comparability regarding the measurement and the meaning of the three social roles - parenthood, partnership and paid labour - across societies. It should be noted that all surveys were nationally representative (see Table 5-1 for a general overview of the surveys and their characteristics). 
Table 5-1 Survey characteristics and sample size by age and sex among all respondents aged between 25 and 54

\begin{tabular}{lccrrr}
\hline & Survey year & Survey mode & Women & Men & Total \\
\hline Austria & 1993 & face-to-face & 2071 & 2077 & 4148 \\
Czech Republic & 2002 & face-to-face & 825 & 796 & 1621 \\
Finland & 2000 & face-to-face ${ }^{1}$ & 563 & 587 & 1150 \\
France & 1999 & telephone & 4265 & 3452 & 7717 \\
Germany & 2000 & postal & 3253 & 2675 & 5928 \\
Norway & 1999 & face-to-face & 663 & 608 & 1271 \\
Sweden & 2002 & telephone & 1418 & 1373 & 2791 \\
Switzerland & 2002 & telephone & 5253 & 4817 & 10070 \\
UK & 2000 & face-to-face (CAPI) & 591 & 570 & 1161 \\
USA & $1995 / 1996$ & face-to-face & 1650 & 1439 & 3089 \\
\hline
\end{tabular}

Remark: ${ }^{1}$ partly self-administered; CAPI: computer assisted personal interviewing

Survey-based estimates usually cover between 30 and 70\% of a country's per capita consumption, as derived from sales statistics (e.g. Knibbe \& Bloomfield, 2001; Rehm, 1998). While a major concern is the possible difference in under-reporting between social categories, which are defined by the roles held, previous studies have shown that rank orders of drinking were preserved and thus do not influence associations between variables (see Gmel \& Rehm, 2004). We therefore assumed that it was unlikely that categories of respondents who differed in terms of the social roles they held also differed in terms of under-reported consumption. In addition, the study aimed to analyse the effects within countries and not to focus on prevalence comparisons across countries (see Bloomfield, Stockwell, Gmel, \& Rehn, 2003).

The GenACIS project developed a core questionnaire which was used by the majority of participating countries. However, countries could also take part by providing a nationally representative survey on alcohol use that used similar questions; this was primarily the case in Europe. To enable a comparison of these surveys, a centralised data bank management system was installed, which encoded variables according to fixed rules. The results were summarised in a codebook, which was accessible to all participants (Kuntsche et al., 2008).

\section{Dependent variables}

The present study focused exclusively on drinkers. Drinkers were defined as individuals who consumed alcohol during the past 12 months. The decision to exclude abstainers was motivated by our main research aim: to explain problematic alcohol use, 
not abstention. Previous studies which focused on abstention indicate that the factors which distinguish abstainers from drinkers are quite different from those which differentiate drinkers according to their level of consumption (e.g. Shaper \& Wannamethee, 1998). The percentage of current drinkers within all countries can be found in Table 5-2. Among drinkers two measures were used. First, we used a dichotomised heavy-volume drinking measure based on the volume of drinking, with a cut-off of 20 grams of pure ethanol a day for women and 30 grams for men; this reflects a compromise between the various thresholds commonly used in the literature (Bondy, Ashley, Rehm, \& Walsh, 1999; Edwards, et al., 1994; World Health Organization (WHO), 2000), as well as the need to have a sufficiently large number of individuals per country in the heavy-volume drinking group. Ethanol measures were derived from beverage-specific, quantity-frequency instruments for the last 12 months and for most countries. The exceptions were France, where the usual quantity was derived from the consumption "yesterday" and "last Saturday", as well as the UK and Austria, where the drinking volume was derived from a recall period of seven days.

The second alcohol use measure was risky single occasion drinking during the past 12 months (RSOD; also called heavy episodic or binge drinking). France, Austria, and the UK were unable to provide RSOD data and therefore were not included in the respective analyses. For the other countries, RSOD was determined by questions that dealt with the consumption of a given amount of alcohol on a single occasion. The number of drinks varied across countries. For Switzerland a gender-specific measure was used: six glasses (about 60g pure ethanol) for women and eight glasses (about 80g) for men. In Finland $(60 \mathrm{~g})$ and Sweden $(72 \mathrm{~g})$, the measure was six glasses or more; in Germany (70g), the US $(60 \mathrm{~g})$, and the Czech Republic (90g) it was five glasses, although these differed in terms of size and alcohol content. Norway asked for the following maximum beverage-specific, consumption frequencies: two litres of beer, or $3 / 4$ litre of wine or $1 / 3$ litre of spirits; it does not use a measure for beverage combinations (e.g. 11 of beer and $1 / 21$ of wine). RSOD was dichotomised with a cut-off of experiencing such occasions at least on a monthly basis.

\section{Independent variables}

The "partnership" role was dichotomised into married or cohabiting (code=1) versus other $(\operatorname{code}=0)$. 
The "parenthood" role included information about the existence of children in the household. It was dichotomised into child(ren) (1) versus no child(ren) (0).

The third role, "paid labour", summarises the employment situation of the respondent. Paid workers, independent of whether they were employed part-time or full-time, as well as the self-employed were coded as 1; all others, including those in education, housewives, those not working for payment and those with an occupational disability, were coded as 0 .

The indicator "number of social roles" is the sum of the three codes, ranging from zero to three, with all roles carrying equal weight.

Analysis was limited to respondents aged between 25 and 54. Within this age range it can be assumed that either the child or at least one of the children living in the household was a minor. Consequently, we further assumed that the presence of a child or children in the household implied that the parent still had child-rearing responsibilities. Based on the assumption that people in this age range are no longer in education, being in paid labour should reflect more stable personal circumstances than being in temporary employment (e.g. students working to finance their studies).

Age and educational level were taken as two possible confounders. Educational level accounts for the confounding effects of socio-economic status on alcohol use and has the advantage over confounders, such as income or occupation, in that it varies less over time (Gottfredson \& Deary, 2004). To derive comparable educational groups across countries, we applied the ISCED-97 (International Standard Classification of Education: UNESCO Institute for Statistics, 1997). In addition, three levels - low, average and high - were defined in such a way that the majority of respondents were classified in the average category (for more details, see Bloomfield, Grittner, Kramer, \& Gmel, 2006). Individuals with missing values on education, age, or one of the three social roles $(2.8 \%$ of the total sample (including men)) were excluded from the analysis.

\section{Statistical analysis}

Two approaches were used to analyse the data. Using SPSS 15.0 a set of logistic regression models, stratified by gender and country, formed the basis of a two-stage analysis of the association between the number of social roles and drinking: 
1. Taking as our starting point classic role theory which posits that those holding all three social roles have the lowest risk of alcohol use, logistic regressions of the number of social roles on the two alcohol measures - heavy-volume drinking and RSOD - were examined. The number of social roles was used as a categorical variable to enable the identification of situations where there is neither a monotonically increasing nor a monotonically decreasing association between the number of roles and alcohol consumption (see Hosmer \& Lemeshow, 2000). According to this theory, holding any one of these roles should be associated with an $\mathrm{OR}<1$, compared with holding no role at all; as the number of roles increases, there should be a corresponding decrease in the OR. The strongest protective effect should be found in the three-role model. Furthermore, according to this theory detrimental effects will be indicated by odds ratios greater than 1 for holding three roles.

2. In countries where fewer social roles rather than the three-role combination were shown to have the greatest beneficial effect, a further analysis was carried out to identify which particular roles or role combination(s) led to an increase in the risk of heavyvolume drinking or RSOD. This involved examining the different role combinations of: a) holding no role, b) single roles and c) two roles. Using multiple logistic regression models, the individual impact of each possible role combination was examined for all countries where the three-role model was not associated with the lowest risks of heavyvolume drinking or RSOD.

The description and discussion of the findings were based not only on their significance but also on their consistency across countries. Significance is largely dependent on sample size and, following the suggestions of Rothmann (2002), the strength or importance of the findings also depends on the consistency of the direction of effects across different studies (or, in our case, countries). As the number of social roles was tested as a categorical variable, significances for categories of one, two and three roles compared to the reference category (no role) can be derived. Furthermore, the significance level of the overall test for the number of roles, where the variable was taken as a block with three degrees of freedom (Hosmer \& Lemeshow, 2000), and aligned to the reference groups in Tables 5-3 to 5-6.

To estimate the impact of the number of social roles across countries, the association between the number of social roles and alcohol use was analysed using a multilevel 
approach. A random intercept, random slope model (Hox, 2002) on binary data was estimated in HLM 6.0 (Raudenbush, Bryk, Cheong, Congdon, \& du Toit, 2004). To account for the differences in sample size across countries (see Table 5-1), we decided to weight all countries equally, according to a uniform sample size of 1,000 per gender for all four multilevel models (heavy-volume drinking and RSOD for men and women separately). Logistic HLM models were stratified by gender and adjusted for age and educational level. While all ten countries were included in the analysis of heavy-volume drinking, the RSOD models were limited to those seven countries where the variable was available.

\section{Results}

In almost all countries around nine out of ten male respondents reported alcohol use during the past 12 months. Among women the prevalence of current drinkers was slightly lower, but still exceeded $80 \%$ in eight out of ten countries. Exceptions were found among women in the United States and Switzerland (see Table 5-2). Among those who drank in the past 12 months, the percentage of heavy-volume drinking and RSOD varied widely across countries. Despite these differences, men in all countries showed a higher prevalence of RSOD and heavy-volume drinking, even though the cut-off for heavyvolume drinking was higher for them (30g pure ethanol per day) than it was for women (20g pure ethanol per day). 


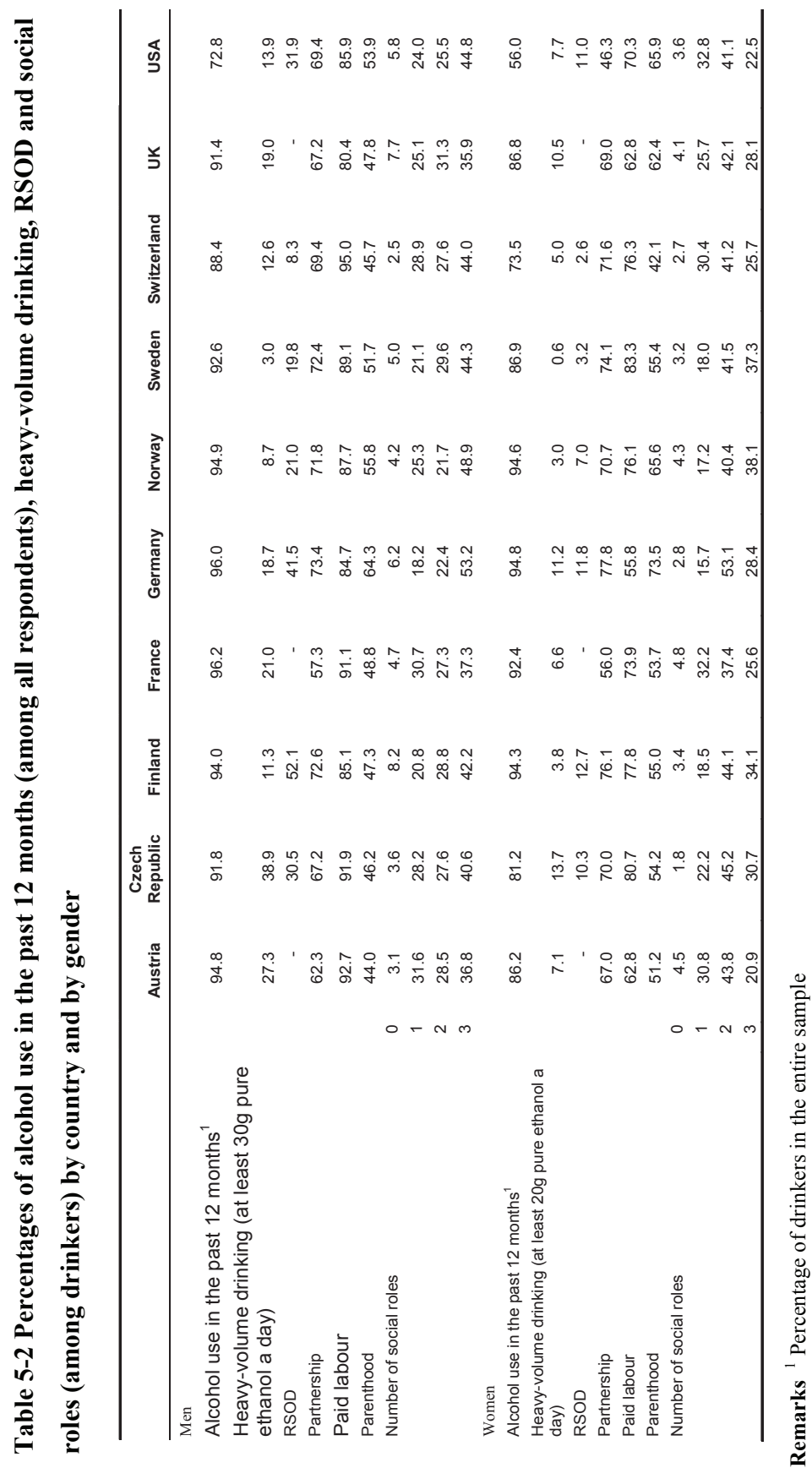


Regarding social roles, women in all countries were less often in paid labour than men and, with the exception of Switzerland, more frequently had children living with them. No gender differences could be found for the partnership role. The majority of men held all three social roles (partner, parent and paid worker), while women most often held only two.

As can be seen in Table 5-3, in most countries the greater the number of social roles a person has, the lower his or her risk of heavy-volume drinking is. Likewise, taking all countries together (see the total effect across countries at the bottom of Table 5-3), the number of social roles has significantly negative associations with heavy-volume drinking for men and for women. In general, the more roles both genders had, the lower their risk of heavy-volume drinking was.

Nevertheless, if tested as a block, the number of social roles had no significant effect on heavy-volume drinking in five countries for either men (Austria, Czech Republic, Finland, France, and Switzerland) or women (Czech Republic, Finland, France, Switzerland, and UK). Also, among these countries it appeared that for Finnish men and for women from the UK, the Czech Republic and Finland, the three-role model had the lowest OR. Among Swedish and Norwegian women no heavy-volume drinking was reported by those holding two social roles in Sweden and those with three roles in Norway. 
Table 5-3 Cell sizes, odds ratios, $\mathrm{Cl} 95 \%$ and significance level of heavy-volume drinking on the number of social roles by gender and by country; HLM-model

\begin{tabular}{|c|c|c|c|c|c|c|c|c|c|}
\hline & & \multicolumn{4}{|c|}{ Men } & \multicolumn{4}{|c|}{ Women } \\
\hline & & $\mathbf{n}$ & OR & CI $95 \%$ & Sig. & $\mathbf{n}$ & OR & $\mathrm{Cl} 95 \%$ & Sig. \\
\hline \multirow[t]{4}{*}{ Austria } & no role & 59 & & & 0.082 & 79 & & & 0.043 \\
\hline & one role & 615 & 1.021 & $0.564-1.850$ & 0.945 & 536 & 0.782 & $0.368-1.661$ & 0.522 \\
\hline & two roles & 556 & 0.769 & $0.421-1.405$ & 0.393 & 776 & 0.499 & $0.234-1.061$ & 0.071 \\
\hline & three roles & 720 & 0.769 & $0.425-1.391$ & 0.385 & 371 & 0.439 & $0.191-1.008$ & 0.052 \\
\hline \multirow[t]{4}{*}{ Czech Republic } & no role & 26 & & & 0.512 & 12 & & & 0.051 \\
\hline & one role & 206 & 0.796 & $0.346-1.831$ & 0.591 & 149 & 1.293 & $0.264-6.331$ & 0.751 \\
\hline & two roles & 202 & 0.627 & $0.272-1.447$ & 0.274 & 303 & 0.862 & $0.179-4.143$ & 0.853 \\
\hline & three roles & 297 & 0.794 & $0.350-1.797$ & 0.579 & 206 & 0.540 & $0.108-2.690$ & 0.452 \\
\hline \multirow[t]{4}{*}{ Finland } & no role & 45 & & & 0.277 & 18 & & & 0.151 \\
\hline & one role & 114 & 0.500 & $0.202-1.241$ & 0.135 & 98 & 0.454 & $0.081-2.555$ & 0.370 \\
\hline & two roles & 159 & 0.433 & $0.179-1.046$ & 0.063 & 234 & 0.290 & $0.056-1.501$ & 0.140 \\
\hline & three roles & 233 & 0.434 & $0.186-1.013$ & 0.054 & 181 & 0.131 & $0.020-0.871$ & 0.035 \\
\hline \multirow[t]{4}{*}{ France } & no role & 156 & & & 0.455 & 191 & & & 0.051 \\
\hline & one role & 1019 & 1.070 & $0.629-1.820$ & 0.803 & 1270 & 1.853 & $0.731-4.697$ & 0.193 \\
\hline & two roles & 908 & 0.891 & $0.525-1.512$ & 0.668 & 1471 & 1.814 & $0.724-4.548$ & 0.204 \\
\hline & three roles & 1239 & 0.908 & $0.541-1.523$ & 0.714 & 1009 & 1.222 & $0.477-3.127$ & 0.676 \\
\hline \multirow[t]{4}{*}{ Germany } & no role & 160 & & & 0.000 & 86 & & & 0.049 \\
\hline & one role & 468 & 0.639 & $0.440-0.927$ & 0.018 & 485 & 0.528 & $0.279-0.999$ & 0.050 \\
\hline & two roles & 575 & 0.588 & $0.405-0.854$ & 0.005 & 1638 & 0.429 & $0.235-0.782$ & 0.006 \\
\hline & three roles & 1366 & 0.402 & $0.280-0.577$ & 0.000 & 876 & 0.418 & $0.222-0.787$ & 0.007 \\
\hline \multirow[t]{4}{*}{ Norway } & no role & 24 & & & 0.000 & 27 & & & 0.000 \\
\hline & one role & 146 & 0.534 & $0.197-1.448$ & 0.217 & 108 & 0.458 & $0.126-1.688$ & 0.236 \\
\hline & two roles & 125 & 0.164 & $0.051-0.529$ & 0.003 & 253 & 0.163 & $0.044-0.609$ & 0.007 \\
\hline & three roles & 282 & 0.048 & $0.014-0.161$ & 0.000 & 239 & 0.000 & - & 0.994 \\
\hline \multirow[t]{4}{*}{ Sweden } & no role & 63 & & & 0.001 & 40 & & & 0.001 \\
\hline & one role & 267 & 0.798 & $0.225-2.824$ & 0.726 & 222 & 1.380 & $0.120-15.921$ & 0.796 \\
\hline & two roles & 376 & 0.739 & $0.214-2.555$ & 0.633 & 510 & 0.000 & - & 0.992 \\
\hline & three roles & 563 & 0.168 & $0.042-0.667$ & 0.011 & 459 & 0.115 & $0.006-2.413$ & 0.164 \\
\hline \multirow[t]{4}{*}{ Switzerland } & no role & 105 & & & 0.753 & 103 & & & 0.184 \\
\hline & one role & 1230 & 0.912 & $0.464-1.793$ & 0.790 & 1175 & 1.226 & $0.405-3.709$ & 0.718 \\
\hline & two roles & 1048 & 0.993 & $0.509-1.934$ & 0.983 & 1590 & 0.801 & $0.269-2.390$ & 0.691 \\
\hline & three roles & 1873 & 1.045 & $0.543-2.012$ & 0.896 & 994 & 0.867 & $0.288-2.611$ & 0.800 \\
\hline \multirow[t]{4}{*}{ UK } & no role & 40 & & & 0.000 & 21 & & & 0.405 \\
\hline & one role & 131 & 1.507 & $0.668-3.402$ & 0.323 & 132 & 0.546 & $0.161-1.850$ & 0.331 \\
\hline & two roles & 163 & 0.589 & $0.256-1.356$ & 0.213 & 216 & 0.444 & $0.135-1.458$ & 0.181 \\
\hline & three roles & 187 & 0.399 & $0.170-0.935$ & 0.035 & 144 & 0.350 & $0.100-1.227$ & 0.101 \\
\hline \multirow[t]{4}{*}{ USA } & no role & 60 & & & 0.000 & 33 & & & 0.023 \\
\hline & one role & 251 & 1.173 & $0.501-2.745$ & 0.713 & 302 & 0.306 & $0.073-1.275$ & 0.104 \\
\hline & two roles & 266 & 0.460 & $0.194-1.093$ & 0.079 & 380 & 0.129 & $0.030-0.552$ & 0.006 \\
\hline & three roles & 469 & 0.444 & $0.192-1.027$ & 0.058 & 208 & 0.241 & $0.058-1.010$ & 0.052 \\
\hline \multirow{5}{*}{$\begin{array}{l}\text { Total effect } \\
\text { across all } \\
\text { countries }\end{array}$} & & & & & & & & & \\
\hline & no role & & & & & & & & \\
\hline & one role & & 0.817 & $0.594-1.125$ & 0.197 & & 0.665 & $0.520-0.850$ & 0.006 \\
\hline & two roles & & 0.702 & $0.586-0.841$ & 0.002 & & 0.579 & $0.450-0.747$ & 0.001 \\
\hline & three roles & & 0.700 & $0.551-0.891$ & 0.011 & & 0.566 & $0.430-0.748$ & 0.001 \\
\hline
\end{tabular}

Remarks: All adjusted for age and educational level Block likelihood ratio tests are aligned to the references group (no role). ${ }^{*}$ no woman drinking at least $20 \mathrm{~g}$ pure ethanol per day; ${ }^{1}$ as estimated in a random slope, random intercept model in HLM 
With regard to the multiple burden hypothesis, the most interesting countries were those in which individuals holding three roles presented a higher risk than individuals holding two. There were two countries where for men holding three roles was not more protective than having two roles: the Czech Republic and Switzerland. For women in the United States and Switzerland, holding three roles was less protective than two. Another notable case was France, where women holding no roles had the lowest risk of heavyvolume drinking, although the difference was not significant. Table 5-4 shows the impact of specific role combinations on heavy-volume drinking for Czech and Swiss men, as well as for French, Swiss and US women, i.e. for those countries in which the three-role model did not produce the lowest odds ratios. Given that all countries had a very small group of unemployed single fathers, this role combination was not included in the analysis of alcohol use among men.

The differences in the number of roles held by men in Switzerland and in the Czech Republic, and those held by French women were not statistically significant. In contrast, among women in Switzerland and the United States a significant relation was found between heavy-volume drinking and specific role combinations. The risk of heavyvolume drinking was lower among Swiss women who were not in paid labour and shared a household with partners and children $(\mathrm{OR}=0.423)$ than among those with three roles. All other role combinations resulted in higher risks than the three-role model, and significantly for single women in paid labour with $(\mathrm{OR}=2.723)$ or without children $(\mathrm{OR}=1.610)$.

The single role of being in paid labour was associated with a lower risk of heavyvolume drinking $(\mathrm{OR}=0.818)$ among US women compared to those holding all three roles. The effects of also being a mother $(\mathrm{OR}=0.494)$ or partner $(\mathrm{OR}=0.223)$ further reduced the risk. It should be noted, however, that women in the United States who held all three roles were at lower risk than those who held none of the three $(\mathrm{OR}=4.139)$, or who were single mothers and not in paid labour $(\mathrm{OR}=2.734)$. 
Table 5-4 Cell sizes, odds ratios, $\mathrm{Cl} 95 \%$ and significance level of heavy-volume drinking on the combination of social roles by gender and by country, adjusted for age and educational level; drinkers only

\begin{tabular}{|c|c|c|c|c|c|c|c|c|c|}
\hline & & \multicolumn{4}{|c|}{ Men* } & \multicolumn{4}{|c|}{ Women } \\
\hline & & $\mathbf{n}$ & OR & $\mathrm{Cl} 95 \%$ & Sig. & $\mathbf{n}$ & OR & $\mathrm{Cl} 95 \%$ & Sig. \\
\hline \multirow[t]{7}{*}{$\begin{array}{l}\text { Czech } \\
\text { Republic }\end{array}$} & all roles & 297 & & & 0.595 & & & & \\
\hline & no role & 26 & 1.261 & $0.557-2.854$ & 0.578 & & & & \\
\hline & $\begin{array}{l}\text { partner } \\
\text { child(ren) }\end{array}$ & 14 & 0.892 & $0.293-2.713$ & 0.840 & & & & \\
\hline & paid labour & 191 & 0.998 & $0.684-1.457$ & 0.992 & & & & \\
\hline & partner \& child (ren) & 18 & 0.835 & $0.310-2.250$ & 0.722 & & & & \\
\hline & child(ren) \& paid labour & 22 & 1.464 & $0.609-3.517$ & 0.394 & & & & \\
\hline & partner \& paid labour & 162 & 0.718 & $0.475-1.083$ & 0.114 & & & & \\
\hline \multirow[t]{8}{*}{ France } & all roles & & & & & 1009 & & & 0.053 \\
\hline & no role & & & & & 191 & 0.828 & $0.324-2.116$ & 0.693 \\
\hline & partner & & & & & 212 & 2.095 & $1.264-3.472$ & 0.004 \\
\hline & child(ren) & & & & & 189 & 1.812 & $0.888-3.698$ & 0.102 \\
\hline & paid labour & & & & & 869 & 1.204 & $0.767-1.888$ & 0.420 \\
\hline & partner \& child(ren) & & & & & 435 & 1.771 & $1.131-2.775$ & 0.013 \\
\hline & child(ren) \& paid labour & & & & & 485 & 1.184 & $0.705-1.991$ & 0.523 \\
\hline & partner \& paid labour & & & & & 551 & 1.542 & $1.018-2.336$ & 0.041 \\
\hline \multirow[t]{8}{*}{ Switzerland } & all roles & 1873 & & & 0.933 & 994 & & & 0.001 \\
\hline & no role & 105 & 0.957 & $0.497-1.843$ & 0.895 & 103 & 1.149 & $0.382-3.461$ & 0.805 \\
\hline & partner & 45 & 0.827 & $0.368-1.860$ & 0.647 & 236 & 1.043 & $0.541-2.009$ & 0.900 \\
\hline & child(ren) & & & & & 10 & 4.212 & $0.745-23.827$ & 0.104 \\
\hline & paid labour & 1185 & 0.877 & $0.679-1.134$ & 0.317 & 928 & 1.610 & $1.015-2.553$ & 0.043 \\
\hline & partner \& child(ren) & 61 & 0.797 & $0.410-1.550$ & 0.503 & 565 & 0.423 & $0.215-0.830$ & 0.012 \\
\hline & child(ren) \& paid labour & 12 & 1.373 & $0.413-4.563$ & 0.605 & 56 & 2.723 & $1.222-6.065$ & 0.014 \\
\hline & partner \& paid labour & 975 & 0.956 & $0.773-1.183$ & 0.679 & 969 & 1.100 & $0.723-1.675$ & 0.655 \\
\hline \multirow[t]{8}{*}{ USA } & all roles & & & & & 208 & & & 0.009 \\
\hline & no role & & & & & 33 & 4.139 & $0.957-17.568$ & 0.054 \\
\hline & partner & & & & & 34 & 1.274 & $0.409-3.973$ & 0.676 \\
\hline & child(ren) & & & & & 112 & 2.734 & $0.989-7.560$ & 0.053 \\
\hline & paid labour & & & & & 156 & 0.818 & $0.331-2.021$ & 0.664 \\
\hline & partner \& child(ren) & & & & & 94 & 1.237 & $0.485-3.156$ & 0.657 \\
\hline & child(ren) \& paid labour & & & & & 194 & 0.494 & $0.140-1.737$ & 0.272 \\
\hline & partner \& paid labour & & & & & 92 & 0.223 & $0.060-0.827$ & 0.025 \\
\hline
\end{tabular}

Remarks: * Unemployed single fathers were not taken into account due to small cell sizes; Block likelihood ratio tests are aligned to the references group (all roles).

Regarding the link between the number of social roles and RSOD (see Table 5-5), having three roles was associated with the lowest risk of RSOD for both genders and across most countries. Correspondingly, the total multi-level effect across all countries and across genders resulted in a significant decrease in the risk of RSOD as the number of social roles increased (see last line of Table 5-5). Nevertheless, some variations were 
found in individual countries. In Germany, the risk of RSOD was lower for men holding one role or a combination of the three, regardless of the number of roles they held. Among German women the two-role model resulted in the lowest risk of RSOD. Significant associations between the number of social roles (tested as a block) and RSOD could not be found for Swedish and Finnish women, or for German men. 
Table 5-5 Cell sizes, odds ratios, $\mathrm{Cl} 95 \%$ and significance level of RSOD on number of social roles by gender and by country; multilevel model by gender; all adjusted for age and educational level; drinkers only

\begin{tabular}{|c|c|c|c|c|c|c|c|c|c|}
\hline & & \multicolumn{4}{|c|}{ Men } & \multicolumn{4}{|c|}{ Women } \\
\hline & & n & OR & Cl $95 \%$ & Sig. & $\mathbf{n}$ & OR & Cl $95 \%$ & Sig. \\
\hline \multirow[t]{4}{*}{ Czech Republic } & no role & 26 & & & 0.041 & 12 & & & 0.048 \\
\hline & one role & 206 & 0.512 & $0.223-1.175$ & 0.114 & 147 & 1.123 & $0.222-5.673$ & 0.888 \\
\hline & two roles & 202 & 0.648 & $0.283-1.483$ & 0.304 & 302 & 0.927 & $0.190-4.527$ & 0.925 \\
\hline & three roles & 296 & 0.405 & $0.179-0.918$ & 0.030 & 206 & 0.425 & $0.081-2.215$ & 0.309 \\
\hline \multirow[t]{4}{*}{ Finland } & no role & 40 & & & 0.022 & 17 & & & 0.090 \\
\hline & one role & 107 & 1.658 & $0.785-3.501$ & 0.185 & 87 & 1.150 & $0.321-4.124$ & 0.830 \\
\hline & two roles & 153 & 1.269 & $0.625-2.575$ & 0.510 & 216 & 0.642 & $0.190-2.172$ & 0.476 \\
\hline & three roles & 212 & 0.811 & $0.405-1.625$ & 0.554 & 169 & 0.436 & $0.121-1.567$ & 0.204 \\
\hline \multirow[t]{4}{*}{ Germany } & no role & 160 & & & 0.066 & 86 & & & 0.002 \\
\hline & one role & 468 & 0.662 & $0.482-0.910$ & 0.011 & 485 & 0.950 & $0.520-1.733$ & 0.866 \\
\hline & two roles & 575 & 0.694 & $0.505-0.955$ & 0.025 & 1638 & 0.550 & $0.308-0.981$ & 0.043 \\
\hline & three roles & 1365 & 0.677 & $0.498-0.920$ & 0.013 & 876 & 0.698 & $0.378-1.288$ & 0.250 \\
\hline \multirow[t]{4}{*}{ Norway } & no role & 24 & & & 0.000 & 27 & & & 0.000 \\
\hline & one role & 146 & 1.724 & $0.068-4.453$ & 0.260 & 108 & 0.388 & $0.138-1.094$ & 0.074 \\
\hline & two roles & 125 & 0.757 & $0.277-2.066$ & 0.586 & 253 & 0.152 & $0.055-0.422$ & 0.000 \\
\hline & three roles & 282 & 0.318 & $0.121-0.838$ & 0.020 & 239 & 0.065 & $0.021-0.207$ & 0.000 \\
\hline \multirow[t]{4}{*}{ Sweden } & no role & 64 & & & 0.000 & 40 & & & 0.151 \\
\hline & one role & 267 & 0.957 & $0.531-1.725$ & 0.885 & 222 & 1.033 & $0.239-4.471$ & 0.965 \\
\hline & two roles & 376 & 0.532 & $0.294-0.963$ & 0.037 & 510 & 0.789 & $0.188-3.313$ & 0.746 \\
\hline & three roles & 563 & 0.398 & $0.222-0.715$ & 0.002 & 458 & 0.354 & $0.074-1.705$ & 0.196 \\
\hline \multirow[t]{4}{*}{ Switzerland } & no role & 97 & & & 0.000 & 102 & & & 0.002 \\
\hline & one role & 1207 & 1.154 & $0.611-2.180$ & 0.660 & 1154 & 0.789 & $0.296-2.103$ & 0.636 \\
\hline & two roles & 977 & 0.635 & $0.330-1.222$ & 0.174 & 1548 & 0.398 & $0.151-1.048$ & 0.062 \\
\hline & three roles & 1739 & 0.453 & $0.238-0.862$ & 0.016 & 981 & 0.264 & $0.094-0.744$ & 0.012 \\
\hline \multirow[t]{4}{*}{ USA } & no role & 61 & & & 0.002 & 33 & & & 0.025 \\
\hline & one role & 250 & 0.530 & $0.264-1.065$ & 0.075 & 302 & 0.549 & $0.129-2.332$ & 0.417 \\
\hline & two roles & 266 & 0.354 & $0.178-0.704$ & 0.003 & 380 & 0.363 & $0.086-1.532$ & 0.168 \\
\hline & three roles & 468 & 0.346 & $0.177-0.677$ & 0.002 & 207 & 0.215 & $0.049-0.948$ & 0.042 \\
\hline \multirow[t]{4}{*}{$\begin{array}{l}\text { Total effect } \\
\text { across all } \\
\text { countries }{ }^{1}\end{array}$} & no role & & & & & & & & \\
\hline & one role & & 1.052 & $0.636-1.740$ & 0.833 & & 0.744 & $0.480-1.153$ & 0.186 \\
\hline & two roles & & 0.875 & $0.741-1.033$ & 0.124 & & 0.665 & $0.486-0.910$ & 0.029 \\
\hline & three roles & & 0.793 & $0.700-0.899$ & 0.008 & & 0.617 & $0.481-0.791$ & 0.006 \\
\hline
\end{tabular}

Remarks: Block likelihood ratio tests are aligned to the references group (no role). ${ }^{1}$ as estimated in a random slope, random intercept model in HLM 
Since the risks of RSOD among German men decreased for all social role combinations, we decided against an analysis of the relevance of specific role combinations. Therefore, the analysis for countries in which the three-role model did not produce the best protection is limited to German women (see Table 5-6). The risk of RSOD was lower for those living with partners and children, but who were not in paid labour $(\mathrm{OR}=0.654)$ than it was for women holding all three social roles. All other role combinations resulted in higher risks of RSOD compared to those with the three-role model.

Table 5-6 Cell sizes, odds ratios, $\mathrm{Cl} 95 \%$ and significance level of RSOD on the combination of social roles among German women; adjusted for age and educational level; drinkers only

\begin{tabular}{llrrrr}
\hline & $\mathbf{n}$ & OR & CI 95\% & Sig. \\
\hline Germany & all roles & 876 & & & 0.001 \\
& no role & 86 & 1.451 & $0.784-2.684$ & 0.236 \\
& partner & 69 & 1.140 & $0.547-2.376$ & 0.726 \\
& child(ren) & 99 & 1.111 & $0.580-2.127$ & 0.751 \\
& paid labour & 317 & 1.511 & $1.023-2.233$ & 0.038 \\
& partner \& child(ren) & 1109 & 0.654 & $0.475-0.899$ & 0.009 \\
& child(ren) \& paid labour & 182 & 1.280 & $0.785-2.088$ & 0.322 \\
& partner \& paid labour & 347 & 0.994 & $0.657-1.502$ & 0.977 \\
\hline
\end{tabular}

Remarks: Block likelihood ratio tests are aligned to the references group (all roles).

\section{Discussion}

The present study used two alcohol measures to investigate the association between the number of social roles and alcohol use in ten countries. For both genders and in almost all countries, the higher the number of social roles was, the stronger the protective effect it had on both alcohol measures (heavy-volume drinking and RSOD). However, on closer examination, this finding does not hold. In many countries the single-role model was associated with a more detrimental pattern than no role. Generally, the main results of the study were in line with classic role theory, which posits that the more social roles a person holds the lower his or her risk of heavy-volume drinking and RSOD is. Moreover, this theory generally also held for both genders, thereby supporting the results of previous research on alcohol use, which found a significant association exclusively among men (Knibbe, et al., 1987). Potential confirmation of the multiple burden hypothesis was found 
in the United States, Switzerland and Germany; all three cases concerned heavy-volume drinking (US and $\mathrm{CH}$ ), and RSOD (DE).

As regards heavy-volume drinking, no clear pattern for its association with the number of social roles was found among Swiss and Czech men, or among French women. All three countries are known for their high integration of alcohol in everyday life - wine in Switzerland and France, beer in the Czech Republic. Correspondingly, the Global Burden of Disease study (Rehm et al., 2004) classified them as "wet" countries. It has been suggested that in such countries, there is less variation in drinking between subcategories of the population, including subpopulations defined by roles (Skog, 1985).

In terms of heavy-volume drinking among women in Switzerland and the US, the two-role model was associated with a lower risk of heavy-volume drinking than the threerole model. A comparable pattern was found among German women regarding RSOD. Among Swiss and German women the lower risks were due to the high prevalence of the most protective two-role model (parent and partner). Interestingly, the situation was different for women in the United States. Those at the lowest risk of heavy-volume drinking were gainfully employed women (with or without a partner and with children). In contrast to their Swiss and German counterparts, women in the United States benefited from being employed but not from living at home with children despite the presence of a partner. A possible explanation may lie in the nature of paid labour within these societies. Whereas in the United States, paid labour seems to play a central role in one's sense of identity irrespective of gender, it may be a source of conflict for women in Switzerland and Germany, where a more traditional role model of being a partner and mother is favoured, and where paid labour may therefore constitute an additional source of stress. This explanation is also confirmed by the results of earlier studies (e.g. Gmel, et al., 2000; Lahelma, et al., 2002). Trying to reconcile the need to earn money and raise a family may create a conflict of roles, particularly among individuals who cannot share child-rearing responsibilities with a partner, or who live in countries where day care is less readily available (affordable), as is the case in Switzerland. In such instances, the three cases cited above may support the multiple burden hypothesis for women in these countries. To evaluate this further, future research should focus on the possible association between social roles and alcohol use among women in these countries. 
However, there is another explanation for this finding. Previous studies reported that being employed offers more opportunities for alcohol use among women (e.g. HaavioMannila, 1991; Hammer \& Vaglum, 1989; Shore, 1997). Based on our findings, it remains unclear whether it was the simple fact of having more opportunities to drink or the resulting stress of combining family obligations with a career that led women with three roles to drink more.

Some drawbacks of the present study must be mentioned. It focused on a comparison of several western industrialised countries that participated in the GenACIS project. In the interests of comparability, the analysis was restricted to rather crude measures of social roles, which in turn only permits a generalized interpretation of the results. Future studies should focus on the impact of possible confounders, including family factors like the number of children, their age, and job-related variables, such as being in part-time or fulltime employment. Nevertheless, despite the lower specificity and the cross-country differences in alcohol use measures and social roles, a rather consistent association was found between the number of social roles and alcohol use: the more roles that a person had, the lower their risk of detrimental alcohol use was. This strengthens the likelihood that the associations found in this study are robust rather than spurious.

Given the wide age range of the study ( 25 to 54 year olds), broad categories like having no children, no partner or no paid labour may have a different meaning for each age group. For example, in the younger age groups having no children at home may mean that pregnancy has not been considered, while in older age groups children may have already left home. Similarly, unemployment may have different effects in older age groups than among those who have recently completed their further education. Given the design of the present study, it was not possible to address these issues. More specific studies are needed to establish whether the association between roles and alcohol use varies according to the nature of or the time spent on paid labour, the age of the respondent, the age of his or her children and his or her relationship with a partner.

Owing to the cross-sectional design of the study, we were unable to establish any causal association between the number of social roles and alcohol use. Thus, we cannot categorically say whether the number of social roles someone holds results in reduced alcohol use or that someone's alcohol use limits his/her access to certain social roles, such as finding a partner or work. Another limitation concerns the drinker-only focus; 
conclusions can be drawn exclusively for individuals who have consumed alcohol in the past 12 months. This selection may be problematic in countries with high abstention rates, which means that sub-populations may be over- or under-represented in the group of abstainers.

The present study found that for both genders and in most countries, the existence of one social role was associated with an OR below 1. Thus, we posit that all three social roles (parenthood, partnership and paid labour) impose a structure on everyday life, hence the possible association with alcohol use. Consequently, we perceive social roles more as a measure of how well a person is integrated in a society and how the responsibilities which these roles bring lead to fewer opportunities to drink. The only notable exceptions were found in countries where alcohol use is highly integrated into everyday life (men in France, Switzerland and the Czech Republic) and among women in certain societies (US, Germany, and Switzerland). 


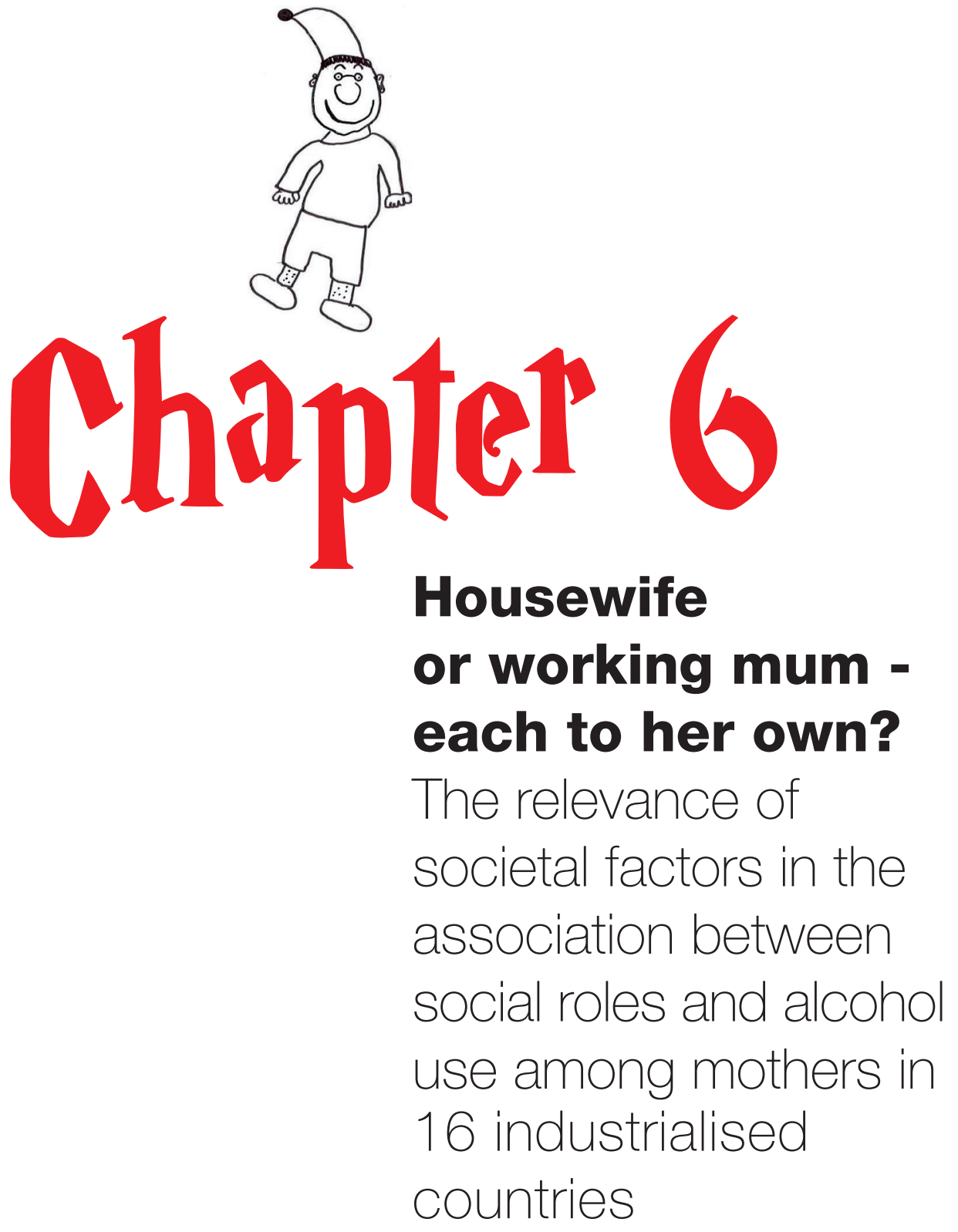




\section{Summary}

Objectives: To investigate whether differences in gender-income equity at country level explain national differences in the links between alcohol use, and the combination of motherhood and paid labour.

Participants: 12,454 mothers (aged 24 to 49) of 16 established market economies participating in the GenACIS study

Method: Alcohol use was assessed as the quantity per drinking day. Paid labour, having a partner, gender-income ratio at country level, and the interaction between individual and country characteristics were regressed on alcohol consumed per drinking day using multilevel modelling.

Results: Mothers with a partner who were in paid labour reported consuming more alcohol on drinking days than partnered housewives. In countries with high gender-income equity, mothers with a partner who were in paid labour drank less alcohol per occasion, while alcohol use was higher among working partnered mothers living in countries with lower income equity.

Conclusion: In countries which facilitate working mothers, daily alcohol use decreases as female social roles increase; in contrast, in countries where there are fewer incentives for mothers to remain in work, the protective effect of being a working mother (with partner) on alcohol use is weaker. These data suggest that a country's investment in measures to improve the compatibility of motherhood and paid labour may reduce women's alcohol use.

\section{Published as:}

Kuntsche, S., Knibbe, R., Kuntsche, E., \& Gmel, G. (2011). Housewife or working mum - each to her own? The relevance of societal factors in the association between social roles and alcohol use among mothers in 16 industrialised countries. Addiction, 106(11), 1925-1932. 


\section{Introduction}

Social roles, such as being a partner, a parent, or in paid work, have been found to be associated with differences in alcohol use (Gmel, et al., 2000; Knibbe, et al., 1987; R. W. Wilsnack \& Cheloha, 1987). Since social roles define the position of an individual within a given social system, their impact on alcohol use is likely to vary across different societies. So far, only a handful of studies have focused on the consistency of this association in different countries (Gmel, et al., 2000K; Kuntsche, et al., 2006; Kuntsche, et al., 2009). This study concentrates on differences in women's status which may affect the link between the combination of motherhood, paid labour and alcohol use.

The classic role theory (Kuntsche, et al., 2009) posits that the more social roles a person holds, the more his or her life is structured by activities that others expect them to engage in, and therefore the more care a person will take to ensure that drinking does not interfere with their role obligations. But it also suggests that, the fewer roles an individual holds, the more likely a person is to use alcohol to cope with the lack of meaningful everyday activities (Knibbe, et al., 1987; R. J. Neve, et al., 1997; Paradis, et al., 1999). These considerations lead to the assumption that the more roles a person holds, the less likely he or she is to engage in heavy drinking (Knibbe, et al., 1987; Kuntsche, et al., 2009; S. C. Wilsnack \& Wilsnack, 1991).

A recent study investigated the association between the number of social roles and alcohol use in 10 countries, and found that across almost all countries, participants who held all three roles were the least likely to drink heavily, thus supporting the assumptions of classic role theory (Kuntsche, et al., 2009). Nevertheless, there was considerable variation among countries with respect to the association between paid labour and women's alcohol use. For example, German and Swiss women who were partners, mothers and in paid labour reported higher levels of heavy drinking. Characteristics at the societal level seem, especially for women, to moderate the relationship between social roles and alcohol use.

Despite the substantial increase in female labour force participation, women still spend more time running the (shared) household and fulfilling childcare obligations than men (Bird, 1999). This mismatch between the old and new role of women in society could be a possible explanation for the increase in women's alcohol use over the past decades (Holmila \& Raitasalo, 2005). In a study on the relevance of societal factors on alcohol use, Rahav et al. (Rahav, Wilsnack, Bloomfield, Gmel, \& Kuntsche, 2006) concluded "that the societal 
differences between men's and women's drinking are largely a function of the differentiation between men's and women's positions in society (p. i54)". Yet, countries may differ in the extent to which they provide the societal circumstances to enable equal sharing of household and childcare responsibilities. The differences between men's and women's earnings can be seen as a major variable for the description of women's status in society (Rahav, et al., 2006). A low gender-income ratio may reflect a more traditional view of social roles: men as breadwinners and women as housewives, who stay at home and care for the family. Consequently, mothers in countries with less gender-income equity may experience paid labour as an additional burden, and therefore report higher drinking levels (e.g. to compensate for the additional stress). By contrast, mothers in countries with smaller gender differences in income equity, the responsibilities of being in paid labour in addition to being a parent are more socially valued and also more likely to result in lower alcohol use.

To date, cross-cultural comparative studies are scant. Notable exceptions have shown that countries differ in how social roles affect women's drinking habits (Gmel, et al., 2000; Kuntsche, et al., 2006; Kuntsche, et al., 2009), in particular those of single and partnered mothers (Gmel, et al., 2000). As all previous studies have failed to include country-level factors, the explanations for these differences have remained elusive. This study therefore examines possible effects of gender-income equity on the relationship between paid labour and alcohol use among mothers. Among other factors known to be related to women's drinking is their level of education. In most countries, women with a higher level of education tend to drink more alcohol (Bloomfield, Grittner, et al., 2006). As level of education might be associated with paid labour, educational level was considered as a possible confounder at individual level.

Mothers may seek paid employment purely out of economic necessity. The extent to which mothers work out of material necessity may also explain cross-country differences in the association between the social roles held by mothers and their alcohol use. It appears that this applies in particular to those mothers who feel forced to accept work which gives little or no satisfaction, and who thus use alcohol to alleviate tensions that this situation may engender. This may explain country differences in the association between social roles and women's drinking. To address this issue the country's Gross National Income (GNI) was included as a confounder at country level. 
More precisely, this study focuses on three specific adult roles in 16 established market economies: taking care of children (parenting), taking care of oneself by earning an income (paid labour), and forming a permanent and stable relationship with a partner (partnership). This paper focuses on the relevance of societal factors on cross-country differences in alcohol use among mothers. The first stage therefore involved testing the relevance of paid labour on the quantity of alcohol consumed in a drinking day. The second stage involved testing the relevance of the country's gender-income equity on the country's alcohol use and the final stage involved testing the associations between alcohol use and whether or not women were in paid labour. GNI was included as a possible confounder at country level.

\section{Method}

\section{Sample}

Data came from the project Gender, Alcohol and Culture: An International Study (GenACIS: see also: Bloomfield, Gmel, et al., 2006, www.genacis.org), which currently comprises 45 surveys from 37 countries included in a centralised data bank management system, which encoded variables according to fixed rules (Kuntsche, et al., 2008). The study included women from 16 established market economies $(n=51,559)$, which provided sufficient information on social roles and alcohol use. The focus on established market economies ensured a minimum level of comparability regarding the measurement and the meaning of social roles across societies. Apart from the surveys carried out in Spain and the Netherlands, all surveys were nationally representative. The analyses were conducted among mothers who had consumed alcohol during the past 12 months $(n=15,405)$. Abstainers were excluded because previous studies which focused on abstention indicate that the factors which distinguish abstainers from drinkers are quite different from those which differentiate between drinkers according to their level of consumption (e.g. Shaper \& Wannamethee, 1998).

Our analysis was further limited to those aged 25 to $49(n=12,690)$; an age range in which it can be assumed that either the child or at least one of the children living in the household was a minor, given that many of the surveys included in the study did not assess the children's ages. The presence of a child or children in the household implied that the parent still had child-rearing responsibilities. Since it would be fair to assume that people in this age range are no longer in education, paid labour reflects stable employment rather than only temporary employment (e.g. students working to finance their studies). 


\section{Individual level variables}

\section{Dependent variable}

All surveys provided comparable data on the usual amount an individual consumed on a drinking day, and this measure was of higher informative value compared with heavy episodic drinking (Mäkelä et al., 2006) among women. As drink sizes and alcohol contents varied between countries, the measure used was transformed into consumed grams of pure ethanol (detailed information can be found in Mäkelä, et al., 2006). The variable was log-transformed to approximate a normal distribution and to reduce the impact of outliers (Tabachnick \& Fidell, 2001). The mean quantity of pure ethanol (in g) per drinking day per country can be found in Table 6-2.

\section{Independent variables}

The "partnership" role was dichotomised into married or cohabiting (code=1) versus other $($ code $=0)$.

The "paid labour" role summarises the employment situation of the respondent. Paid workers, regardless of whether they were employed part-time or full-time, as well as the selfemployed were coded as 1 ; otherwise as 0 .

For analyses, the two dichotomous variables "paid labour" and "partnership" were combined to create the following four groups: mothers without a partner and not in paid labour (non-working single mothers); mothers without a partner but in paid labour (working single mothers); mothers with a partner and in paid labour (partnered working mothers); and mothers with a partner but not in paid labour (housewives; reference group).

\section{Societal variables}

We used internationally standardised indicators derived from international databases (e.g. Human Development Reports). As the greatest cross-country variations were found in the association between the paid labour-motherhood role combination and alcohol use (Kuntsche, et al., 2009), particular focus was on societal indicators of gender equality, as these also reflect the possibilities available to women for remaining in work after the birth of a child. Unfortunately, many of these indicators reflect only very specific facets (e.g. female MPs and childcare expenditure) of the rather complex issues behind the possible conflict between the paid work and childrearing roles. Moreover, due to the limited number of countries $(\mathrm{N}=16)$ on 
the societal level, this study was not able to include a large number of societal indicators on the social situation of mothers in a given society. Consequently, an indicator for the society's acceptance and support of combining motherhood and paid labour on a more general level was sought. In addition to national differences in childcare provision, gender-income equity may be a factor behind maternal employment. A low gender-income ratio may reflect a more traditional view of social roles: men as breadwinners and women as housewives, who stay at home and care for the family. This measure was taken from the Human Development Report 2006 (United Nations Development Programme (UNDP), 2006).

Age and educational level were considered as two possible individual-level confounders. Educational level accounts for the effects of socio-economic status on alcohol use, and has the advantage that it varies less over time than income or occupation (Gottfredson \& Deary, 2004). To derive comparable educational groups across countries, we applied the International Standard Classification of Education (ISCED-97) (UNESCO Institute for Statistics, 1997).

The country level analyses (Models 2 and 3) were adjusted for countries' GNI per capita in US Dollars to consider the effect that countries may differ in the extent to which mothers take up paid work out of material necessity. The indicator was based on data closest to the survey year from the World Bank.

\section{Statistical analysis}

Individuals with missing values on educational level, age, paid labour, partnership, or alcohol use $(1.9 \% ; n=236)$ were excluded from the analysis. The final sample comprised 12,454 alcohol-using mothers (see Table 6-1). HLM 6 (Raudenbush, et al., 2004) was used to estimate three multilevel models with increasing complexity (Hox, 2002). At individual level, all models were adjusted for age and level of education.

Model 1 estimated the association between paid labour, partnership, the combination of the two, and the quantity of alcohol consumed per drinking day, whereby all coefficients could vary across countries (random coefficient model). Model 2 included the gender-income ratio as an independent variable at country level (level-two, intercept-only model) to evaluate the impact of this factor on the reference group's drinking (housewives). Model 3 included the interaction between the societal factor and the partnership-paid work role combination (crosslevel interaction model). This model tests whether cross-country variations in the association 
between the paid labour-partner role combination and alcohol use can be explained by the country's gender-income ratio.

Table 6-1 Survey characteristics and sample size among alcohol-consuming mothers aged between 25 and 49

\begin{tabular}{lccc}
\hline & Survey year & Survey mode & $\mathbf{n}$ \\
\hline Australia & 2007 & CATI & 424 \\
Austria & 1993 & face-to-face & 876 \\
Canada & 2004 & CATI & 1,845 \\
Czech Republic & 2002 & face-to-face & 352 \\
Denmark & 2003 & telephone & 270 \\
Finland & 2000 & face-to-face & 1 \\
France & 1999 & telephone & 271 \\
Germany & 2000 & postal & 2,059 \\
Hungary & 2001 & face-to-face & 1,860 \\
Netherlands & 1999 & postal & 375 \\
Norway & 1999 & face-to-face & \\
Spain & 2003 & face-to-face & 538 \\
Sweden & 2002 & telephone & 397 \\
Switzerland & 2002 & telephone & 100 \\
UK & 2000 & face-to-face (CAPI) & 636 \\
USA & $1995 / 1996$ & face-to-face & 1,573 \\
& & & 304 \\
\hline
\end{tabular}

Remark: ${ }^{1}$ partly self-administered; CAPI: computer assisted personal interviewing; CATI: computer assisted telephone interviewing

\section{Results}

Descriptive results showed that among mothers aged 25 to 49 , the percentage reporting alcohol use in the past 12 months varied from $49.0 \%$ in Spain to $100 \%$ in the UK (Table 6-2). Considerable variations were also found for the country's mean quantity of pure ethanol in grams per drinking day. In France, women in this age group drank approximately $11 \mathrm{~g}$ on a drinking day, while women in Norway drank nearly five times more $(52 \mathrm{~g})$. The proportion of those in paid work varied between $45.6 \%$ in Germany and $82.2 \%$ in Sweden. Comparable variations were found for the percentage of cohabiting mothers. In the US, only $49.7 \%$ of the mothers reported that they lived with a partner, compared to $96.2 \%$ in Switzerland. 


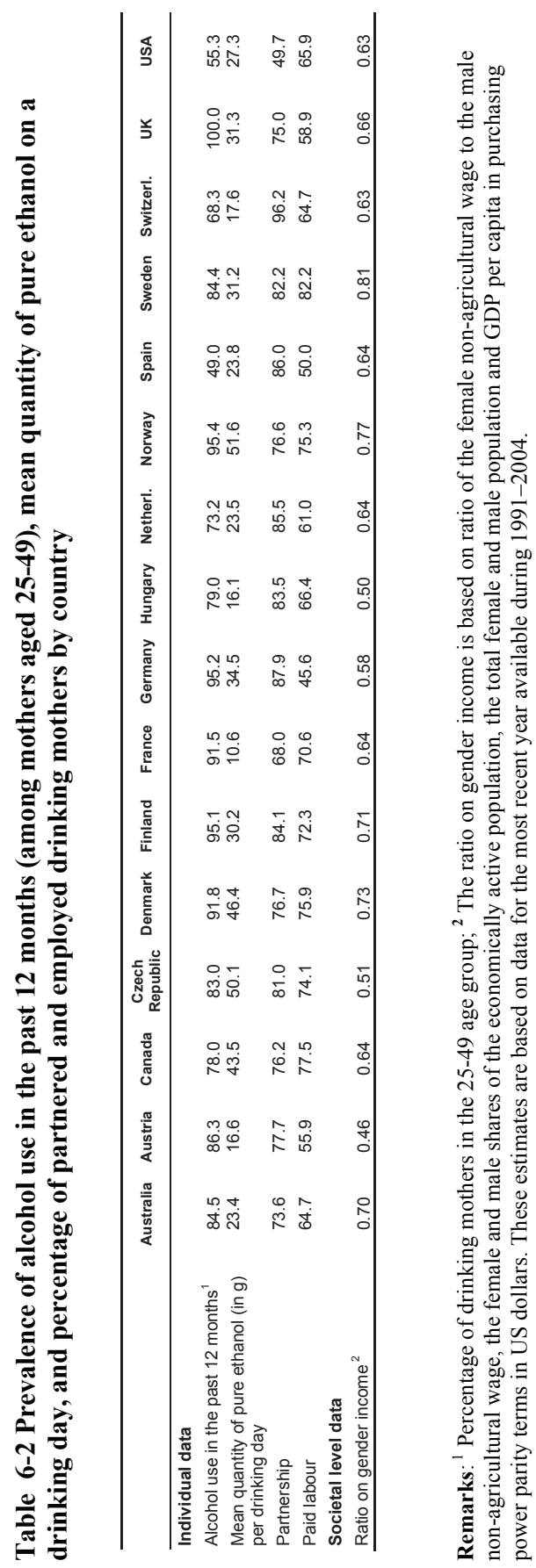


The results of Model 1 reveal significant differences between partnered mothers who were not in paid labour (henceforth called 'housewives') and partnered working mothers; the latter reported higher amounts per drinking day (see Table 6-3 and Figure 6-1). Compared to housewives, single mothers also reported significantly higher alcohol consumption on a drinking day regardless of their employment status.

Model 2 shows that GNI as well as the gender-income ratio in a country had no effect per se on alcohol use among housewives (Table 6-3). However, the interaction between the gender-income ratio and being a partnered working mother had a significant impact on the usual quantity consumed (Model 3). No moderation effect of the gender-income ratio was found among single mothers.

Figure 6-2 Interaction between partnership and paid labour on quantity consumed per drinking day (random coefficient model; Model 1in Table 6-3)

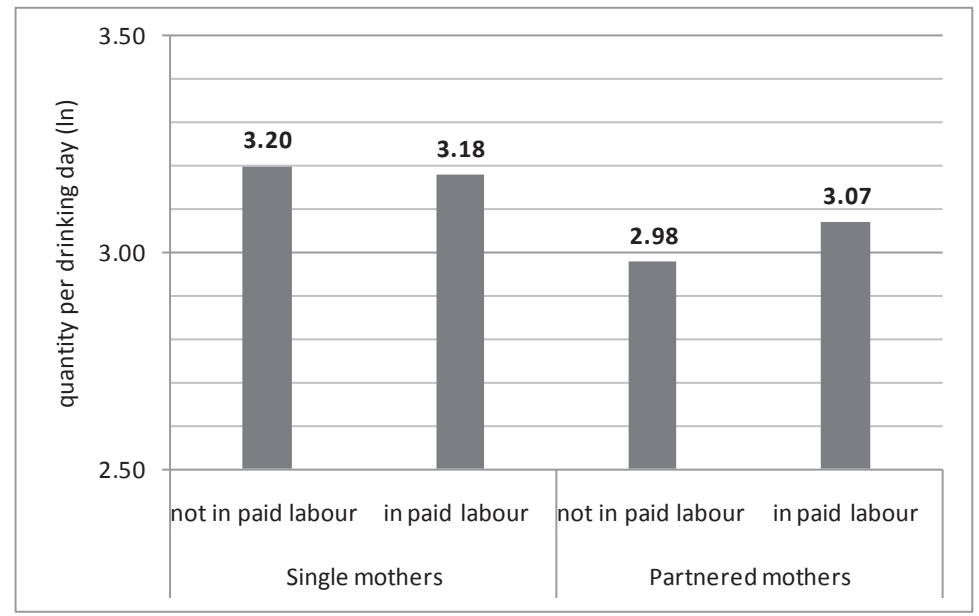




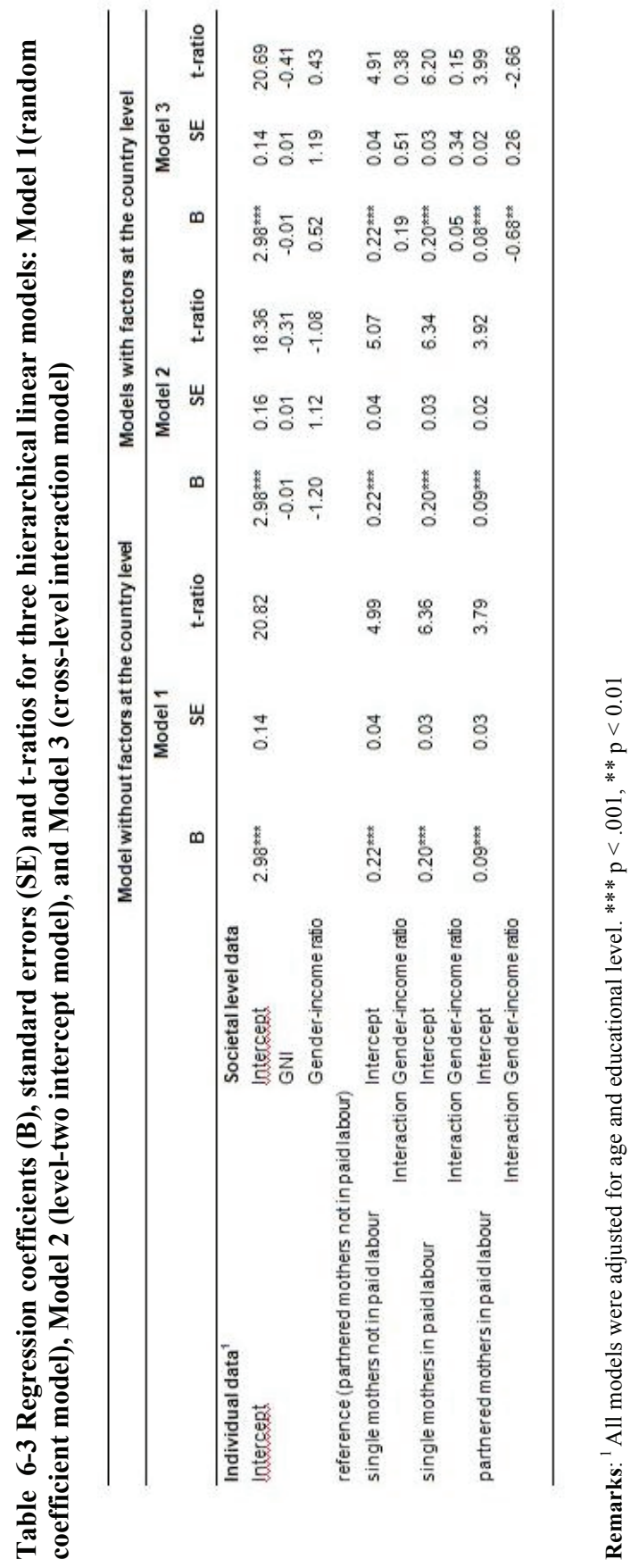


The detrimental effect of paid work on the usual quantity consumed by partnered mothers per drinking day remained, but this effect was moderated by the country's gender-income ratio. In countries where pay equity was higher, alcohol intake per drinking day among partnered working mothers was lower than among housewives. In countries where genderincome equity was lower, paid labour was associated with higher alcohol intake per drinking day among partnered working mothers compared to housewives.

To illustrate the country differences in the group of partnered mothers, we plotted the strength of the relationship between paid labour and alcohol use on the country's genderincome ratio. The results in Figure 6-2 reveal that, in countries with higher gender income equity (Nordic countries), mothers living with a partner who were also in employment drank smaller amounts per drinking day than housewives. In countries with lower income equity, like Hungary or the Czech Republic, a positive association was found between quantity per drinking day and the role combination of being mother, partner, and in paid labour. In fact, based on the relationships presented in Figure 6-2, differences in the gender-income ratio explained $51 \%$ of the cross-country variance in the impact that role combinations had on alcohol use. 
Figure 6-2: Relevance of the gender-income ratio on the association between quantity per day and paid labour among partnered mothers

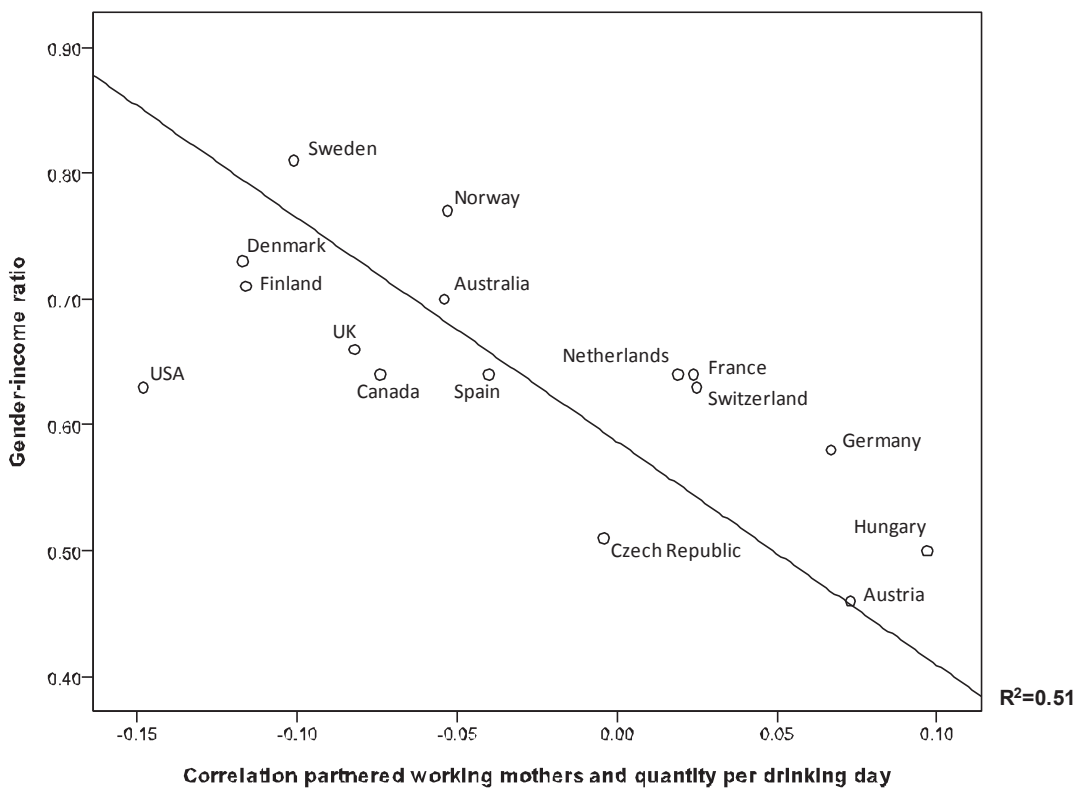

\section{Discussion}

The aim of this study was to investigate whether country differences in the association between social roles and maternal alcohol use can be explained by societal characteristics. In all countries, the results confirmed those of an earlier study (Kuntsche, et al., 2009): among partnered mothers, being in employment led to larger amounts of alcohol consumed on a drinking day than not being employed. The significant cross-level interaction of partnered working mothers and gender-income ratio provided evidence that the classic role theory is less likely to explain women's drinking for countries with lower gender-income equity.

This study therefore provides evidence to support the findings of a previous study which reported that the protective effects of combining motherhood with paid labour and partnership were rather low in certain countries (Kuntsche, et al., 2009). The results of this study demonstrate that combining motherhood, paid labour and partnership was only protective in countries with high gender-income equity (e.g. the Nordic countries), whereas in countries with less gender-income equity, this role combination did not demonstrate the same protective effect. 
Based on reported high correlations between different measures on women's status by a previous study (Rahav, et al., 2006) the authors assume that the gender-income ratio used in this study is most likely associated with other societal aspects which make it easier or more difficult for women to combine motherhood with paid work. One factor probably related to the gender-income ratio is the social norms of a country regarding a mother's role in society. These culturally embedded norms may either impede or encourage women's employment. It can be assumed that countries with more gender-income equity are less traditional in their social expectations about maternal behaviour. In contrast, in countries with lower genderincome equity the traditional roles - fathers being the main breadwinner and mothers taking care of the family - are likely to dominate. In those countries, women in the atypical role of combining motherhood and paid labour may receive less social support. In addition, in countries where the more traditional maternal roles dominate - staying at home to take care of the children and the household -specific policies such as access to childcare, maternity leave, reduced working hours due to parenthood are also likely to discourage the motherhood-paid labour role combination. This is likely to render the lives of working mothers more complicated - over and above the lower level of social support - and may lead to individual stress due to the role overload which may ultimately lead to the coping use of alcohol, consequences suggested by the multiple burden theory (Doyal, 1995; Macran, et al., 1996; Ross \& Mirowsky, 1992).

In summary, this study indicates that in Nordic countries with historically high levels of emancipation and gender equality, combining motherhood and paid labour resulted in lower quantities per drinking day whereas in central and eastern European countries the less conventional combination of motherhood with paid work did not provide such a protective effect. In this respect the higher alcohol consumption of single mothers compared to partnered mothers may be understood as a way of coping with the stresses and strains of single motherhood and a possible resulting overload regardless of the gender equity in the country.

This study has several strengths, such as the inclusion of more than 12,000 alcoholconsuming mothers in a multinational sample. The focus was on established market societies to ensure comparability regarding the definition and meaning of the social roles, as they were applied in the study. However, a combination of societal characteristics was most likely responsible for the variation between countries in how social roles relate to maternal drinking. Our study is a first step towards presenting such an association. Further studies are necessary to document societal factors that explain country differences in the association between social 
roles and drinking. The economic prosperity of countries measured by GNI had no effect on the differences in maternal alcohol use across the 16 countries considered in this study.

We must also acknowledge the study's limitations. To ensure a minimum of comparability, the analysis was restricted to rather crude measures of social roles, which in turn only permits a general interpretation of the results. Future studies should include more specific factors like the number of children, their ages, and job-related variables, such as being in part-time or full-time employment, and additionally consider other societal indicators which may better reflect the societal support for women to combine motherhood and paid labour roles, such as childcare provision. In addition, the inclusion of education level at best only partially accounted for differences in affordability. Similarly, social availability is likely to be only partially accounted for by including the different roles in the analysis. This may have led to a less precise estimate of the country coefficients for the influence of paid labour on mothers' drinking. However, assuming that this imprecision is approximately equal for all countries, no major influence on the main finding is expected: mothers in paid work, who are more likely to be able to afford to drink, and may have a larger and more diverse social network than mothers without paid work, still drink less if the gender-income ratio is high. Despite the limited precision in which country differences between working and non-working mothers could be estimated, the associations between social roles and alcohol use found across the 16 countries considered in the study were rather consistent. This, in addition to the high effect size of the country-level effect (Figure 6-2), increases the likelihood that the associations found in this study are robust rather than spurious.

Due to the cross-sectional design of the study, we were unable to establish any causal association between social roles and alcohol use. Thus, we cannot say with certainty whether the combination of roles an individual holds results in reduced alcohol use or that an individual's alcohol use limits her access to certain social roles, such as finding a partner or work. Another limitation concerns the drinker-only focus; conclusions can only be drawn for individuals who have consumed alcohol in the past 12 months. This selection may be problematic in countries with high abstention rates. Consequently, certain sub-populations may be over- or under-represented in the abstainer group. Another limitation relates to country differences in the alcohol measures and survey years. Despite a generalized databank management, no identical measures for alcohol could be obtained. However, the high effect size and the consistency across 16 countries increase the likelihood that the associations found in this study are valid. 
To conclude, this study provides evidence that in countries which facilitate the combination of motherhood and paid labour, the amount of alcohol consumed on a drinking day decreases the more roles a woman holds (being a mother, partner and employee). By contrast, in countries where there are fewer incentives for mothers to remain in work, the effect of the number of social roles is weaker, indicating that a country's investment in measures to improve the compatibility of motherhood and paid labour can reduce women's alcohol use. 


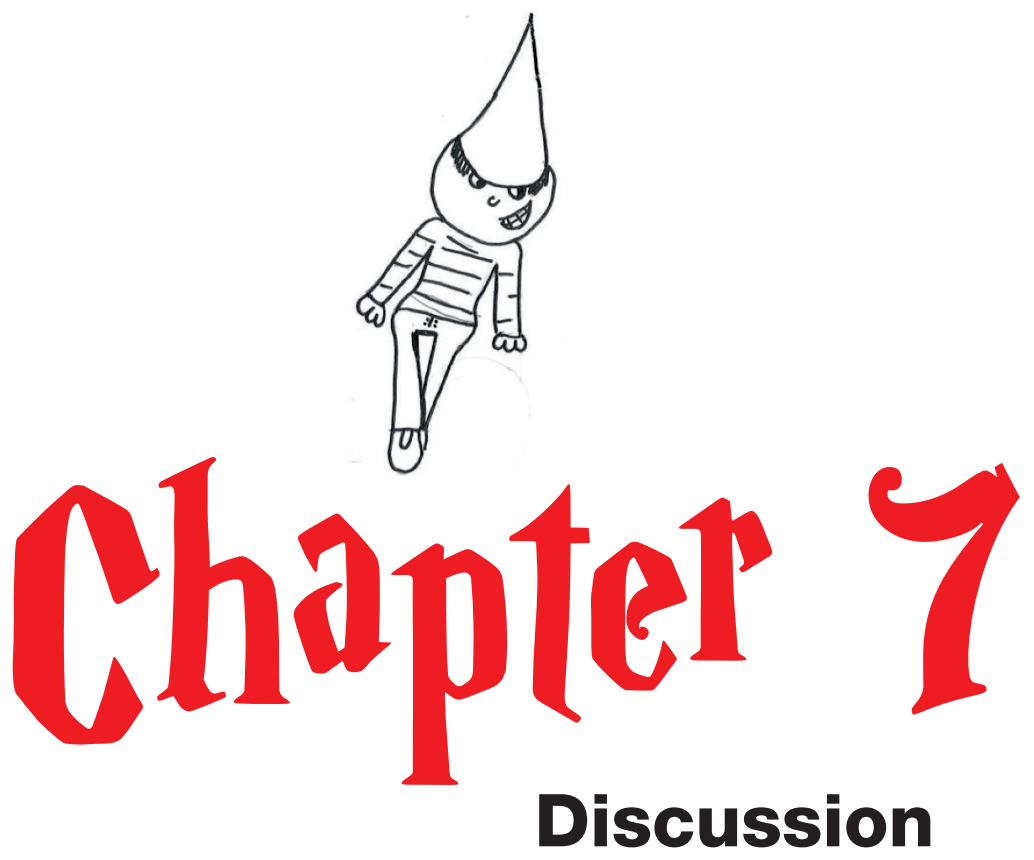




\section{Main outcomes of the study}

The main findings that emerged from chapters 2 to 6 are summarized in Table 7-1.

\section{Table 7-1: Overview of the key findings of Chapters 2 to 6}

Chapter 2: A step beyond - the relevance of depressed mood and mastery in the interplay between the number of social roles and alcohol use

This chapter examined whether the relationship between the number of social roles and heavy drinking was mediated or moderated by depressed mood or external control among drinkers. Holding more social roles was associated with lower alcohol use, lower external control and lower depressed mood. No evidence was found that depressed mood or external control mediated the social roles-alcohol relationship. Social roles were associated with a number of drinking aspects other than depressed mood and external control.

A moderation effect was identified among women only, whereby the protective effect of having more roles was not found among those who scored highly on external control.

Chapter 3: Alcohol use among parents: gender differences in the impact of household and family chores

This chapter examined the effect of family characteristics on parental alcohol use in Switzerland.

The study showed that in Switzerland, women's drinking is more systematically related to the parental role and family related variables than men's drinking. There was evidence that maternal responsibilities per se may protect from alcohol use but mothers who are also in paid employment may benefit less or not at all from this protective effect as suggested by the moderation effects of paid labour and the impact of the number of children on alcohol use.

Chapter 4: Gender and cultural differences in the association between family roles, social stratification and alcohol use: A European cross-cultural analysis

This chapter examined the relevance of cultural and gender differences in the association between family roles and social stratification with heavy drinking in eight European countries. Whereas in general family roles had a higher protective impact on alcohol use among women; among men, socioeconomic factors had a higher impact on alcohol use than family roles. In addition, among women correlations between alcohol use and country characteristics revealed that:

- Women in countries with a strong social welfare system, such as Nordic countries, tended to drink more heavily if they were employed, had fewer formal qualifications and a nontraditional family role.

- In countries with weaker social welfare systems or lower female work desirability, heavy drinking was associated with a high level of education, while the effects of family roles and employment were small. 
Table 7-1: Overview of the key findings of Chapters 2 to 6 (continued)

\section{Chapter 5: Social roles and alcohol consumption: a study of 10 industrialised countries}

A study was conducted into the relationship between the number of social roles and heavy drinking among men and women in 10 industrialised countries. Among men, a higher number of social roles was associated with a lower risk of heavy alcohol use and RSOD. Among women, the same pattern was found for the majority of countries, thus supporting the assumptions of classic role theory. It was also found that the protective effect of multiple roles was more consistent for RSOD. There were a few countries where among women a two-role model gave a better fit. Results for Germany (RSOD), Switzerland, and the US (heavy volume) indicate that the role of paid employment appears to be particularly relevant for risky alcohol use among women.

Chapter 6: Housewife or working mum - each to her own? The relevance of societal factors in the association between social roles and alcohol use among mothers in 16 industrialised countries

A study of mothers in 16 Western industrialised countries examined the impact of combining paid labour with motherhood on usual quantity of alcohol consumed. The study also considered whether country differences in the effect of work on women's drinking could be explained by means of country differences on gender income equity. Irrespective of their employment status, single mothers reported higher quantities per occasion than partnered mothers. In countries with high genderincome equity, mothers with a partner and paid work drank less alcohol per occasion, while alcohol use was higher among their peers living in countries with lower income equity.

Evidence was found that in countries which facilitate the combination of motherhood and paid labour, the amount of alcohol consumed on a drinking day decreased as the number of social roles increased. By contrast, in countries with fewer incentives for mothers to remain in work, being in paid work in addition to holding the roles of partnership and parenthood was associated with an increase in alcohol use.

All the previous chapters clearly demonstrate the correlation between social roles and alcohol use. Nevertheless, the influence a social role may have on alcohol use varied over the different positional roles and between the two genders. The section below discusses the relevance of each separate role on alcohol use. This discussion will be limited because in the previous chapters our main interest has been on the extent to which additional roles (mostly regardless of whether it concerned partnership, parenthood or paid employment) led to reduced alcohol use. 
Later in this chapter the results of previous chapters about factors explaining the relationship between social roles and alcohol use will be discussed in more detail (see below: Factors explaining the relationship between roles and drinking). The chapter will then examine the relevance of the classic role theory or multiple burden role theory for alcohol use (see below: Role theory: classic role theory or multiple burden). The last section of this chapter includes a paragraph pointing out the relevance of a multiple role perspective on alcohol use for public health policy and prevention as well as an outline for future research (Looking to the future-public health relevance and future research).

\section{Impact of each individual social role on alcohol use}

\section{Parenthood}

Based on the results of Chapters 3 and 4, having a child or children when living in a partnership in general reduced alcohol use among both fathers and mothers. By contrast, single mothers in particular tended to drink more frequently or higher amounts than partnered mothers. Previous studies confirm this correlation. The majority of previous studies on parenthood are based on US American data. Christie-Mizell \& Peralta (2009) found a decrease in the frequency of drinking when becoming or being a parent, but only among women. Little and colleagues (Little, Handley, Leuthe, \& Chassin, 2009) found a parent-role related decline in alcohol use for both genders. However this decline varied according to the age at which the individual became a parent. Adolescent fathers increased their alcohol use when becoming parents. Power \& Estaugh (1990b) found a decrease in all consumption measures for both men and women who became parents. Longitudinal studies found a drop in alcohol use when the respondents became parents (Hajema \& Knibbe, 1998; Power \& Estaugh, 1990b). Nevertheless, single parenthood was associated with elevated psychological distress and alcohol use among Canadian women, but not among men (Avison \& Davies, 2005).

\section{Partnership}

In this thesis, individuals living with a partner or spouse reported lower rates of heavy alcohol use than singles (compare Chapter 4). This finding was more consistent for men. A US study by Matzger et al. (2004) found that married individuals drank significantly less than 
those who never married. Merline et al. (2004) reported that being married was associated with a lower risk for heavy alcohol use at the age of 35 .

The relationship between specific social roles and alcohol use has also been the focus of longitudinal studies (e.g. Hajema \& Knibbe, 1998) which confirm the protective effect of partnership on alcohol use. A meta-analysis of social role changes conducted by Temple et al. (1991) found a negative association between getting married and drinking for both women and men.

\section{Paid labour}

A central aspect in this study was the gender moderated influence of paid labour on alcohol use. In general, paid employment more often showed a detrimental rather than beneficial effect on heavy drinking among women, although this was not statistically significant (compare Chapter 3). In other words, whereas men in all the countries included in this thesis tended to engage in less risky drinking when in paid labour, women tended to drink more in most countries. However, there were significant country differences in the effect of paid employment on alcohol use among mothers. Whereas in countries with higher gender equity, paid employment was found to have a protective effect on the amount of alcohol consumed on a drinking day, the opposite was true for countries with lower gender equity. In addition, the impact of paid labour on alcohol use was stronger among men (Chapter 4), whereas paid labour primarily moderated the impact of parenthood among women (Chapters 4, 5 and 6).

Regarding the relationship between employment status and alcohol use, previous studies have drawn mixed conclusions. MacDonald and Schields (2004) reported that unemployment significantly affected overall alcohol use in Britain. Another British study found associations between unemployment and heavy drinking among men but not among women (Power \& Estaugh, 1990a). By contrast, a Finnish study found no correlation between employment status and the frequency of drinking or intoxication (Lahelma, Kangas, \& Manderbacka, 1995), whereas a French study (Khlat, Sermet, \& Le Pape, 2004) again found a significant correlation between heavy drinking and unemployment.

The gender and cultural differences outlined above appear to underline the fact that when interpreting the relationship between social roles and alcohol use, status roles have to be considered as important parameters, a fact that will be discussed later in this chapter. 
Besides the two previously mentioned status roles, gender and culture, Wilsnack and Cheloha (1987) suggested that the impact of social roles on alcohol use may also vary across different age groups. Thus, given the wide age range of the study (25 to 54 year olds), factors such as having no children, no partner or no paid labour may vary in significance for each age group. For example, in the younger age groups having no children at home may mean that pregnancy has not been considered, while in older age groups children may have already left home. Similarly, unemployment may have different effects in older age groups than among those who have recently completed their further education. A limitation of the present study is that, given the existing design, it was not possible to address these issues. Therefore, age was only considered as a possible confounder in all analyses.

\section{Factors explaining the relationship between roles and drinking}

A central focus of this study was to examine the possible explanatory factors behind the mechanisms and processes which shape the interplay between social roles and alcohol use. In general, social roles may affect the individual's health via two underlying mechanisms. First, by limiting the opportunities to engage in situational roles offering immediate gratification. The second way via which social roles may influence health behaviour and related activities is via a lack of structure in everyday life and a possible resulting frustration due to a lack of relevant social roles. Having no or few roles makes it potentially more difficult to structure one's life around meaningful relationships, which may result in a certain frustration. Consequently, a lack of social roles may be more often associated with negative emotions like feeling externally controlled or feeling depressed.

The interrelation between social roles, alcohol use and individual factors, such as psychological wellbeing and family characteristics were the central focus of Chapters 2 and 3 . The chapters aimed to examine:

- The extent to which psychological factors mediate (or moderate) the relationship between the number of social roles and alcohol use (Chapter 2), in other words whether a lack of structure influences alcohol use via the individual's psychological characteristics.

- The extent to which gender differences in household and parenting activities explain gender differences in alcohol use (Chapter 3), in other words whether 
having a higher parental and family workload reduces the opportunities to engage in alcohol use.

\section{Do psychological factors mediate the relationship between a lack of structure and alcohol use?}

The answers provided in Chapter 2 were rather straightforward: no proof was found to support the assumption that depressed mood or external control mediated the relationship between the number of social roles and alcohol use. In addition, with a single exception, there was no indication that either of these factors moderated the relationship between the number of social roles and alcohol use. The only exception concerned women with a high score on external control, where no protective effect of multiple social roles on average quantity per day was found.

The two variables indicating psychological well-being did not mediate the relationship between the number of social roles and alcohol use. However, this was not due to a lack of inter-relations between the sets of variables, but due to the fact that the number of social roles and depressed mood/external control were related to different aspects of alcohol use.

Among men a lack of psychological well-being was associated with higher average consumption, whereas a lack of positional roles was associated with an increased frequency of RSOD. Among women, poor psychological well-being was associated with an increased frequency of RSOD, while a lack of structure in everyday life appeared to be associated with a higher average consumption. One may conclude that both genders tend to cope with negative emotions or a lack of structure through higher alcohol use. In previous studies it has been suggested that men are more likely to use alcohol to cope with negative emotions or circumstances (Berger \& Adesso, 1991; Timmer, et al., 1985). In the previous chapters no such gender difference was found, although there is a definite gender difference in which specific drinking behaviour (e.g. RSOD or average consumption) is used to cope.

The processes behind the lack of moderating effects of factors for psychological wellbeing were similar to those found for mediation: the number of social roles and depressed $\operatorname{mood} /$ external control were related to different aspects of alcohol use.

As a result, three general conclusions can be drawn: 
- Multiple roles and depressed mood or external control differ in the aspects of drinking pattern they are related to.

- There is a gender difference in the aspect of alcohol use that is influenced by the number of social roles and variables indicating psychological well-being.

- For these reasons there is, despite the necessary interrelations between social roles and depressed mood and external control, no mediation of the effect of roles on men's or women's drinking.

Although the relationship between mental health and social roles is well documented, to the best of our knowledge there are no other studies examining the effect of psychological factors on the interplay between social roles and alcohol use. Although the study only examined the relationships in Switzerland, it is assumed that the conclusions can be generalized to other countries. A limitation of this study was that it only examined two psychological factors possibly influencing social roles and alcohol use. Other psychological factors, such as differences in coping styles, i.e. whether the individual drinks to cope or not, may be more relevant to the relationship between social roles and alcohol use. Nevertheless, the fact that social roles and psychological variables influence different aspects of alcohol use makes it likely that the effect of social roles is mediated by factors other than psychological variables. The following paragraph discusses such other factors, more specifically whether the varying time constraints of social roles lead to differences in alcohol consumption.

\section{Family characteristics and parental alcohol use: Does a higher parental and family workload reduce the opportunities to engage in alcohol use?}

The explanatory value of opportunities to drink as an underlying mechanism of the relationship between social roles and alcohol use was only investigated indirectly. Apart from this study on family related role obligations and men's and women's alcohol use, there are very few studies (Mansdotter, Backhans, \& Hallqvist, 2008; Mansdotter, Lindholm, Lundberg, Winkvist, \& Öhman, 2006; Paradis, 2011; Paradis, et al., 2011) examining in detail how social roles structure everyday life and the extent to which they reduce the opportunties to participate in drinking situations.

Chapter 3 examined the relevance of detailed family factors like the age of the youngest child, the number of children and the share of childcare and household duties on the alcohol 
use of Swiss fathers and mothers. The detailed analysis revealed that among mothers, the age of the youngest child and the quantity of childcare duties were of high importance for the prediction of alcohol use. Among mothers, the majority of family-related indicators examined followed the general rule that the more obligations and demands of household and childcare duties, the lower the alcohol use. However, having both paid labour and more than two children resulted in higher alcohol use. The study clearly shows that, depending on how much time the role of being a partner or parent requires, a corresponding decrease in alcohol use can be expected, but only among women. The fact that such an association was only found among women can, without doubt, be explained by the fact that men' activities associated with being a partner and parent have less to do with the specific and daily recurring activities included in the study and possibly more with specific jobs such as gardening and maintenance. Of course, a limitation of this study is the fact that the analyses are based on Swiss data only, a country which still has a very traditional understanding of the maternal and paternal role. Future studies should include a far larger and varied range of family related activities to further examine whether the influence of being a partner and parent is mostly mediated by the time constraints due to the obligations of these roles. Of course, as well as a limitation in the number of opportunities to drink, social roles like partnership and parenthood are likely to be associated with more stringent social control of others on someone's drinking. This factor should also be included in future studies seeking to explain how social roles may influence alcohol use.

The results of Chapter 3 stating that in Switzerland working mothers reported higher alcohol use than their non working counterparts indicates a possible role conflict for this specific group of women as suggested in the context of multiple burden hypothesis. This will be discussed in more detail in a specific paragraph later in this chapter (Women and multiple roles).

\section{Role theory: classic role theory or multiple burden}

The central theoretical perspective examined in this study concerned the classic role theory (or role accumulation), which focuses on the beneficial health effects of holding multiple social roles (Aneshensel, et al., 1981; Hibbard \& Pope, 1991; Hong \& Seltzer, 1995). As regards alcohol use, this theory posits that the greater the number of social roles a person holds, the more his or her life is structured by meaningful activities that others expect one to engage in. This leads one to expect that the more social roles a person holds, the less likely he 
or she is to engage in heavy-volume drinking or risky single occasion drinking (Knibbe, et al., 1987; S. C. Wilsnack \& Wilsnack, 1991).

The second theoretical perspective, the multiple burden hypothesis, assumes that role overload arising from holding too many social roles and from possible conflicts between the demands of these roles (e.g. childcare and having to take on paid labour) is related to stress, since each person only has a finite amount of time and energy. Based on the assumptions of the alcohol regulation theory, alcohol use may be considered a possible mechanism for coping with distress or with negative stress-related emotions (e.g. McCreary \& Sadava, 1998; Peirce, et al., 1994).

The multiple burden hypothesis has mainly been applied in studies involving women usually looking at the combination of parenthood, or more specifically motherhood, and paid work (e.g. Doyal, 1995). The main reasons behind the assumption that women are more likely to feel overburdened by holding multiple social roles compared to men are: (1) they may spend more time running the (shared) household than men; and (2) they may spend more time performing childcare duties than men (Arber \& Khlat, 2002; Lahelma, et al., 2002). For example, the higher morbidity among women was explained by the higher demands of family life on women in combination with the (mostly) lower rate of paid labor and lower wages (Bird \& Fremont, 1991). Gove (1984) distinguished the two genders by the type of social roles they typically occupy. Whereas men usually have well structured or "fixed" social roles like paid labour, women are more likely to occupy nurturing roles, which are less structured and not easy to plan. The authors assumed that the unpredictability of the latter is associated with stress and negative health consequences. Both of these more general explanations can be seen as a reflection of possible tensions between the roles of having paid work and having children, especially among women. The kind of work a woman does may also play a role here. Arber (1997) found that the multiple burden related to holding contradictory social roles had adverse health consequences for women in Britain who work full time in lower manual and non manual occupations, but not for women working in professional or managerial jobs. Glover and Arber (1995) concluded that working in professional and managerial jobs provided greater financial resources that can be used to ease some of the burdens of housework and childcare, thereby reducing role strain and fatigue. 


\section{Paid labour and parenthood: multiple burden or protective effect?}

As already noted, the multiple burden theory has been used far less often to explain alcohol consumption among men. Although it is highly interesting to address the question as to why there is no single indication that the multiple burden theory is relevant for men's alcohol use, this thesis was limited to the question of whether it is relevant to explain women's alcohol use.

\section{Women and multiple roles}

Most women in industrialised countries perform the role of full-time housewife, if at all, for only a few years while their children are small (Ginn, Street, \& Arber, 2001; McRae, 1999; Rake, 2000). However, female labour market participation is often weaker because of their high levels of part-time employment during the child-rearing phase (Arber \& Khlat, 2002). Although there has been a sharp increase in the number of women who combine the role of mother with paid employment in recent decades (Bird, 1999), studies have only identified a slight increase in the share of household chores undertaken by men in that time (Coltrane, 2000; Crompton, et al., 2005). The example of parenthood illustrates this: although the parental role is associated with lower alcohol use also among men, the majority of childcare tasks are still carried out by women. Women are therefore for the most part still responsible for all unforeseen events. Sick children or unscheduled play-dates in the afternoon are primarily left to women to deal with while men are out at work. This not only limits the mother's opportunities to engage in alcohol use but also increases the potential of role conflicts since these mothers may be employed outside the home, an activity which may clash with the demands of a sick child. Therefore, the differences in the nature of social roles as described by Gove (1984) may contribute to the gender differences found. The less structured family roles and the higher share of women in this field may complicate the combination of paid labour and family work.

Given the female emancipation of the past five decades, one would assume a redistribution of household and childcare and that these developments will also modify the influence of household chores and childcare on the drinking habits of fathers and mothers. This imbalance between higher female employment rates on the one hand and the fact that men's share in household duties is lacking on the other may result in double shifts, with women trying to combine paid employment with childcare and household chores. Women may therefore feel overburdened, an effect even more likely or pronounced if responsibilities in general cannot be shared with a partner. 


\section{Single mothers and multiple burden}

Being a single mother is particularly disadvantageous (e.g. Bernstein, 2001; Whitehead, et al., 2000), since this group may feel the contradictory pressures of working outside the home and caring for their children more strongly than partnered mothers (Ali \& Avison, 1997).

This thesis only partly supports these assumptions. Although single mothers drank significantly higher amounts of alcohol than partnered housewives with children, whether or not they were employed had no supplementary impact on the alcohol use of single mothers (see Chapter 6 for more details). Following the assumption of the multiple burden hypothesis, those single mothers who needed to take care of their children and had to work should have reported higher alcohol levels due to a potentially greater conflict between such contradictory roles.

Nevertheless, it can be assumed that the lack of a major social role, namely partnership, when having children one needs to care for results in a conflict-ridden situation as all obligations and demands have to be shouldered by a single person. Additional roles or the lack of additional roles like paid labour may not necessarily increase or decrease such conflicts. Quite another question is the extent to which there are cross national differences in the amount single mothers tend to drink compared to their partnered counterparts. In other words, the societal conditions a woman lives in may influence the life of single mothers. In countries with a lower gender equity, a less established childcare system and fewer possibilities for women to easily combine motherhood and paid employment, single mothers may be subject to more potential conflicts than single mothers in countries with a higher gender equity, and therefore more childcare facilities, a higher pay equity etc.. This study tested this assumption but found no evidence to support it (compare Chapter 6).

\section{Partnered mothers and multiple burden}

Among partnered women, too, being in paid labour and having children to care for resulted in higher levels of alcohol use in some countries (compare Chapters 4 and 6). This seems to contradict the assumptions of the classic role theory - the more roles and therefore the more structured life is, the lower the alcohol use. The results in Chapter 5 revealed that especially in Germany and Switzerland, the combination of all three roles was associated with higher consumption levels. The combination of paid labour on the one hand and family and childcare duties on the other may lead to role conflicts and to higher alcohol use, as suggested by the multiple burden hypothesis. 
This outcome was repeated in Chapter 6. The results of this chapter revealed that mothers in countries with low gender income equity (including Germany and Switzerland) tended to drink more when in paid work whereas in countries with higher gender income equity, more social roles were associated with less risky alcohol use. Although pay equity is only one indicator, it can be seen as a central factor in a country's commitment to gender equity - same money for the same job - and it appears to be strongly related to aspects such as comprehensive and affordable childcare services, paid leave to care for a sick child etc.. It is also considered a good indicator of a country's commitment to female employment (Rahav, et al., 2006). It can therefore be assumed that the support for the multiple burden hypothesis to explain alcohol use is restricted to mothers in countries with a low gender income equity. In all other cases the classical role theory offers a better explanation of men's and women's drinking.

However, the increased alcohol use of working mothers in countries with a low gender income equity can also be interpreted differently. The combination of parenthood and paid work may also lead to more drinking opportunities compared to housewives, related to e.g. after work drinks or informal meetings with workmates or the simple fact of having a higher disposable income to spend on alcohol. In this interpretation the higher drinking level of working mothers can be seen as a marker for a higher degree of freedom and emancipation among these women compared to the more traditional role of housewives. In favour of such an interpretation is that this thesisfound no indication that the effect of social roles on alcohol use may be mediated by stress or more precisely a lack of mastery or depression. The multiple burden theory assumes that it is actually the stress associated with multiple roles which makes people drink more.

To conclude, the role accumulation theory -more roles equals more structure and fewer opportunities - plays a centrally important role in explaining the influence of social roles on alcohol use for both men and women. However, among women the societal context and culture is also of central importance. The cultural translation and adaptation of social roles or rather the specific role combination of paid labour and motherhood, has an important impact on alcohol use. Under less favourable societal conditions women do not benefit, but show an increased risk when combining paid work and parenthood. Female paid labour has, compared to the other social roles such as parenthood or partnership, a rather young tradition. Consequently, working women and especially working mothers are not yet entirely accepted and supported in all societies and especially the interplay between paid labour and motherhood may still cause conflicts in societies which do not facilitate this role combination. 
Future studies on the interplay between situational and positional roles should not only try to examine the impact of opportunities to drink alcohol, but also consider day-to-day matters (e.g. sick child, difficult day in the office) as these more situational and unforeseen aspects of a social role like parenthood or paid labour may have an important impact on an individuals's alcohol use. Days which do not follow the usual structure may create a special, additional burden that can result in alcohol use in the short term and, if they occur more frequently due to inflexible childcare solutions or fixed office hours, may lead to an increase in individual alcohol use. Little is currently known about these relationships as we have only just started to understand the relevance of social roles and alcohol use in the daily lives of men and women.

\section{Looking to the future - public health relevance and future research}

Social roles, such as partnership, parenthood, and paid labour bring individuals into regular contact with others and are associated with activities that are defined by the expectations of significant others. Following the assumptions of the classic role theory, the more everyday life is structured by regular social activities and reciprocal obligations which the individual and others deem important, the more likely it is that he or she will ensure that the time spent in situational roles not linked to these regular activities does not interfere with their role obligations due to the position(s) they occupy (e.g. Knibbe, et al., 1987; R. J. Neve, et al., 1997). Thus, social roles are an important factor in structuring everyday life and as a result limit the opportunities to drink, therefore preventing people from engaging in heavy alcohol use.

The following illustrates the importance of such a daily structure. Every day 24 hours have to be filled. Eight hours of sleep a day reduce the time to be filled with other activities to 16 hours. Other regular necessities like eating, personal hygiene etc. will take at most three additional hours, leaving the individual with 13 hours to fill. Although it can be quite relaxing to spend some time or sometimes even an entire day on leisure activities, like reading a book, hiking or watching TV, having this much free time on a regular basis leaves the individual with a great deal of time to fill. Under these circumstances it is quite difficult to get to the end of the day with the good feeling of having used one's time in a productive and successful manner. To conclude, positional roles provide a framework that allows the individual to fill everyday life with meaningful, regular demands and obligations. Although these activities may sometimes be stressful, difficult to combine and require a great deal of flexibility and 
organisation, they provide the individual with the feeling of having something worthwhile to do. Combining the demands of different social roles may sometimes be an overwhelming and difficult task. Nevertheless, these demands limit the individual's opportunities and most probably also interest in engaging in heavy drinking and the completion of daily demands leaves the individual with the feeling of having had a full but successful day. From a public health perspective it is relevant to identify individuals with few or no social roles as they can be considered as a risk group for heavy alcohol use. Thus, screening processes for treatment or intervention, e.g. brief interventions should focus more actively on individuals with fewer or no social roles.

These assumptions lead to the conclusion that for those with few roles, a policy facilitating participation in formal activities (e.g. volunteer work and sport clubs) and informal networks (e.g. community initiatives) which structure social contact with others may have a protective effect on alcohol use. Such activities, as long as they are regular and valued, may help to fill the gap of lacking social roles and lend a role and structure to these individuals' lives.

In addition, given the results of this thesis, policy strategies promoting an early and easy adoption of social roles, like finding paid employment after finishing an apprenticeship or studies can be considered a necessary element of effective alcohol policy. Social roles have been a central paradigm of human life for centuries. Although the definition of these roles and the gender stereotypes vary tremendously, the central definition of providing guidance and structure to everyday life remain largely unchanged. The example of youth drinking may illustrate this assumption, whereby the high percentage of alcohol intoxication and excessive drinking among young people may be partly due to a lack of structure in their lives. Having the obligation to get up early to go to work and organise a household while no longer living with parents will limit the possibilities and opportunities to engage in heavy drinking too frequently. As a result such daily structures and the ensuing demands may reduce young people's alcohol use. Numerous studies have confirmed the maturing out of problematic alcohol use (Bachman, Wadsworth, O'Malley, Schulenberg, \& Johnston, 1997; Gotham, Sher, \& Wood, 2003; Labouvie, 1996; Moffitt, 1993). However, modern societies expect individuals, especially young women, to engage in several sometimes contradictory social roles, what may result in either a postponement of certain roles, first a career and having children afterwards, or concentrating on one role only (either paid employment or having children). Therefore, the amount a country invests in assisting women who want to combine a career and children is a crucial indicator of success. Nevertheless, the efforts facilitating the 
adoption of social roles may take various forms in different societies and will certainly vary over different age groups.

Clear evidence was found to support the protective effect of social roles on men's alcohol use. Nevertheless, a more equal distribution of family and parenting obligations between men and women could increase this positive effect on alcohol use even further. Political approaches encouraging higher gender equity in childcare responsibilities such as paid paternity leave will not only simplify the combination of sometimes contradictory roles for mothers but also strengthen the protective effect of family roles on men's alcohol use. In addition, policies which encourage higher gender equity will also help to increase women's participation in the labour force as long as the necessary conditions, such as paid parental leave, affordable childcare, day schools (without an unmonitored two-hour lunch break as in Switzerland), paid parental leave to care for sick children etc. are provided. Incentives in the form of equal pay for men and women will further help to keep women in paid labour after having children. Thus, a country's investment in pay equity - and in the long run gender equity - achieves the same protective effect as the number of social roles on alcohol use for both men and women.

Based on the assumption that limited opportunities reduce heavy alcohol use, there need to be more general policy measures aiming to reduce situations in which heavy drinking usually occurs and the promotion of leisure time activities with no or moderate alcohol use. Therefore, earlier closing times for pubs, higher pricing for alcoholic drinks and alcohol free sporting events may help to reduce risky alcohol use not only among those with social roles but also for those with few or no roles.

To conclude, this thesis clearly demonstrates that any effective alcohol prevention policy needs to integrate societal actions that enable individuals to combine more social roles. This signifies that intervention efforts on alcohol use can be more effective if they not only focus on psychological theories and approaches but also consider the protective effect of having more responsibilities and obligations. Social roles are of central relevance and the more social roles a man holds, the less he will engage in risky alcohol use. Among women the country's gender equity seems to be of crucial importance, as women in countries with a higher gender equity benefit from having more roles. Encouraging men to be more involved in household chores by enabling part-time work or home office solutions may help to counterbalance the possible overload effects of women holding several social roles.

Moreover, although this thesis focused on the impact of social roles on alcohol use only, social roles such as paid employment, parenthood and partnership also help to structure 
everyday life on a very general level. Therefore, the above not only relates to changes in alcohol use but also to other behaviours leading to immediate gratification, like shopping or eating. The correlation between these different factors has not yet been studied and where alcohol use fits in to such a set of possible expressive situational roles is therefore unknown. Future studies should try to set the presented results for alcohol use in a broader context of situational roles with immediate gratification, especially in the context of gender and cultural differences.

\section{Future research}

Looking to the future and armed with the knowledge gleaned from this thesis, several new and unknown avenues open up on the horizon.

There is a dearth of studies examining the various aspects of a social role that may or may not contribute to the extent to which positional roles result in reduced 'time' to drink. Little is known about the determinants and processes that convert the simple fact of holding a positional role into a limitation of time and opportunity to engage in situational roles with alcohol use. These mechanisms are not only limited to time but should include the social reactions of significant others, such as partners, colleagues and children.

In addition, little is currently known about the underlying rules behind the contextual influences that either inhibit or encourage drinking in a given situation or that encourage an individual to participate in situations where drinking takes place. Is it really true that those who have more social roles tend to drink less than those with fewer roles? A study by Paradis et al. (Paradis, et al., 2011) suggests that in a drinking situation, parents do not drink less than non parents. But those with children tend to avoid such situations more often. The influence of factors like informal control is still unknown and more detailed research on rules in contextual influences in drinking situations is needed.

Besides the interplay between situational and positional roles, future studies should also focus on the relevance of daily matters (e.g. an important working meeting has to be organized around a sick child). These unforeseeable changes are an inherent aspect of having children but are by far easier to cover when the mother is not in paid work. The simple fact of managing the demands of various social roles is a challenging task for women trying to combine a career and family. But days which do not follow the usual structure may create a special additional burden that can result in alcohol use in the short term and, if they occur 
more frequently due to inflexible childcare solutions or fixed office hours, may lead to an increase in individual alcohol use. As things currently stand, the relevance of such unpredictable role conflicts is unknown as we have only just started to understand the relevance of social roles and daily matters on men's and women's alcohol use. 


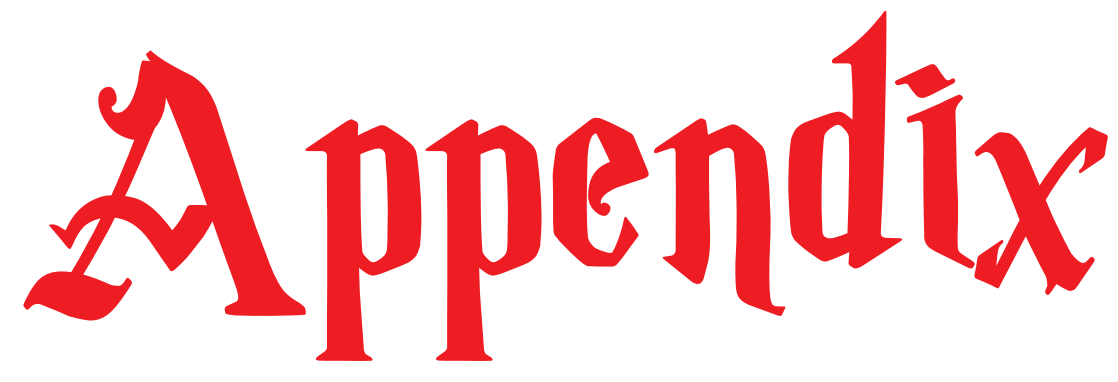




\section{Data}

Chapters 4, 5 and 6 of this thesis are based on data from the project Gender, Alcohol and Culture: An International Study (GenACIS) a worldwide unique database of around 155,00 individuals. The project currently comprises 45 surveys from 36 countries. The analyses on Swiss data were based on two surveys from the Swiss Health Survey (1997 and 2002); while the 1997 dataset was included in the GenACIS project, the latter (2002) was added for more refined analysis of the Swiss data, as it includes more in-depth data on social roles. Within Chapters 4 to 6 the number of countries varies depending on the countries and data sets included in the GenACIS database at the time of writing the chapter. This dissertation used the largest number of countries available and focused on industrialised countries in Europe, North America and Australia. The focus on established market economies ensured a minimum level of comparability regarding the measurement and the meaning of the three social roles parenthood, partnership and paid labour - across societies. It should be noted that most surveys were nationally representative. Table A-1 gives a general overview of all surveys and the survey characteristics.

The GenACIS project developed a core questionnaire which was used by the majority of participating countries. However, countries could also take part by providing a nationally representative survey on alcohol use that used similar questions; this was primarily the case in Europe. To enable a comparison of these surveys, a centralized data bank management system was installed, which encoded variables according to fixed rules. The results were summarized in a codebook, which was accessible to all participants (Kuntsche, et al., 2008).

This thesis focuses exclusively on drinkers. Drinkers are defined as individuals who have consumed alcohol within the past 12 months. The decision to exclude abstainers was motivated by our main research aim: to explain problematic alcohol use, not abstention. Previous studies which focused on abstention indicate that the factors which distinguish abstainers from drinkers are quite different from those which differentiate drinkers according to their level of consumption (Shaper \& Wannamethee, 1998). The percentage of current drinkers for the different surveys considered in this thesis can be found in Table 2. 
Table A-1 Survey characteristics and number of participants by country

\begin{tabular}{|c|c|c|c|c|c|c|c|c|}
\hline & $\begin{array}{l}\text { sampling } \\
\text { frame }\end{array}$ & $\begin{array}{c}\text { if regional, } \\
\text { where? }\end{array}$ & $\begin{array}{c}\text { survey } \\
\text { mode }\end{array}$ & $\begin{array}{c}\text { survey } \\
\text { year }\end{array}$ & $\begin{array}{c}\% \text { of } \\
\text { drinkers* }\end{array}$ & $\mathbf{n}$ & $\begin{array}{c}\mathbf{n} \\
\text { men }\end{array}$ & $\begin{array}{c}\text { n } \\
\text { women }\end{array}$ \\
\hline Australia & regional & Victoria & CATI & 2007 & 84.4 & 2,434 & 1,000 & 1,434 \\
\hline Austria & national & & $\begin{array}{l}\text { face-to- } \\
\text { face }\end{array}$ & 1993 & 87.2 & 7,475 & 3,525 & 3,950 \\
\hline Canada & national & & CATI & 2004 & 77.8 & 13,812 & 5,940 & 7,872 \\
\hline $\begin{array}{l}\text { Czech } \\
\text { Republic }\end{array}$ & national & & $\begin{array}{l}\text { face-to- } \\
\text { face }\end{array}$ & 2002 & 85.0 & 2,526 & 1,244 & 1,282 \\
\hline Denmark & national & & telephone & 2003 & 94.1 & 2,030 & 897 & 1,133 \\
\hline Finland & national & & $\begin{array}{l}\text { face-to- } \\
\text { face }^{a}\end{array}$ & 2000 & 91.1 & 1,931 & 945 & 986 \\
\hline France & national & & telephone & 1999 & 91.7 & 13,684 & 6,026 & 7,658 \\
\hline Germany & national & & postal & 2000 & 94.7 & 8,119 & 3,676 & 4,443 \\
\hline Hungary & national & & $\begin{array}{l}\text { face-to- } \\
\text { face }^{\text {a }}\end{array}$ & 2001 & 83.5 & 2,243 & 1,086 & 1,157 \\
\hline Netherlands & regional & Limburg & postal & 1999 & 75.5 & 4,222 & 2,008 & 2,214 \\
\hline Norway & national & & $\begin{array}{l}\text { face-to- } \\
\text { face }^{a}\end{array}$ & 1999 & 90.0 & 2,170 & 1,034 & 1,136 \\
\hline Spain & regional & $\begin{array}{c}\text { Galicia, } \\
\text { Valencia, } \\
\text { Cantabria }\end{array}$ & $\begin{array}{l}\text { face-to- } \\
\text { face }^{\text {a }}\end{array}$ & 2003 & 55.7 & 1,850 & 894 & 956 \\
\hline Sweden & national & & telephone & 2002 & 83.7 & 5,472 & 2,656 & 2,816 \\
\hline Switzerland & national & & telephone & 1997 & 81.3 & 12,994 & 5,755 & 7,239 \\
\hline UK & national & & $\begin{array}{l}\text { face-to- } \\
\text { face }^{b}\end{array}$ & 2000 & 85.6 & 2,001 & 963 & 1,038 \\
\hline USA & national & & $\begin{array}{l}\text { face-to- } \\
\text { face }\end{array}$ & $1995 / 96$ & 57.2 & 4,920 & 2,219 & 2,701 \\
\hline
\end{tabular}

Notes: ${ }^{a}$ partly self-administered using questionnaires; ${ }^{b}$ using CATI method technology

* total sample varying in age structure and gender composition

\section{Alcohol measures}

A first set of alcohol measures used was based on the best available measures for quantity per drinking day (usual quantity) either using the indicator itself or multiplying it by the annual frequency to achieve a measure for annual volume. The latter was divided by 365 to 
get an estimate for the quantity per day. This indicator differs from quantity per drinking day as the former gives an average daily amount of alcohol based on the total volume per year whereas the second indicator gives a mean consumption for the days the individual actually drank alcohol. To adjust for differences in the volume percentage of alcohol and differences in the standard drink size, both indicators were translated into grams of pure ethanol instead of drinks. A second indicator used in the following chapters was the frequency of risky single occasion drinking (RSOD). This indicator describes the annual frequency of drinking a given amount of alcohol on a single situation. RSOD was measured via the annual frequency of drinking a minimum number of glasses (e.g. 4/5 or 6 glasses or more). As countries differ in the content of standard glasses and in cut-off points for number of glasses constituting 'risky single occasion drinking", countries may vary in how exactly RSOD has been measured. Not all countries provided an indicator for RSOD so analyses involving this indicator are limited to the Czech Republic, Finland, Germany, Norway, Sweden, Switzerland and the US. The RSOD measure varied across countries regarding the number of drinks and the alcohol content of each drink. 
Befepences 
Ahlström, S., Bloomfield, K., \& Knibbe, R. A. (2001). Gender differences in the drinking patterns in nine European countries: descriptive findings. Substance Abuse, 22(1), 69-85.

Ali, J., \& Avison, W. R. (1997). Employment transitions and psychological distress: the contrasting experiences of single and married mothers. Journal of Health and Social Behavior, 38(4), 345-362.

Aneshensel, C. S., Frerichs, R. R., \& Clark, V. A. (1981). Family roles and sex differences in depression. Journal of Health and Social Behavior, 22(4), 379-393.

Arber, S. (1991). Class, paid employment and family roles: Making sense of structural disadvantage, gender and health status. Social Science and Medicine, 32(4), 425-436.

Arber, S. (1997). Comparing inequalities in women's and men's health: Britain in the 1990s. Social Science \& Medicine, 44(6), 773-787.

Arber, S., \& Cooper, H. (2000). Gender and inequalities in health across the life course. In E. Annandale \& K. Hunt (Eds.), Gender inequalities in health (pp. 123-149). Buckingham: Open University Press.

Arber, S., \& Khlat, M. (2002). Introduction to 'social and economic patterning of women's health in a changing world.'. Social Science and Medicine, 54(5), 643-647.

Avison, W. R., \& Davies, L. (2005). Family structure, gender, and health in the context of the life course. The Journals of Gerontology. Series B, Psychological Sciences and Social Scienes, 60 Spec No 2, 113-116.

Babor, T. F., Caetano, R., Casswell, S., Edwards, G., Giesbrecht, N., Graham, K., et al. (2003). Alcohol: No Ordinary Commodity. Research and Public Policy. Oxford: Oxford Medical Publication, Oxford University Press.

Bachman, J. G., O'Malley, H. M., Schulenberg, J. E., Johnston, L. D., Bryant, A. L., \& Merline, A. C. (2002). The Decline of Substance Use in Young Adulthood: Changes in social Activities, Roles, and Beliefs. Mahwah, NJ: Lawrence Erlbaum.

Bachman, J. G., Wadsworth, K. N., O'Malley, P. M., Schulenberg, J., \& Johnston, L. D. (1997). Marriage, divorce, and parenthood during the transition to young adulthood: impact on drug use and abuse. In J. Schulenberg, J. L. Maggs \& K. Hurrelmann (Eds.), Health Risks and Developmental Transitions During Adolescence (pp. 246-279). Cambridge: Cambridge University Press. 
Barnett, R. C., \& Marshall, N. L. (1991). The relationship between women's work and family roles and their subjective well-being and psychological distress. In M. Frankenhaeuser, U. Lundberg \& M. Chesney (Eds.), Women, work and health: Stress and opportunities (pp. 111-136). New York: Plenum Press.

Baron, R. M., \& Kenny, D. A. (1986). The moderator-mediator variable distinction in social psychological research: Conceptual, strategic, and statistical considerations. Journal of Personality and Social Psychology, 51(6), 1173-1182.

Bartley, M., Martikainen, P., Shipley, M., \& Marmot, M. (2004). Gender differences in the relationship of partner's social class to behavioural risk factors and social support in the Whitehall II study. Social Science and Medicine, 59(9), 1925-1936.

Bartley, M., Popay, J., \& Plewis, I. (1992). Domestic condition, paid employment and women's experience of ill-health. Sociology of Health and Illness, 14, 313-343.

Baumeister, S. E., Alte, D., Meyer, C., \& John, U. (2005). Riskanter Alkoholkonsum und alkoholbezogene Störungen in Vorpommern: Die Studie „Leben und Gesundheit in Vorpommern” (SHIP) und der Bundesgesundheitssurvey 1998 im Vergleich.

Gesundheitswesen, 67(1), 39-47.

Berger, B. D., \& Adesso, V. J. (1991). Gender differences in using alcohol to cope with depression. Addictive Behaviors, 16(5), 315-327.

Bernstein, A. B. (2001). Motherhood, health status, and health care. Womens Health Issues, 11(3), 173-184.

Bird, C. E. (1999). Gender, household labor, and psychological distress: The impact of the amount and division of housework. Journal of Health and Social Behavior, 40(1), 32-45.

Bird, C. E., \& Fremont, A. M. (1991). Gender, time use, and health. Journal of Health and Social Behavior, 32(2), 114-129.

Bland, J. M., \& Altman, D. G. (1997). Cronbach's alpha. BMJ, 314(7080), 572.

Bloomfield, K., Gmel, G., \& Wilsnack, S. C. (2006). Introduction to special issue 'Gender, culture and alcohol problems: a multi-national study'. Alcohol and Alcoholism, 41(Suppl. 1), i3-i7.

Bloomfield, K., Grittner, U., Kramer, S., \& Gmel, G. (2006). Social inequalities in alcohol consumption and alcohol-related problems in the study countries of the EU concerted 
action 'Gender, Culture and Alcohol Problems: A Multi-National Study'. Alcohol and Alcoholism, 41(Suppl. 1), i26-i36.

Bloomfield, K., Stockwell, T., Gmel, G., \& Rehn, N. (2003). International comparison of alcohol consumption. Alcohol Research and Health, 27(1), 95 - 109.

Bondy, S. J., Ashley, M. J., Rehm, J., \& Walsh, G. W. (1999). Do Ontarians drink in moderation? A baseline assessment against Canadian low risk drinking guidelines. Canadian Journal of Public Health, 90(4), 272-276.

British Medical Association. (1995). Alcohol: Guidelines on Sensible Drinking. London: British Medical Association.

Bromet, E. J., Dew, M. A., \& Parkinson, D. K. (1990). Spillover between work and family: a study of blue-collar working women. In J. S. G. Eckenrode (Ed.), Stress Between Work \& Family (pp. 133-151). New York: Plenum Press.

Brown, G. W. (2002). Social roles, context and evolution in the origins of depression. Journal of Health and Social Behavior, 43(3), 255-276.

Burton, R. P. D., Armstrong, D. A., \& Rushing, B. (1993). Social roles and subjective wellbeing: a decomposition of race differences. Sociological Spectrum, 13, 415-431.

Burton, R. P. D., Johnson, R. J., Ritter, C., \& Clayton, R. R. (1996). The effects of role socialization on the initiation of cocaine use: an event history analysis from adolescence into middle adulthood. Journal of Health and Social Behavior, 37(1), 75-90.

Cappell, H. D., \& Greeley, J. (1987). Alcohol and tension reduction: An update on research and theory. In H. T. Blance \& K. E. Leonard (Eds.), Psychological Theories of Drinking and Alcoholism (pp. 15-54). New York, NY: Guilford Press.

Christie-Mizell, C. A., \& Peralta, R. L. (2009). The gender gap in alcohol consumption during late adolescence and young adulthood: gendered attitudes and adult roles. Journal of Health and Social Behavior, 50(4), 410-426.

Cohen, J. (1988). Statistical power analysis for the behavioral sciences (2nd ed.). Hillsdale, NJ: Lawrence Erlbaum Associates, Inc. Publishers.

Coltrane, S. (2000). Research on houshold labor: modeling and measuring the social embeddedness of routine family work. Journal of Marriage and the Family, 62, 12081233. 
Congdon, P. (2003). Applied Bayesian Modelling. Chichester, UK: John Wiley \& Sons, Ltd.

Copeland, J., \& Hall, W. D. (1992). A comparison of predictors of treatment drop-out of women seeking drug and alcohol treatment in a specialist women's and two traditional mixed-sex treatment services. British Journal of Addiction, 87(6), 883-890.

Crompton, R., Brockmann, M., \& Lyonette, C. (2005). Attitudes, women's employment and the domestic division of labour: a cross-national analysis in two waves. Work, Employment and Society, 19(2), 213-233.

Darrow, S. L., Russell, M. A., Cooper, M. L., Mudar, P., \& Frone, M. R. (1992).

Sociodemographic correlates of alcohol consumption among African-American and white women. Women and Health, 18(4), 35-51.

DeRubeis, R. J., \& Crits-Christoph, P. (1998). Empirically supported individual and group psychological treatments for adult mental disorders. Journal of Consulting and Clinical Psychology, 66(1), 37-52.

Doyal, L. (1995). What Makes Women Sick, Gender and the Political Economy of Health. London: Macmillan.

Durkheim, E. (1951). Suicide: A Study in Sociology. New York, NY: Free Press.

Dusseldorp, E., Spinhoven, P., Bakker, A., van Dyck, R., \& van Balkom, A. J. L. M. (2007). Which panic disorder patients benefit from which treatment: cognitive therapy or antidepressants? Psychotherapy and Psychosomatics, 76(3), 154-161.

Edwards, G., Anderson, P., Babor, T. F., Casswell, S., Ferrence, R. G., Giesbrecht, N., et al. (1994). Alcohol Policy and the Public Good. New York, NY: Oxford University Press.

Fillmore, K. M. (1988). Alcohol use across the life course: A critical review of 70 years of international longitudinal research. Toronto, Canada: Addiction Research Foundation.

Flynn, H. A. (2000). Comparison of cross-sectional and daily reports in studying the relationship between depression and use of alcohol in response to stress in college students. Alcoholism: Clinical and Experimental Research, 24(1), 48-52.

Folkman, S., Chesney, M., Pollack, L., \& Coates, T. (1993). Stress, control, coping, and depressive mood in human immunodeficiency virus-positive and -negative gay men in San Francisco. Journal of Nervous and Mental Disease 181(7), 409-416. 
Forssén, K. (1999). Family policies and the well-being of children in the OECD countries. In O. Kangas (Ed.), Social Policy in Tandem with the Labour Market in teh European Union. Helsinki: Ministry of Social Affairs and Health.

Frone, M. R. (1999). Work stress and alcohol use. Alcohol Research and Health, 23(4), 284291.

Frone, M. R., Russell, M., \& Barnes, G. M. (1996). Work-family conflict, gender, and healthrelated outcomes: a study of employed parents in two community samples. Journal of Occupational Health Psychology, 1(1), 57-69.

Frone, M. R., Russell, M., \& Cooper, M. L. (1997). Relation of work-family conflict to health outcomes: a four-year longitudinal study of emplyoed parents. Journal of Occupational and Organizational Psychology, 70(4), 325-335.

Fukuda, Y., Nakamura, K., \& Takano, T. (2005). Accumulation of health risk behaviours is associated with lower socioeconomic status and women's urban residence: a multilevel analysis in Japan. BMC Public Health, 5(1), 53.

Galea, S., Nandi, A., \& Vlahov, D. (2004). The social epidemiology of substance use. Epidemiologic Reviews, 26, 36-52.

Gerhardt, U. (1971). Rollenanalyse als kritische Soziologie. Berlin: Luchterhand.

Gilks, W. R., Richardson, S., \& Spiegelhalter, D. J. (Eds.). (1996). Markov Chain Monte Carlo in practice. Interdisciplinary statistics. London: Chapman \& Hall.

Ginn, J., Street, D., \& Arber, S. (Eds.). (2001). Work, work and pensions: International issues and prospects. Buckingham: Open University Press.

Glover, J., \& Arber, S. (1995). Polarisation in mother's employment. Gender, Work and Organisation, 2(4), 165-179.

Gmel, G., Bloomfield, K., Ahlström, S., Choquet, M., \& Lecomte, T. (2000). Women's roles and women's drinking: a comparative study in four European Countries. Substance Abuse, 21(4), 249-264.

Gmel, G., \& Rehm, J. (2004). Measuring alcohol consumption. Contemporary Drug Problems, 31(Fall), 467-540. 
Gotham, H. J., Sher, K. J., \& Wood, P. K. (1997). Predicting stability and change in frequency of intoxication from the college years to beyond: Individual-difference and role transition variables. Journal of Abnormal Psychology, 106(4), 619-629.

Gotham, H. J., Sher, K. J., \& Wood, P. K. (2003). Alcohol involvement and developmental task completion during young adulthood. Journal of Studies on Alcohol, 64(1), 32-42.

Gottfredson, L. S., \& Deary, I. J. (2004). Intelligence predicts health and longevity, but why? Current Directions in Psychological Science, 13(1), 1-4.

Gove, W. R. (1984). Gender differences in mental and physical illness: the effects of fixed roles and nurturant roles. Social Science and Medicine, 19(2), 77-91.

Grassi, L., Righi, R., Sighinolfi, L., Makoui, S., \& Ghinelli, F. (1998). Coping styles and psychosocial-related variables in HIV-infected patients. Psychosomatics, 39(4), 350-359.

Gutjahr, E., \& Gmel, G. (2001). Defining alcohol-related fatal medical conditions for socialcost studies in Western societies: an update of the epidemiological evidence. Journal of Substance Abuse, 13(3), 239-264.

Haavio-Mannila, E. (1991). Impact of co-workers on female alcohol use. Contemporary Drug Problems, 18(4), 597-627.

Hajema, K.-J., \& Knibbe, R. A. (1998). Changes in social roles as predictors of changes in drinking behaviour. Addiction, 93(11), 1717-1727.

Hajema, K.-J., Knibbe, R. A., \& Drop, M. J. (1997). Changes in alcohol consumption in a general population in The Netherlands: a 9-year follow-up study. Addiction, 92(1), 49-60.

Hammer, T., \& Vaglum, P. (1989). The increase in alcohol consumption among women: a phenomenon related to accessibility or stress? A general population study. British Journal of Addiction, 84(7), 767-775.

Hausmann, R., Tyson, L. D., \& Zahidi, S. (2007). The Global Gender Gap - Report 2007. Retrieved February 2008, from http:/www.weforum.org/en/initiatives/gcp/Gender\%20Gap/index.htm or http://www.weforum.org/pdf/gendergap/report2007.pdf

Hayes, R. L., \& Halford, W. K. (1996). Time use of unemployed and employed single male schizophrenia subjects. Schizophrenia Bulletin, 22(4), 659-669. 
Hibbard, J. H., \& Pope, C. R. (1987). Employment characteristics and health status among men and women. Women and Health, 12(2), 85-102.

Hibbard, J. H., \& Pope, C. R. (1991). Effect of domestic and occupational roles on morbidity and mortality. Social Science and Medicine, 32(7), 805-811.

Holmila, M., \& Raitasalo, K. (2005). Gender differences in drinking: why do they still exist? Addiction, 100(12), 1763-1769.

Hong, J., \& Seltzer, M. M. (1995). The psychological consequences of multiple roles: The nonnormative case. Journal of Health and Social Behavior, 36(December), 386-398.

Hosmer, D. W., \& Lemeshow, S. (2000). Applied Logistic Regression (2 ed.). New York, NY: John Wiley \& Sons, Inc.

Hox, J. J. (2002). Multilevel Analysis: Techniques and Applications. Mahwah, NJ: Lawrence Erlbaum Associates.

Hu, L., \& Bentler, P. M. (1999). Cut-off criteria for fit indexes in covariance structure analysis: Conventional criteria versus new alternatives. Structural Equation Modeling, 6, $1-55$.

Jennison, K. M. (1992). The impact of stressful life events and social support on drinking among older adults: a general population survey. International Journal of Aging and Human Development, 35(2), 99-123.

Johnson, P. B. (1982). Sex differences, women's roles and alcohol use: preliminary national data. Journal of Social Issues, 38(2), 93-116.

Johnstone, B. M., Leino, E. V., Ager, C. R., Ferrer, H. P., \& Fillmore, K. M. (1996).

Determinants of life-course variation in the frequency of alcohol consumption: metaanalysis of studies from the collaborative alcohol-related longitudinal project. Journal of Studies on Alcohol, 57(5), 494-506.

Joosten, J., Knibbe, R. A., Derickx, M., Hradilova-Selin, K., \& Holmila, M. (2009). Criticism of drinking as informal social control: a study in 18 countries. Contemporary Drug Problems, 36, 85-109.

Jöreskog, K. G., \& Sörbom, D. (2001). LISREL software version 8.51. Chicago, IL: Scientific Software International, Inc. 
Kaplan, L., \& Boss, P. (1999). Depressive symptoms among spousal caregivers of institutionalized mates with Alzheimer's: boundary ambiguity and mastery as predictors. Family Process, 38(1), 85-103.

Katerndahl, D. A. (1991). Relationship between panic attacks and health locus of control. Journal of Family Practice, 32(4), 391-396.

Kendall, P. C., Cantwell, D. P., \& Kazdin, A. E. (1989). Depression in children and adolescents: Assessment issues and recommendations Cognitive Therapy and Research, 13(2), 109-146.

Khlat, M., Sermet, C., \& Le Pape, A. (2004). Increased prevalence of depression, smoking, heavy drinking and use of psycho-active drugs among unemployed men in France. European Journal of Epidemiology, 19(5), 445-451.

Knabe, A., Rätzel, S., Schöb, R., \& Weimann, J. (2010). Dissatisfied with life but having a good day: time-use and well-being of the unemployed. The Economic Journal, 120(547), 867-889.

Knibbe, R. A., \& Bloomfield, K. (2001). Alcohol consumption estimates in survey in Europe: comparability and sensitivity for gender differences. Substance Abuse, 22(1), 23-38.

Knibbe, R. A., Drop, M. J., \& Muytjens, A. (1987). Correlates of stages in the progression from everyday drinking to problem drinking. Social Science and Medicine, 24(5), 463473.

Kromhout, D. (1998). Problems in detecting small effects in case-control and cohort studies. In H. Hoffmeister, M. Szklo \& M. Thamm (Eds.), Epidemiological Practices in Research on Small Effects (pp. 17-23). Berlin: Springer Verlag.

Kuntsche, S., Gmel, G., Grisel-Staub, E., Astudillo, M., Inglin, S., Kuendig, H., et al. (2008). Gender, Alcohol, and Culture: An International Study (GENACIS). Retrieved 08.12., 2008, from http://www.genacis.org

Kuntsche, S., Gmel, G., Knibbe, R. A., Kuendig, H., Bloomfield, K., Kramer, S., et al. (2006). Gender and cultural differences in the association between family roles, social stratification, and alcohol use: a European cross-cultural analysis. Alcohol and Alcoholism, 41(Suppl. 1), i37-i46.

Kuntsche, S., Knibbe, R. A., \& Gmel, G. (2009). Social roles and alcohol consumption: A study of 10 industrialised countries. Social Science and Medicine, 68(7), 1263-1270. 
Kuntsche, S., Knibbe, R. A., Kuntsche, E., \& Gmel, G. (resubmitted). Housewife or working mum - each to her own? The relevance of societal factors in the association between social roles and alcohol use among mothers in 16 industrialised countries. Addiction.

Labouvie, E. W. (1996). Maturing out of substance use: selection and self-correction. Journal of Drug Issues, 26(2), 457-476.

Lahelma, E., Arber, S., Kivela, K., \& Roos, E. (2002). Multiple roles and health among British and Finnish women: the influence of socioeconomic circumstances. Social Science and Medicine, 54(5), 727-740.

Lahelma, E., Kangas, R., \& Manderbacka, K. (1995). Drinking and unemployment: contrasting patterns among men and women. Drug and Alcohol Dependence, 37(1), 71-82.

Lennon, M. C., \& Rosenfield, S. (1994). Relative fairness and the division of housework: The importance of options. American Journal of Sociology, 100(2), 506-531.

Leonard, K. E., \& Blane, H. T. (1999). Psychological Theories of Drinking and Alcoholism (2nd ed.). New York, NY: Guilford Press.

Leonard, K. E., \& Rothbard, J. C. (1999). Alcohol and the marriage effect. Journal of Studies on Alcohol. Supplement, 13, 139-146.

Little, M., Handley, E., Leuthe, E., \& Chassin, L. (2009). The impact of parenthood on alcohol consumption trajectories: variations as a function of timing of parenthood, familial alcoholism, and gender. Development and Psychopathology, 21(2), 661-682.

MacDonald, Z., \& Shields, M. A. (2004). Does problem drinking affect employment? Evidence from England. Health Economics, 13(2), 139-155.

Maclean, H., Glynn, K., \& Ansara, D. (2004). Multiple roles and women's mental health in Canada. BMC Women's Health, 4(Suppl. 1), S3.

Macran, S., Clarke, L., \& Joshi, H. (1996). Women's health: Dimensions and differentials. Social Science and Medicine, 42(9), 1203-1216.

Macran, S., Clarke, L., Slogget, A., \& Bethune, A. (1994). Women's socioeconomic status and self-assessed health: Identifying some disadvantaged groups. Sociology of Health and Illness, 16, 182-208.

Mäkelä, P. (1999). Alcohol-related mortality as a function of socio-economic status. Addiction, 94(6), 867-886. 
Mäkelä, P., Gmel, G., Grittner, U., Kuendig, H., Kuntsche, S., Bloomfield, K., et al. (2006). Drinking patterns and their gender differences in Europe. Alcohol and Alcoholism, 41(Suppl. 1), i8-i18.

Malyutina, S., Bobak, M., Kurilovitch, S., Nikitin, Y., \& Marmot, M. G. (2004). Trends in alcohol intake by education and marital status in urban population in Russia between the mid 1980s and the mid 1990s. Alcohol and Alcoholism, 39(1), 64-69.

Mansdotter, A., Backhans, M., \& Hallqvist, J. (2008). The relationship between a less genderstereotypical parenthood and alcohol-related care and death: a registry study of Swedish mothers and fathers. BMC Public Health, 8, 312.

Mansdotter, A., Lindholm, L., Lundberg, M., Winkvist, A., \& Öhman, A. (2006). Parental share in public and domestic spheres: a population study on gender equality, death, and sickness. Journal of Epidemiology and Community Health, 60(7), 616-620.

Matthews, S., \& Power, C. (2002). Socio economic gradients in psychological distress: A focus on women, social roles and work - home characteristics. Social Science and Medicine, 54(5), 799-810.

Matzger, H., Delucchi, K., Weisner, C., \& Ammon, L. (2004). Does marital status predict long-term drinking? Five-year observations of dependent and problem drinkers. Journal of Studies on Alcohol, 65(2), 255-265.

McCall, G., \& Simmons, R. (1996). Identities and Interactions. New York: Free Press.

McCreary, D. R., \& Sadava, S. W. (1998). Stress, drinking, and the adverse consequences of drinking in two samples of young adults. Psychology of Addictive Behaviors, 12(4), $247-$ 261.

McRae, S. (1999). Changing Britain: Families and households in the 1990s. Oxford: Oxford University Press.

Menaghan, E. G. (1989). Role changes and psychological well-being: variations in effects by gender and role repertoire. Social Forces, 67, 693-714.

Merline, A. C., O'Malley, P. M., Schulenberg, J. E., Bachman, J. G., \& Johnston, L. D. (2004). Substance use among adults 35 years of age: prevalence, adulthood predictors, and impact of adolescent substance use. American Journal of Public Health, 94(1), 96-102. 
Moffitt, T. E. (1993). Adolescence-limited and life-course-persistent antisocial behavior: a developmental taxonomy. Psychological Review, 100(4), 674 - 701.

Moss, N. E. (2002). Gender equity and socioeconomic inequality: A framework for the patterning of women's health. Social Science and Medicine, 54(5), 649-661.

Muthén, L. K., \& Muthén, B. O. (2004). Mplus: Statistical Analysis With Latent Variables User's Guide (3rd ed.). Los Angeles, CA: Muthén \& Muthén.

Nathanson, C. A. (1980). Social roles and health status among women: The significance of employment. Social Science and Medicine, 14A(6), 463-471.

Neve, R. J., Lemmens, P. H., \& Drop, M. J. (1997). Gender differences in alcohol use and alcohol problems: mediation by social roles and gender-role attitudes. Substance Use and Misuse, 32(11), 1439-1459.

Neve, R. J. M., Lemmens, P. H., \& Drop, M. J. (2000). Changes in Alcohol Use and Drinking Problems in Relation to Role Transitions in Different Stages of the Life Course. Substance Abuse, 21(3), 163-178.

Nunnally, J. C., \& Bernstein, I. (1994). Psychometric Theory (3rd ed.). New York, NY: McGraw-Hill.

Paradis, C. (2011). Parenthood, drinking locations and heavy drinking. Social Science and Medicine, 72(8), 1258-1265.

Paradis, C., Demers, A., \& Nadeau, L. (1999). Positional role changes and drinking patterns: Results of a longitudinal study. Contemporary Drug Problems, 26(1), 53-73.

Paradis, C., Demers, A., Nadeau, L., \& Picard, E. (2011). Parenthood, alcohol intake, and drinking contexts: occasio furem facit. Journal of Studies on Alcohol and Drugs, 72(2), 259-269.

Parry, C. D. H., Pluddemann, A., Steyn, K., Bradshaw, D., Norman, R., \& Laubscher, R. (2005). Alcohol use in South Africa: findings from the first Demographic and Health Survey (1998). Journal of Studies on Alcohol, 66(1), 91-97.

Pearlin, L. I., Lieberman, M. A., Menaghan, E. G., \& Mullan, J. T. (1981). The stress process. Journal of Health and Social Behavior, 22(4), 337-356. 
Peirce, R. S., Frone, M. R., Russell, M., \& Cooper, M. L. (1994). Relationship of financial strain and psychosocial resources to alcohol use and abuse: the mediating role of negative affect and drinking motives. Journal of Health and Social Behavior, 35(4), 291-308.

Pinquart, M., \& Sörensen, S. (2000). Influences of socioeconomic status, social network, and competence on subjective well-being in later life: a meta-analysis. Psychology and Aging, $15(2), 187-224$.

Power, C., \& Estaugh, V. (1990a). Employment and drinking in early adulthood: a longitudinal perspective. British Journal of Addiction, 85(4), 487-494.

Power, C., \& Estaugh, V. (1990b). The role of family formation and dissolution in shaping drinking behavior in early adulthood. British Journal of Addiction, 85(4), 521-530.

Power, C., Rodgers, B., \& Hope, S. (1999). Heavy alcohol consumption and marital status: disentangling the relationship in a national study of young adults. Addiction, 94(10), 14771487.

Prescott, C. A., Neale, M. C., Corey, L. A., \& Kendler, K. S. (1997). Predictors of problem drinking and alcohol dependence in a population-based sample of female twins. Journal of Studies on Alcohol, 58(2), 167-181.

Rahav, G., Wilsnack, R. W., Bloomfield, K., Gmel, G., \& Kuntsche, S. (2006). The influence of societal level factors on men's and women's alcohol consumption and alcohol problems. Alcohol and Alcoholism, 41(Suppl. 1), i47-i55.

Rake, K. (2000). Women's incomes over the lifetime (A report to the Women's Unit, Cabinet Office). London: HMSO.

Raudenbush, S. W., Bryk, A. S., Cheong, Y. F., Congdon, R., \& du Toit, M. (2004). HLM 6. Hierarchical Linear and Nonlinear Modeling. Lincolnwood, IL: SSI Scientific Software International.

Rehm, J. (1998). Measuring quantity, frequency, and volume of drinking. Alcoholism: Clinical and Experimental Research, 22(2 Suppl), 4S-14S.

Rehm, J., Room, R., Graham, K., Monteiro, M. G., Gmel, G., \& Sempos, C. T. (2003). The relationship of average volume of alcohol consumption and patterns of drinking to burden of disease: an overview. Addiction, 98(9), 1209-1228. 
Rehm, J., Room, R., Monteiro, M. G., Gmel, G., Graham, K., Rehn, N., et al. (2004). Alcohol use. In M. Ezzati, A. D. Lopez, A. Rodgers \& C. J. L. Murray (Eds.), Comparative Quantification of Health Risks. Global and Regional Burden of Disease Attributable to Selected Major Risk Factors (Vol. 1, pp. 959-1108). Geneva: World Health Organization (WHO).

Rehm, J., Room, R., Monteiro, M. G., Gmel, G., Graham, K., Rehn, N., et al. (2003). Alcohol as risk factor for global burden of disease. European Addiction Research, 9(4), 157-164.

Room, R., Babor, T. F., \& Rehm, J. (2005). Alcohol and public health. Lancet, 365(9458), 519-530.

Room, R., \& Mäkelä, K. (2000). Typologies of the cultural position of drinking. Journal of Studies on Alcohol, 61(3), 475-483.

Ross, C. E., \& Mirowsky, J. (1992). Households, employment and the sense of control. Social Psychology Quarterly, 55(3), 217-235.

Ross, C. E., Mirowsky, J., \& Huber, J. (1983). Dividing work, sharing work, and in-between: Marriage patterns and depression. American Sociological Review, 48(6), 809-823.

Rothman, K. J. (2002). Epidemiology - An Introduction. Oxford: Oxford University Press.

Rotter, J. B. (1966). Generalized expectancies for internal versus external control of reinforcement. Psychological Monographs, 80(1), 1-28.

Schafer, J. L. (1997). Analysis of incomplete multivariate data. London: Chapman \& Hall.

Schnorr, R. C., Høbjerre, L., Riegels, M., Ledet, L., Larsen, T., Schultz-Larsen, K., et al. (2004). Does educational level influence the effects of smoking, alcohol, physical activity, and obesity on mortality? A prospective population study. Scandinavian Journal of Public Health, 32, 250-256.

Schulenberg, J., Bachman, J. G., O'Malley, P. M., \& Johnston, L. D. (1994). High school educational success and subsequent substance use: a panel analysis following adolescents into young adulthood. Journal of Health and Social Behavior, 35(1), 45-62.

Sexton, H., Lipton, R. I., \& Nilssen, O. (1999). Relating alcohol use and mood: results from the Tromso study. Journal of Studies on Alcohol, 60(1), 111-119. 
Shaper, A. G., \& Wannamethee, S. G. (1998). The J-shaped curve and changes in drinking habit. In D. J. Chadwick \& J. A. Goode (Eds.), Alcohol and Cardiovascular Diseases: Novartis Foundation Symposium 216 (pp. 173-188). New York, NY: John Wiley \& Sons.

Shore, E. R. (1997). The relationship of gender balance at work, family responsibilities and workplace characteristics to drinking among male and female attorneys. Journal of Studies on Alcohol, 58(3), 297-302.

Siaroff, A. (1994). Work, welfare and gender equality: A new typology. In D. Sainsbury (Ed.), Gendering Welfare States (pp. 82-100). London: Sage.

Skaff, M. M., \& Pearlin, L. I. (1992). Caregiving: role engulfment and the loss of self. Gerontologist, 32(5), 656-664.

Skaff, M. M., Pearlin, L. I., \& Mullan, J. T. (1996). Transitions in the caregiving career: effects on sense of mastery. Psychology and Aging, 11(2), 247-257.

Skog, O.-J. (1985). The collectivity of drinking cultures: a theory of the distribution of alcohol consumption. British Journal of Addiction, 80(1), 83-99.

Spoth, R., Greenberg, M., \& Turrisi, R. (2008). Preventive interventions addressing underage drinking: state of the evidence and steps toward public health impact. Pediatrics, 121 Suppl 4, S311-S336.

SPSS Inc. (2010). PASW Statistics Base 18. Chicago, IL: SPSS Inc.

Stryker, S. (1980). Symbolic interactionism: A social structural version. Menlo Park, CA: Benjamin-Cummings.

Stryker, S., \& Serpe, R. T. (1982). Commitment, identity salience, and role behavior. In W. Ickes \& E. S. Knowles (Eds.), Personality, roles and social behavior (pp. 199-218). New York, NY: Springer-Verlag.

Tabachnick, B. G., \& Fidell, L. S. (2001). Using multivariate statistics (4th ed.). Boston, MA: Allyn and Bacon.

Temple, M. T., Fillmore, K. M., Hartka, E., Johnstone, B. M., Leino, E. V., \& Motoyoshi, M. (1991). A meta-analysis of change in marital and employment status as predictors of alcohol consumption on a typical occasion. British Journal of Addiction, 86(10), 12691281. 
The World Bank Group. (2002). GenderStats - Database of Gender Statistics. Retrieved 20.02., 2006, from http://devdata.worldbank.org/genderstats/query/default.htm

Thoits, P. A. (1991). On merging identity theory and stress research. Social Psychology Quarterly, 54, 101.

Thomas, B. S., \& Hsiu, L. T. (1993). The role of selected risk factors in predicting adolescent drug use and its adverse consequences. International Journal of the Addictions, 28(14), $1549-1563$

Timmer, S. G., Veroff, J., \& Colten, M. E. (1985). Life stress, helplessness, and the use of alcohol and drugs to cope: An analysis of national survey data. In S. Shiffman \& T. A. Wills (Eds.), Coping and substance use. New York, NY: Academic Press.

Townsend, P., Davidson, N., \& Whitehead, M. (Eds.). (1992). Inequalities in Health: The Black Report and the Health Divide. Harmondsworth: Penguin.

Ullman, J. B. (2001). Structural equation modeling. In B. G. Tabachnick \& L. S. Fidell (Eds.), Using multivariate statistics (4th ed., pp. 653-771). Boston, MA: Allyn and Bacon.

UNESCO Institute for Statistics. (1997). International Standard Classification of Education 1997. Montreal: UNESCO.

United Nations Development Programme (UNDP). (2006). Human Development Report 2006 - Beyond Scarcity: Power, Poverty and the Global Water Crisis. Retrieved from http://hdr.undp.org/en/media/HDR2006 English_Summary.pdf

United Nations Development Programme (UNDP). (2007, January 2008). Human Development Report 2007/2008 - Fighting Climate Change: Human Solidarity in a Diveded World. Retrieved February, 2008, from http://hdr.undp.org/en/media/hdr 20072008 en complete.pdf or http:/hdr.undp.org/en/media/hdr 20072008 summary english.pdf

van Gool, C. H., Kempen, G. I., Bosma, H., van Boxtel, M. P. J., Jolles, J., \& van Eijk, J. T. M. (2007). Associations between lifestyle and depressed mood: longitudinal results from the Maastricht Aging Study. American Journal of Public Health, 97(5), 887-894.

van Oers, J. A., Bongers, I. M., van de Goor, L. A., \& Garretsen, H. F. (1999). Alcohol consumption, alcohol-related problems, problem drinking, and socioeconomic status. Alcohol and Alcoholism, 34(1), 78-88. 
Verbrugge, L. M. (1983). Multiple roles and physical health of women and men. Journal of Health and Social Behavior, 24(1), 16-30.

Wheaton, B. (1990). Life Transitions, Role Histories, and Mental Health. American Sociological Review, 55(2), 209-223.

White, H. R. (1996). Empirical validity of theories of drug abuse: Introductory comments. Journal of Drug Issues, 26(2), 279-288.

Whitehead, M., Burstrom, B., \& Diderichsen, F. (2000). Social policies and the pathways to inequalities in health: A comparative analysis of lone mothers in Britain and Sweden. Social Science and Medicine, 50(2), 255-270.

Wilsnack, R. W., \& Cheloha, R. (1987). Women's roles and problem drinking across the lifespan. Social Problems, 34(3), 231-248.

Wilsnack, S. C., Klassen, A. D., Schur, B. E., \& Wilsnack, R. W. (1991). Predicting onset and chronicity of women's problem drinking: A five-year longitudinal analysis. American Journal of Public Health, 81(3), 305-318.

Wilsnack, S. C., \& Wilsnack, R. W. (1991). Epidemiology of women's drinking. Journal of Substance Abuse, 3(2), 133-157.

World Health Organization (WHO). (2000). International Guide for Monitoring Alcohol Consumption and Related Harm. Geneva: WHO, Department of Mental Health and Substance Dependence, Noncommunicable Diseases and Mental Health Cluster.

World Health Organization (WHO). (2002). The World Health Report 2002 - Reducing Risks, Promoting Healthy Life. Retrieved 29.12., 2009, from http://www.who.int/whr/2002/en/

World Health Organization (WHO). (2008). The Global Burden of Disease: 2004 Update. Retrieved 01.04.2011, from http://www.who.int/healthinfo/global_burden_disease/2004 report update/en/index.html World Health Organization (WHO). (2009). Global Health Risks: Mortality and Burden of Disease Attributable to Selected Major Risks. Retrieved 01.04.2011, from http://www.who.int/healthinfo/global burden disease/global health risks/en/index.html

Yamaguchi, K., \& Kandel, D. B. (1985). On the resolution of role incompatibility: life event history analysis of family roles and marijuana use. American Journal of Sociology, 90, 1284-1325. 
Zywiak, W. H., Longabaugh, R., \& Wirtz, P. W. (2002). Decomposing the relationships between pretreatment social network characteristics and alcohol treatment outcome. Journal of Studies on Alcohol, 63(1), 114-121. 


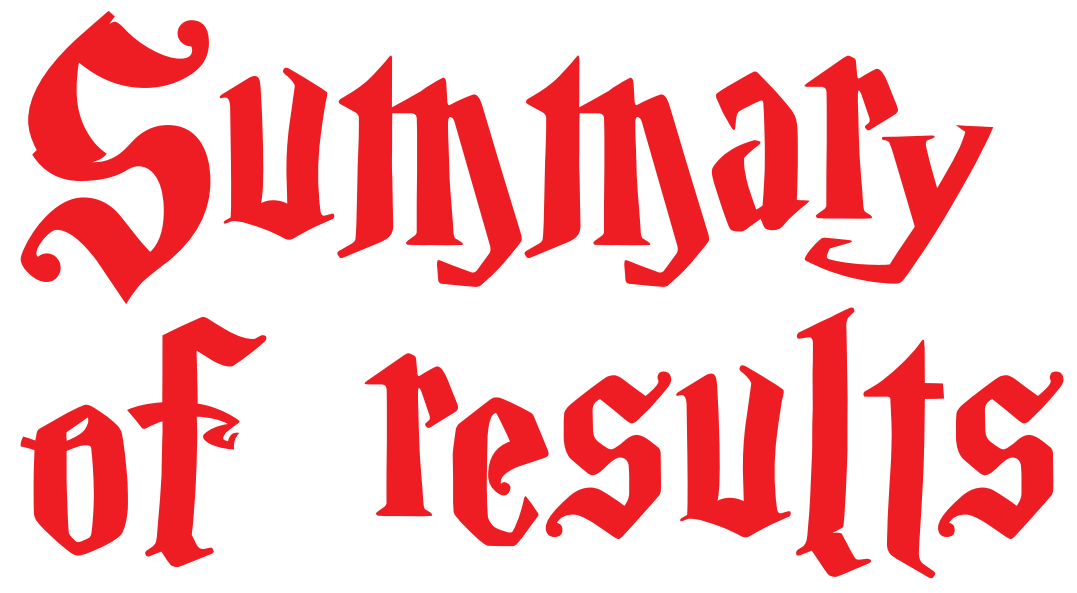


Background: There are many studies showing a relationship between alcohol use and sociodemographic characteristics, such as having paid work or living with a partner. The main objective of this thesis is to use a sociological role theory to explain this relationship and specify the conditions under which the relationship between social roles and alcohol use is most likely to be observed. Social roles, like parenthood, partnership or paid labour, describe the individuals' position in a given social system and are based on enduring relations with other people. Hence they provide the individual both with a sense of identity and behavioural guidance (and affect the individual's health and health behaviour by providing direction and meaning to his or her life). This thesis was based on the assumptions of the classic role theory: the more social roles an individual has, the more structured their everyday life is and the lower their alcohol use. This role theory can be distinguished from the "multiple burden" theory which assumes that holding more social roles increases the chance of role conflicts and stress and is therefore likely to lead to heavier drinking. In the literature the multiple burden theory has been used mostly to explain women's drinking.

This thesis aims to increase knowledge about the relationship between social roles and alcohol use and more specifically focuses on psychological variables which may explain the relationship between roles and alcohol use (Chapter 2), gender differences as explanatory factors of social roles for drinking (Chapter 3) and cultural factors influencing the effect of roles on drinking (Chapters 4 to 6$)$.

Data: Chapters 4 to 6 are based on surveys from the database of "Gender Alcohol and Culture: An international project (GenACIS)". Details of the project and funding can be found at www.genacis.org. For the cross cultural comparisons (Chapters 4 to 6) the selection of surveys was restricted to countries with an established market economy. In these countries there is likely to be some homogeneity in the importance of social roles for a meaningful adult life. Chapters 2 and 3 are exclusively based on the third wave of the Swiss National Survey conducted in 2007. This survey provided greater detail on psychological factors and characteristics of family life than the GenACIS questionnaire.

Results: In a first study (Chapter 2) the explanatory value of psychological factors for the relationship between social roles and alcohol consumption was investigated. The study examined whether depressed mood and external control - variables known to be related to alcohol use - mediated the relationship between social roles and alcohol use. As expected, social roles, depressed mood and external control were related to aspects of alcohol use. Also, 
social roles and the psychological variables were significantly correlated. Nevertheless, the psychological variables did not mediate the relationship between social roles and alcohol use because social roles were associated with drinking aspects other than the two psychological factors. This leads to the conclusion that psychological variables do not explain the relationship between social roles and drinking. Most likely the effect of roles is mediated by the extent to which social roles structure or fail to structure everyday life with meaningful activities. A cross cultural study (Chapter 5) showed that in the ten countries included, a higher number of social roles was associated with a lower risk of heavy alcohol use and Risky Single Occasion Drinking (RSOD) among men. Among women the same pattern was found for the majority of countries. It was also found that the protective effect of multiple roles was more consistent for RSOD. In general the findings support the cross cultural validity of the classic role theory. However, in a few countries a two-role model for women gave a better fit.

In Chapter 3 the effect of family characteristics on parental alcohol use was examined in more detail. In Switzerland, women's drinking was more systematically related to the parental role and family related variables than men's drinking. There was evidence that maternal responsibilities per se may protect from alcohol use but mothers who are additionally in paid employment may benefit from this protective effect to a less extent or not at all as suggested by the moderation effects of paid labour on the impact of the number of children on alcohol use.

In Chapter 4 the focus was explicitly on gender differences in the relevance of family and socioeconomic roles. It was found that, whereas family roles generally showed a higher protective impact on women's alcohol use; among men a higher impact was found for socioeconomic factors. In addition, correlations between women's alcohol use and country characteristics revealed that women in countries with a strong social welfare system, such as Nordic countries, tended to drink more heavily if employed, if they had fewer formal qualifications and a non-traditional family role. In countries with weaker social welfare systems or lower female work desirability, heavy drinking was associated with a high level of education, while the effects of family roles and employment were small.

The influence of social welfare systems on how roles influence mothers drinking was confirmed in an international study in 16 countries (Chapter 6). Irrespective of their employment status, single mothers reported higher quantities per occasion than partnered mothers. However, in countries with high gender-income equity mothers with a partner and 
paid work drank less alcohol per occasion, while alcohol use was higher among their peers living in countries with lower income equity. Additional evidence was found to suggest that in countries with higher gender equity the combination of motherhood and paid labour was facilitated: the amount of alcohol consumed on a drinking day decreased as the number of social roles decreased. By contrast, in countries with fewer incentives for mothers to remain in work, the addition of the role of paid work over and above the roles of partnership and parenthood was associated with an increase in alcohol use. In both studies there were no indications to suggest that the multiple burden theory may explain women's alcohol use better than the classic role theory. However, it has become clear that among women the protective effect of the additional role of work is dependent on gender equity at the societal level.

Chapter 7 discusses the main outcomes of this thesis. It can be concluded that in general there is much support for the explanatory value of the classical role theory for alcohol use. Future research should focus on the mediating mechanisms. However, it seems unlikely that psychological variables explain the relationship between social roles and alcohol use. There is strong evidence for gender differences in how strongly social roles influence drinking. One of the central factors in explaining these gender differences is gender equity at the societal level: in societies with more gender equity, the additional role of maternal employment outside the home is more likely to decrease the mothers' alcohol use.

At the end of this chapter there is a section discussing the implications of the findings of this study for alcohol policy and alcohol prevention. 


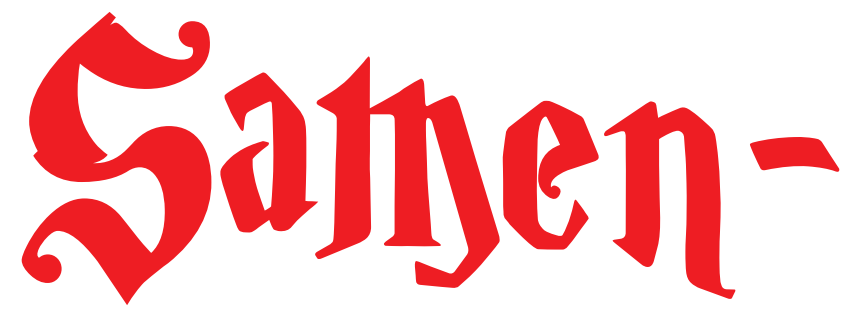

yationg 
Achtergrond: In veel studies wordt een relatie gevonden tussen alcoholconsumptie en het hebben van betaald werk, samenleven met een partner en ouderschap. Het voornaamste doel van dit proefschrift is om aan de hand van een sociologische roltheorie deze relatie te verklaren en te specificeren onder welke omstandigheden de verwachte relatie tussen alcoholgebruik en sociale rollen gevonden wordt.

Sociale rollen als betaald werk, samenleven met een partner en ouderschap beschrijven de positie van een individu in een sociaal systeem, en zijn gebaseerd op langdurige relaties met andere mensen. Deze rollen bepalen mede de sociale identiteit van een individu en geven inhoud en betekenis aan zijn dagelijks leven en beïnvloeden gezondheidsgedrag waaronder alcoholgebruik. In dit proefschrift staat de zogeheten klassieke rol theorie centraal die inhoudt dat naarmate een individu meer sociale rollen heeft, het dagelijks leven sterker gestructureerd is waardoor er minder tijd en behoefte is situatierollen waarin alcohol wordt gebruikt. Deze rol theorie kan onderscheiden worden van de 'multiple burden' theorie die ervan uitgaat dat hoe meer rollen een individu heeft hoe meer kans op rol- conflicten en daarmee gepaard gaande stress die vervolgens leidt tot intensiever drankgebruik. In de literatuur wordt de multiple burden theorie vooral gebruikt om het drankgebruik van alleenstaande en/of werkende moeders te verklaren.

Dit proefschrift is er op gericht om de kennis over de relatie tussen alcoholgebruik en sociale rollen te vergroten en gaat meer specifiek in op de vraag of psychologische variabelen de relatie tussen sociale rollen en alcoholgebruik verklaren (hoofdstuk2), verschillen tussen mannen en vrouwen in de verklarende waarde van rollen voor alcoholgebruik (hoofdstuk 3) en culturele factoren die bepalen of en in welke mate rollen het alcoholgebruik beïnvloeden (hoofdstuk 4,5,6).

Gegevens: Hoofdstuk 4 tot en met 6 zijn gebaseerd op surveys van de database "Gender, Alcohol and Culture: an International Study (GenACIS). Details van deze studie en de financiering zijn te vinden op de website www.genacis.org. De cross-culturele vergelijking (hoofdstuk 4,5,6) is beperkt tot surveys uit landen met een gevestigde markteconomie. In deze landen kan men verwachten dat er enige homogeniteit is in het belang van rollen als betaald werk, samenleven met een partner en ouderschap voor het sociale leven en de levensvoering van een volwassene. Hoofdstuk 2 en 3 zijn gebaseerd op een nationaal survey in Zwitserland dat in 2007 is uitgevoerd. Dit survey bevatte meer informatie over psychologische factoren en gezinsgebonden kenmerken dan de GenACIS vragenlijst. 
Resultaten: In een eerste studie (hoofdstuk 2) werd onderzocht of psychologische variabelen de relatie tussen sociale rollen en alcoholgebruik verklaren. De analyse was er op gericht of twee psychologische variabelen waarvoor bekend is dat ze samenhangen met drankgebruik -depressieve stemming en externe controle - de relatie tussen sociale rollen en alcoholgebruik mediëren. De voor mediatie noodzakelijke correlaties tussen de sociale rollen, de psychologische variabelen en alcoholgebruik werden gevonden. Toch verklaarden de psychologische variabelen niet de relatie tussen sociale rollen en alcoholgebruik omdat de psychologische variabelen andere aspecten van drankgebruik verklaarden dan de sociale rollen. Waarschijnlijk moet de verklaring voor het effect van sociale rollen op drankgebruik gezocht worden in de mate waarin deze rollen het dagelijks leven structureren met betekenisvolle activiteiten.

In hoofdstuk 3 wordt ingegaan op de vraag of mannen en vrouwen verschillen in de mate waarin ouderlijke en gezinsverplichtingen het drankgebruik beïnvloeden. Het blijkt dat in Zwitserland het drankgebruik van vrouwen systematischer gerelateerd was aan ouderlijke en gezinsverplichtingen dan het drankgebruik van mannen. Hoewel de resultaten er op wijzen dat moederlijke verplichtingen op zich beschermen tegen zwaarder drankgebruik, blijkt ook dat moeders die daarnaast ook nog betaald werk hebben niet of minder profiteren van dit beschermend effect. Dit blijkt uit een significant interactie-effect tussen het aantal kinderen en het hebben van betaald werk.

Hoofdstuk 4 is een crossculturele studie die expliciet focust op of mannen en vrouwen verschillen in de relevantie van respectievelijk gezinsgebonden en sociaal-economische rollen voor het drankgebruik. Ook hier blijkt dat bij vrouwen het beschermend effect van gezinsgebonden factoren groter is dan bij mannen. Bij mannen wordt een groter effect van sociaal economische factoren gevonden. Tevens blijkt dat in landen met een sterk ontwikkeld sociaal stelsel, zoals de Scandinavische landen, vrouwen meer drinken als ze betaald werk hebben, lager opgeleid zijn en een niet traditionele gezinsrol (alleenstaand ouder) hebben. In landen met een minder sterk ontwikkeld sociaal stelsel en minder nadruk op toegang van vrouwen tot betaald werk, werd zwaarder drankgebruik gevonden bij vrouwen die hoog opgeleid waren terwijl de invloed van gezinsgebonden rollen en betaald werk klein zijn.

Een crossculturele studie toonde aan dat voor mannen in 10 verschillende Europese en Noord Amerikaanse landen de verwachte samenhang tussen aantal sociaal rollen (0-3) en drankgebruik werd gevonden (hoofdstuk 5). Voor vrouwen gold dit ook voor het overgrote 
deel van de landen, echter er waren een paar landen waar een 2-rollen model een betere verklaring voor het drankgebruik van vrouwen boden dan een 3-rollen model. Het beschermende effect van sociale rollen was duidelijker voor de frequentie van af en toe heel veel drinken ('binge'-drinken) dan voor regelmatig zwaar drinken. Over het geheel genomen ondersteunen de uitkomst van deze studie de klassieke rol theorie hoewel in een beperkt aantal landen voor vrouwen een 2 rollen model adequater lijkt dan een 3 rollen model.

In hoofdstuk 6 wordt dieper ingegaan op de relatie tussen kenmerken op samenlevingsniveau, toegespitst op mate waarin mannen en vrouwen gelijk betaald krijgen voor werk, en de relatie betaald werk met drankgebruik bij moeders. In een studie met 16 landen blijkt dat, onafhankelijk van werkstatus, alleenstaande moeders meer glazen per keer drinken dan moeders met een partner. Echter, in landen met een kleiner verschil in beloning tussen mannen en vrouwen blijkt dat moeders met een partner en betaald werk minder glazen alcohol per keer drinken dan vergelijkbare vrouwen in landen met grotere verschillen tussen mannen en vrouwen in beloning. Tevens blijkt dat in landen met kleinere geslachtsverschillen in beloning het aantal glazen dat gedronken wordt op een dag regelmatig afneemt met het aantal rollen, terwijl in landen met grotere geslachtsverschillen in beloning moeders met een partner die ook nog werken meer glazen alcohol drinken dan moeders met partners die niet werken.

In de verschillende studies die ingaan op hoe rollen het drankgebruik van vrouwen beïnvloed werd geen ondersteuning gevonden voor de 'multiple burden' theorie. Echter het is duidelijk dat geworden dat het beschermend effect van de rol van betaald werk bij vrouwen mede bepaald wordt door de mate waarin op het niveau van een samenleving de gelijkheid tussen mannen en vrouwen bevorderd wordt.

In het laatste hoofdstuk worden de voornaamste uitkomsten besproken. De studie toont aan dat er veel steun is voor de verklarende waarde voor alcoholgebruik in de algemene bevolking van de klassiek sociologische rol theorie. Toekomstig onderzoek zou zich vooral dienen te richten op de mechanismen die het effect van rollen op drankgebruik mediëren. Het is onwaarschijnlijk dat psychologische variabelen hier een grote rol spelen. Er zijn systematische verschillen tussen mannen en vrouwen in het effect van rollen op drankgebruik. Een belangrijke verklarende factoren voor dit verschil tussen mannen en vrouwen is de gelijkheid tussen mannen en vrouwen op samenlevingsniveau. In samenlevingen waar emancipatie sterker (ook) tot uitdrukking komt in inkomensgelijkheid tussen mannen en 
vrouwen, beschermd de rol van betaald werk moeders tegen zwaarder drankgebruik. In samenlevingen waar de ongelijkheid tussen mannen en vrouwen groter is, drinken werkende moeders meer dan moeders zonder betaald werk.

Het hoofdstuk sluit af met een discussie van de implicaties van deze studie voor alcoholbeleid en alcoholpreventie. 


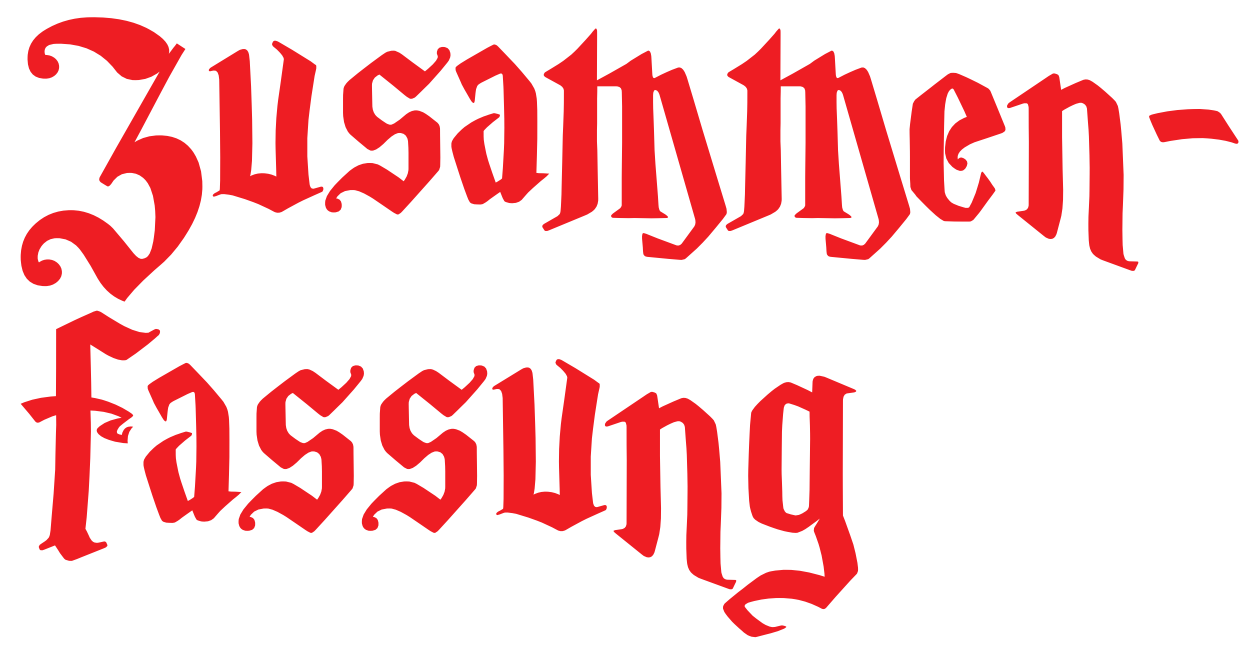


Hintergrund: Zahlreiche Studien belegen den Zusammenhang zwischen Alkoholkonsum und soziodemographischen Charakteristiken, wie etwa der Berufstätigkeit oder dem Zusammenleben mit einem Partner. Das zentrale Anliegen dieser Doktorarbeit war eine genauere Analyse des Zusammenhangs zwischen sozialen Rollen und Alkoholkonsum unter Einbezug gesellschaftlicher Rahmenbedingungen und rolleninherenter Charakteristiken und unter Berücksichtigung soziologischer Rollentheorien. Der mögliche Einfluss sozialer Rollen, wie der Elternschaft, dem Zusammenleben mit einem Partner oder der Berufstätigkeit, basiert auf den Effekten dauerhafter Beziehungen $\mathrm{zu}$ anderen Menschen und der sich daraus ergebenden Positionierung des Einzelnen im vorhandenen Sozialgefüge. Basierend auf den einer Person zugeschriebenen Rollen kann sich diese selbst definieren; sie erhält zudem eine Art rollengeschuldeten Verhaltenskatalogs, welcher in der Konsequenz sowohl das jeweilige Gesundheitsverhalten als auch die Gesundheit beeinflusst, indem der Einzelne sich an der durch die Rollen vorgegebenen Rahmenbedingungen orientiert. Die vorliegende Arbeit basiert auf den Annahmen der Klassischen Rollentheorie. Diese besagt, dass über je mehr soziale Rollen ein Individuum verfügt, desto strukturierte ist dessen Tagesablauf und umso geringer ist der Alkoholkonsum. Diese Rollentheorie gilt es von der Theorie multipler Belastungen zu unterscheiden. Letztere geht davon aus, dass mit steigender Anzahl sozialer Rollen das Risiko für Rollenkonflikte und Stress zunimmt; ein vermehrter Alkoholkonsum wird in der Folge wahrscheinlicher. In der bestehenden Literatur wurde die Theorie multipler Belastungen vorrangig zur Erklärung des Alkoholkonsums von Frauen genutzt.

Die vorliegende Doktorarbeit zielt darauf ab, das Wissen um die Zusammenhänge zwischen sozialen Rollen und Alkoholkonsum zu erweitern, wobei einerseits ein möglicher Einfluss psychologischer Variablen auf die Zusammenhänge zwischen Rollen und Alkoholkonsum im Fokus stand (Kapitel 2), andererseits aber auch Unterschiede der Geschlechter (Kapitel 3) sowie kulturelle Aspekte (Kapitel 4 bis 6) als mögliche Erklärungsfaktoren herangezogen wurden.

Daten: Die Kapitel 4 bis 6 basieren auf im Rahmen des "Gender Alcohol and Culture: An international project" (GenACIS) erhobenen Umfragedaten. Einzelheiten zum Projekt und dessen Finanzierung finden sich unter www.genacis.org. Die kulturübergreifenden Vergleiche (Kapitel 4 bis 6) wurden dabei auf Länder mit einer etablierte Marktwirtschaft begrenzt, da davon ausgegangen werden kann, dass die Relevanz der untersuchten sozialen Rollen auf das alltägliche Leben in diesen Ländern eine gewisse Homogenität aufweist. Die Kapitel 2 und 3 
basieren alleinig auf Daten der dritten Welle der Schweizerischen Gesundheitsbefragung 2007. Diese repräsentative Umfrage in der Schweizerischen Wohnbevölkerung umfasst detailliertere Angaben zu psychischen Faktoren und Familiencharakteristiken als der GenACIS Fragebogen.

Ergebnisse und Schlussfolgerungen: Im Rahmen einer ersten Studie (Kapitel 2) wurden zwei psychische Faktoren mit nachweislichem Zusammenhang zum Alkoholkonsum depressiver Verstimmung und das Gefühl externer Kontrolle - als mögliche Mediatoren für den Zusammenhang zwischen sozialen Rollen und Alkoholkonsum untersucht. Zwischen dem Alkoholkonsum und sozialen Rollen bzw. depressiver Verstimmung, sowie dem Gefühl wichtige Lebensbereiche nicht selbst kontrollieren $\mathrm{zu}$ können fanden sich signifikante Zusammenhänge in die erwartete Richtung. Jedoch, wurde der Zusammenhang der Anzahl sozialer Rollen und Alkoholkonsums nicht durch die untersuchten psychologischen Faktoren mediiert, da die Anzahl sozialer Rollen mit anderen Konsumvariablen assoziiert war als die beiden psychologischen Faktoren. Dies führte $\mathrm{zu}$ der Schlussfolgerung, dass nicht das psychologische Wohlbefinden für den gefundenen Zusammenhang zwischen der Anzahl sozialer Rollen und Alkoholkonsum verantwortlich ist, sondern vielmehr die durch die sozialen Rollen bedingte Alltagsstruktur: eine grössere Zahl sozialer Rollen birgt eine höhere Zahl an Verpflichtung, so dass die Anzahl der Trinkgelegenheiten und damit der Konsum reduziert wird. Im Rahmen eines Vergleichs zehn mehrheitlich europäischer Länder (Kapitel 5) zeigte sich, dass bei Männern eine grössere Anzahl sozialer Rollen mit einem geringeren Risiko für problematischen Alkoholgebrauch und episodische risikoreichen Konsum einherging. Bei den Frauen fand sich für die Mehrzahl der betrachteten Länder ein ähnlicher Zusammenhang. Generell zeigte sich, dass der protektive Effekt einer hohen Anzahl sozialer Rollen hinsichtlich des episodisch risikoreichen Konsums ausgeprägter war. Somit belegen die Ergebnisse die kulturübergreifende Gültigkeit der Klassischen Rollentheorie. Bei den Frauen wies jedoch entgegen der Theorie in einigen Ländern ein Zwei-Rollenmodel (Hausfrau und Mutter) geringere Konsumwerte aus als das berufstätige Mütter mit Partner.

In Kapitel 3 wurde der Einfluss familiärer Charakteristiken auf elterlichen Alkoholkonsum anhand Schweizerischer Daten näher untersucht. Alkoholkonsum war bei Frauen systematischer mit der elterlichen Rolle und familienbezogenen Variablen assoziiert als bei Männern. Der moderierende Effekt der Berufstätigkeit auf den Zusammenhang der Anzahl der Kinder und Alkoholkonsum deutet darauf hin, dass die mit der Mutterrolle assoziierte 
Verantwortung per se vor Alkoholkonsum zu schützen vermag, dass jedoch beruftstätige Mütter weniger bzw. gar nicht von diesen protektiven Effekten profitieren.

Mögliche Geschlechtsunterschiede in der Bedeutung familiär bzw. sozioökonomisch orientierter Rollen standen im Mittelpunkt der im Rahmen des Kapitels 4 vorgenommenen Analysen. Generell hatten familienbezogene Rollen einen protektiveren Einfluss auf den Alkoholkonsum von Frauen während bei Männern ein grösserer Einfluss sozioökonomischer Faktoren nachweisbar war. Der Zusammenhang zwischen dem Alkoholkonsum und Landescharakteristika belegt, dass Frauen in Ländern mit gut ausgebautem Sozialsystem, wie etwa den nordischen Ländern, eher dann problematisch trinken, wenn sie berufstätig sind, geringere formale Bildung aufweisen und nicht in traditionellen Familienrollen leben. Hingegen zeigt sich, dass der problematische Alkoholkonsum bei Frauen in Ländern mit einem nur gering ausgebauten Sozialsystem o mit hoher formaler Bildung assoziiert war, während die Effekte familiärer Rollen bzw. der Berufstätigkeit eher gering waren.

Der Bedeutung des Sozialsystems für den Zusammenhang sozialer Rollen mit mütterlichem Alkoholkonsum wurde im Rahmen einer internationalen Untersuchung in 16 Ländern belegt (Kapitel 6). Unabhängig davon, ob sie berufstätig waren oder nicht, berichteten alleinerziehende Mütter höhere Alkoholmengen pro Konsumgelegenheit als in einer Partnerschaft lebende Mütter. Ferner belegen die Ergebnisse, dass eine hohe Geschlechtergleichheit im Einkommen die Kombination von Mutterschaft und Berufstätigkeit in den entsprechenden Ländern erleichtert: mit steigender Anzahl an sozialen Rollen sank die pro Gelegenheit konsumierte Alkoholmenge. Im Gegensatz dazu war mütterliche Berufstätigkeit in Ländern mit geringeren Anreizen für Mütter nach der Geburt im Berufsleben zu bleiben trotz der positiven Effekte der Elternschaft und des Zusammenlebens mit einem Partner mit höheren Alkoholmengen assoziiert.

In keiner der beiden Untersuchungen (Kapitel 4 und 6) fanden sich Anhaltspunkte dafür, dass die Theorie multipler Belastungen den Alkoholkonsum bei Frauen besser erklären könnte als die Klassische Rollentheorie. Jedoch wird anhand der Ergebnisse deutlich, dass der protektive Effekt der Berufstätigkeit bei Frauen von dem Ausmass der Geschlechtergleichheit auf gesellschaftlicher Ebene abhängt.

Kapitel 7 diskutiert die zentralen Ergebnisse der vorliegenden Doktorarbeit. Allgemein lassen die Resultate den Schluss zu, dass der die im Rahmen der Klassischen Rollentheorie getroffenen Annahmen in Bezug auf Alkoholkonsum für beide Geschlechter und über 
unterschiedliche Kulturen hinweg Gültigkeit besitzen. Zukünftige Forschung in diesem Bereich sollte auf mögliche mediierende Faktoren fokussieren. Diesbezüglich scheint es auf Basis der vorliegenden Befunde unwahrscheinlich, dass psychologische Faktoren die Zusammenhänge zwischen sozialen Rollen und Alkoholkonsum zu erklären vermögen. Hingegen finden sich deutliche Hinweise darauf, dass das Ausmass der Beeinflussung des Alkoholkonsums durch eine spezifische soziale Rolle durchaus Geschlechtsunterschiede aufweist. Eine zentrale Rolle bei der Erklärung dieser Unterschiede zwischen Männern und Frauen spielt die Geschlechtergleichheit auf gesellschaftlicher Ebene: mütterliche Berufstätigkeit ist in Gesellschaften mit höherer Geschlechtergleichheit wahrscheinlicher mit einem geringeren Alkoholkonsum assoziiert.

Am Ende dieses Kapitel werden die vorgelegten Ergebnisse dieser Arbeit hinsichtlich ihrer Bedeutung für die auf soziale Rollen bezogene Alkoholprävention und die Alkoholpolitik diskutiert. 


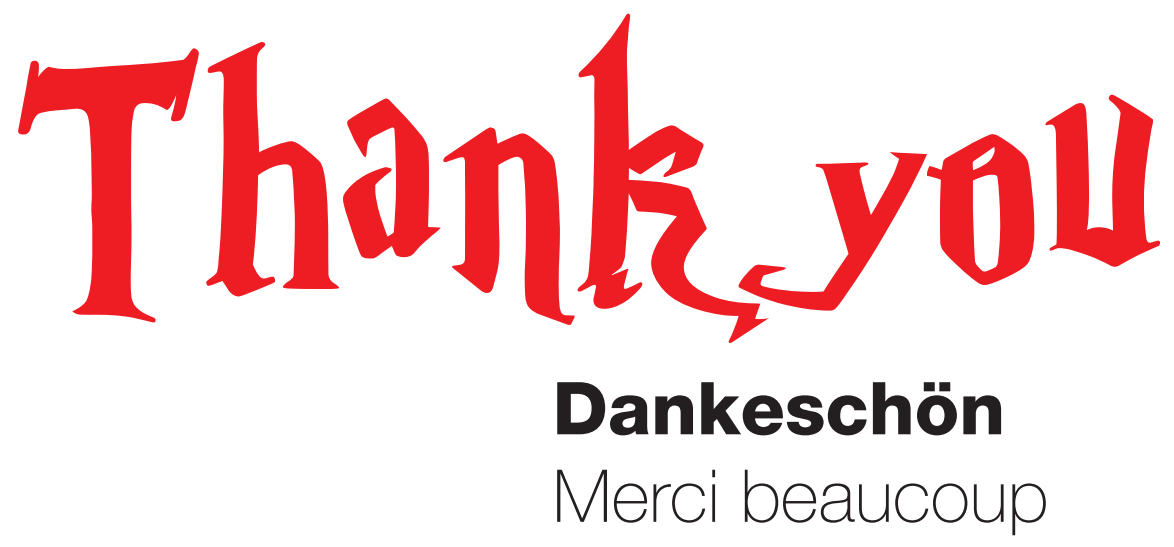




\section{Acknowledgment of the GenACIS project:}

The data used in this thesis are from the project Gender, Alcohol and Culture: An International Study (GENACIS). GENACIS is a collaborative international project affiliated with the Kettil Bruun Society for Social and Epidemiological Research on Alcohol and coordinated by GENACIS partners from the University of North Dakota, Aarhus University, the Alcohol Research Group/Public Health Institute, the Centre for Addiction and Mental Health, the University of Melbourne and the Addiction Info Switzerland Research Institute. Support for aspects of the project came from the World Health Organization, the Quality of Life and Management of Living Resources Program of the European Commission (Concerted Action QLG4-CT-2001-0196), the U.S. National Institute on Alcohol Abuse and Alcoholism/National Institutes of Health (Grants R21 AA012941 and R01 AA015775), the German Federal Ministry of Health, the Pan American Health Organization and the Swiss National Science Foundation. Support for individual country surveys was provided by government agencies and other national sources. The study leaders and funding sources for data sets used in this report are: Australia: Paul Dietze (National Health and Medical Research Council (Grant 398500)), Austria: Irmgard Eisenbach-Stangl (Boltzmann Institute), Canada: Kate Graham (Canadian Institutes of Health Research (CIHR)), Czech Republic: Ladislav Csémy (Ministry of Health (Grant MZ 23752)), Denmark: Kim Bloomfield (Sygekassernes Helsefond; Danish Medical Research Council), Finland: Pia Mäkelä (National Research and Development Centre for Welfare and Health (STAKES)), France: Francois Beck (National Institute of Prevention and Heath Education (INPES)), Germany: Ludwig Kraus (German Federal Ministry of Health (BMGS) and in cooperation with the Institute for Therapy Research, Munich, Germany), Hungary: Zsuzsanna Elekes (Ministry of Youth and Sport), the Netherlands: Ronald A. Knibbe (Ministry of Health and Welfare of the Netherlands), Norway: Sturla Nordlund (Norwegian Institute for Alcohol and Drug Research), Spain: Juan C. Valderrama (Dirección General de Atención a la Dependencia, Conselleria de Sanidad, Generalitat Valenciana; Comisionado do Plan de Galicia sobre Drogas, Conselleria de Sanidade, Xunta de Galicia; Dirección General de Drogodependencias y Servicios Sociales Gobierno de Cantabria), Sweden: Karin Bergmark (Ministry for Social Affairs and Health), Switzerland: Gerhard Gmel (Swiss Federal Office for Education and Science (Contract 01.0366); Swiss Federal Statistical Office; University of North Dakota (Subcontract No. 254, Amendment No.2, UND Fund 4153-0425)), UK: Martin Plant, Moira Plant (Alcohol Education and Research Council; European Forum for Responsible Drinking; University of 
the West of England, Bristol), USA: Tom Greenfield (National Institute on Alcohol Abuse and Alcoholism/National Institutes of Health (Grant P50 AA05595)).

\section{Professional thanks}

I would like to thank the two PIs of the GenACIS project, Prof. Sharon Wilsnack and Prof. Kim Bloomfield. Without your tireless commitment to the project, this thesis would never have obtained the rich dataset on which it is based.

I also want to thank the Swiss Foundation for Alcohol Research for funding three scientific papers that contributed to this thesis (contract number 08.09.2005).

My thanks also go to Addiction Info Switzerland (formerly SIPA) and its director Michel Graf for giving me the opportunity and the time to finalize this thesis.

\section{The personal corner}

There are quite a few people to whom I owe a big thank you for supporting me during the long process of completing this book.

First of all I want to thank my two promoters, Ronald and Gerhard. If you take the picture of "good cop / bad cop" it is obvious who the bad one is - sorry Gerhard (;)

Ronald, you were always there to offer guidance and support in emergencies and moments of complete despair. From the very beginning, you always picked out the key arguments in the messy stuff I sent you and encouraged me not to throw everything in the bin years ago. A huge THANKS for your expertise, for sharing your vast knowledge, for the pleasant lunches and dinners, and simply for being the best promoter a $\mathrm{PhD}$ student could wish for.

Now it gets somewhat complicated :): When I started my internship at SIPA in 2000 I had planned to stay for 2 months. Which just goes to show that things never turn out the way you think. If I'd really wanted to work in HR management, I should never have started to work with you, Gerhard. You sparked my interest in alcohol research and I have already spent one third of my life working, discussing, debating and drinking with you. You promoted my master's thesis, "coerced" me into a PhD and have been "my" PI in so many studies that I've lost count. I learned to become critical, never to trust things that appear obvious, to look at the detail, to check at least twice and the pleasure of simply playing with my data $\odot$. But I also 
learned to persevere, to take criticism and to accept personal responsibility. There have been times during these past few years when I would first check to see whether Herta had won their last game before looking at the comments you made on my papers. Even then, answering some of them took a while because I had to calm down and compose myself first $:$.

Gerhard, I learned so much from you that it is hard to put it all in a simple DANKE. Nevertheless, I want to thank you for being honest, for always being there when needed, for pushing me if necessary, for your sceptical view of the world and for becoming a true friend over the past 10 years.

\section{Very special thanks go to...}

Mama und Papa, danke für alles!

The research department at Addiction Info Switzerland (formerly SIPA) for simply being the best work mates anyone could ask for - vivre l'adolescence!

Special thanks go to Elisabeth Grisel and Ramon Schelleman who helped make this book what it is today...; Marja Vissers for guiding me through the administrative jungle in Maastricht; Gemma Brown for her highly appreciated English proofreading - the reader will thank you too...

Karen it was fun having you here in Lausanne and I really appreciated your help and support in the last few weeks before I finalized this thesis. You became my PhD buddy in Maastricht.

My personal illustrator - you did a great job!!!!

My social network (you know who you are) for being who they are and for keeping me grounded.

\section{Last but certainly not least...on the contrary}

My two little dwarfs for bringing balance to my life, letting me see the world through their eyes, keeping my feet on the ground and giving my life meaning (and structure).

Manuel, thanks for being all I need and more... du stellst meine Füsse auf weiten Raum... 


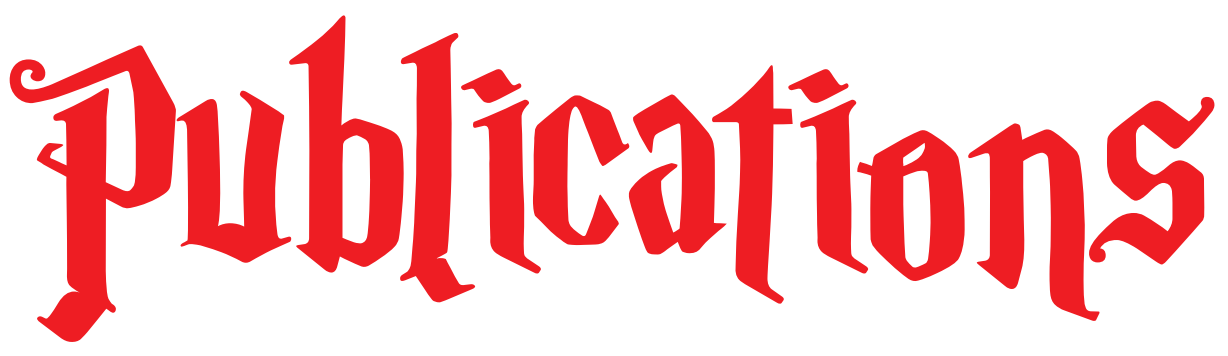




\section{Publications related to the dissertation}

Kuntsche, S., Knibbe, R.A. \& Gmel, G. (2010). A step beyond - the relevance of depressed mood and mastery in the interplay between social roles and alcohol use. Addictive Behaviors, 35, 1013-1020.

Chapter 2

Kuntsche, S., Knibbe, R.A. \& Gmel, G. (in press). Parents' alcohol use: gender differences in the impact of household and family chores. European Journal of Public Health Chapter 3

Kuntsche, S., Gmel, G., Knibbe, R.A., Kuendig, H., Bloomfield, K., Kramer, S., \& Grittner, U. (2006). Gender and cultural differences in the association between family roles, social stratification, and alcohol use: A European cross-cultural analysis. Alcohol and Alcoholism, 41, i37-i46.

\section{Chapter 4}

Kuntsche, S., Knibbe, R.A. \& Gmel, G. (2009). Social roles and alcohol consumption: A study of 10 industrialized countries. Social Science \& Medicine, 68, 1263-1270.

Chapter 5

Kuntsche, S., Knibbe, R., Kuntsche, E., \& Gmel, G. (2011). Housewife or working mum each to her own? The relevance of societal factors in the association between social roles and alcohol use among mothers in 16 industrialised countries. Addiction, 106(11), 1925 1932.

Chapter 6

\section{Other publications}

\section{$\underline{\text { In press }}$}

Plant, M., Miller, P., Plant, M., Gmel, G., \& Kuntsche, S. (in press). The Consequences of Heavy Drinking amongst 24-32 Year Olds in Six European Countries. Substance Use and Misuse

\section{Published (chronological order)}

Graham, K., Bernards, S., Knibbe, R.A., Kairouz, S., Kuntsche, S., Wilsnack, S., Greenfield, T.K., Dietze, P., Obot, I., \& Gmel, G. (2011). Gender and Country Differences in Negative Consequences from Drinking. Addiction, 106, p. 1391-1405 
Kuntsche, E., Kuntsche, S., Knibbe, R., Simons-Morton, B., Farhat, T., Hublet, A., Bendtsen, P., Godeau, E., Demetrovics, Z. (2011). Cultural and gender convergence in adolescent drunkenness: Evidence from 23 European and North American countries. Archives of Pediatrics and Adolescent Medicine, 165(2), 152-158.

Astudillo, M., Kuntsche, S., Graham, K. \& Gmel, G. (2010). The influence of drinking pattern, at individual and aggregate levels, on alcohol-related negative consequences. European Addiction Research, 16, 115-123.

Plant M, Miller P, Plant M, Gmel G, Kuntsche S., Bergmark WK, Bloomfield K, Csémy L, Ozenturk T, Vidal A. (2010). The social consequences of binge drinking among 24-32 Year Olds in Six European Countries. Substance Use \& Misuse, 45(4):528-42.

Plant, M. A., Plant, M. L., Miller, P., Gmel, G., \& Kuntsche, S. (2009). The Social Consequences of Binge Drinking: A comparison of young adults in Six European Countries. Journal of Addictive Diseases, 28 (4), 294-308.

Kuntsche, E. \& Kuntsche, S. (2009). Development and validation of the Drinking Motive Questionnaire Revised Short Form (DMQ-R SF). Journal of Clinical Child and Adolescent Psychology, 38(6), 899-908.

Kuntsche, E., Maffli, E., Kuntsche, S., \& Delgrande Jordan, M. (2009). Past, Present, and Future. The Swiss Institute for the Prevention of Alcohol and Drug Problems. Addiction, 104, 699-704.

Kuendig, H., Plant, M.L., Plant, M.A., Kuntsche, S., Miller, P., \& Gmel, G. (2008). Beyond drinking: Differential Effects of Demographic and Socioeconomic Factors on Alcoholrelated Adverse Consequences across European Countries. European Addiction Research, 14, 150-60.

Plant, M., Miller, P., Plant, M., Kuntsche, S., \& Gmel, G. (2008). Marriage, cohabitation, and alcohol consumption: an international exploration. Journal of Substance Use, 13(2), 8398.

Kuntsche, S., Plant, M., Plant, M, Miller, P., \& Gmel, G. (2008). Spreading or concentrating drinking occasions - who is most at risk. European Addiction Research,14:71-81

Kuendig, H., Plant, M., Plant, M., Miller, P., Kuntsche, S., \& Gmel, G. (2008). Alcoholrelated adverse consequences: cross-cultural variations in attribution process among young adults. European Journal of Public Health, 18: 386-91. 
Gmel, G., Room, R., Kuendig, H. \& Kuntsche, S. (2007). Detrimental drinking patterns: Empirical validation of the pattern values score of the Global Burden of Disease 2000 study in 13 countries Journal of Substance Use, 12(5), 337-358.

Rahav, G., Wilsnack, R., Bloomfield, K., Gmel, G., \& Kuntsche, S. (2006). The influence of societal level factors on men's and women's alcohol consumption and alcohol problems. Alcohol and Alcoholism, 41, i47-i55.

Knibbe, R.A., Derickx, M., Kuntsche, S., Grittner, U., Bloomfield, K. (2006). A comparison of the alcohol use disorder identification test (AUDIT) in general population surveys in nine European countries. Alcohol and Alcoholism, 41, i19-i25.

Mäkelä, P., Gmel, G., Grittner, U., Kuendig, H., Kuntsche, S., Bloomfield, K., \& Room, R. (2006). Drinking Patterns and their gender differences in Europe. Alcohol and Alcoholism, 41, i8-i18.

Gmel, G., Graham, K., Kuendig, H., \& Kuntsche, S. (2006). Measuring alcohol consumption - should the "Graduated Frequency" Approach become the norm in survey research? Addiction, 101, 16-30.

Kuntsche, S. \& Gmel, G. (2005). The smoking epidemic in Switzerland - an empirical examination of the theory of diffusion of innovations. Sozial- und Präventivmedizin, 50, 344-54. 


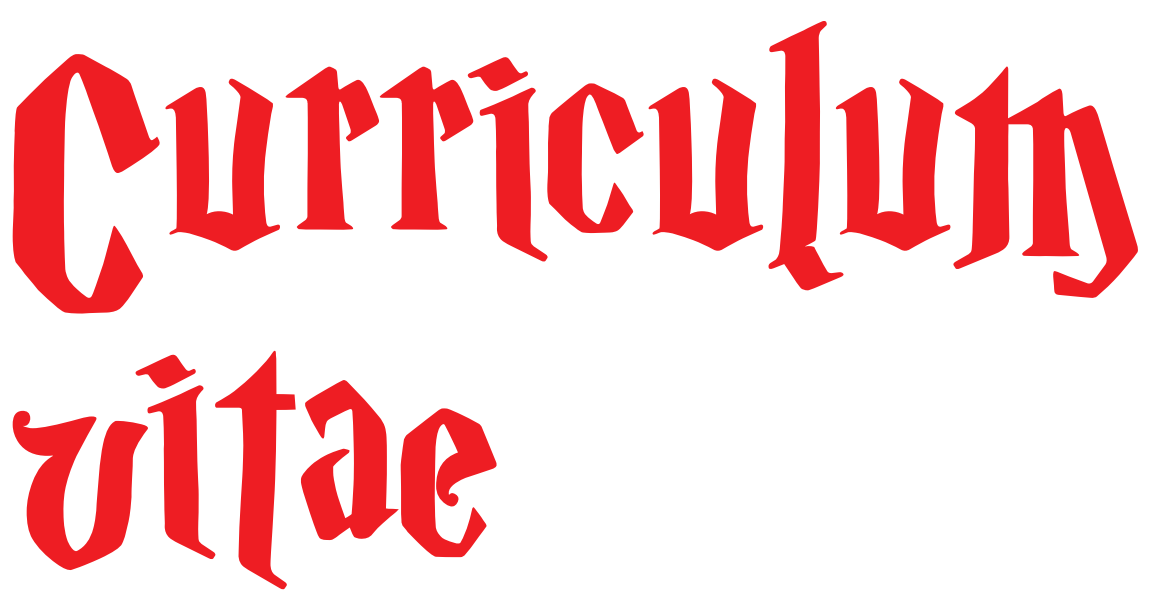


Sandra Kuntsche was born on September 19, 1977 in Pössneck, Germany. From 1996 to 2002 she studied Psychology at the University of Jena. In 2002 she graduated with a Diplom (equivalent to a Master's degree) in Psychology from the same University. She worked as a student assistant at the department of Developmental Psychology from 1997 and later (1999) at the Department of Biological Psychology, before starting an internship at the Swiss Institute for Alcohol and Drug Problems (now Addiction Info Switzerland) in spring 2000. Between 2000 and 2002 she worked as a student assistant in the Research Department of the Swiss Institute for Alcohol and Drug Problems in parallel to her studies. In May 2002 she started a permanent position at the Institute. Since then she has focused mainly on gender and cultural differences in alcohol use in the context of the GenACIS project. In addition, she has contributed to several national monitoring and evaluation projects and contributed to more than 30 scientific articles.

In 2006 she became an external Ph.D student of Prof. Ronald A. Knibbe at Maastricht University. In 2009 she was honoured with the Ole Jørgen Skog Award for Early Career Scientists for a former version of Chapter 6.

Sandra Kuntsche is currently the coordinator of the Research Institute of Addiction Info Switzerland. She has been married to Emmanuel Kuntsche since 2002 and they live together with their two children, Zoë (2003) and Neo (2006) in Lausanne, Switzerland. 
